
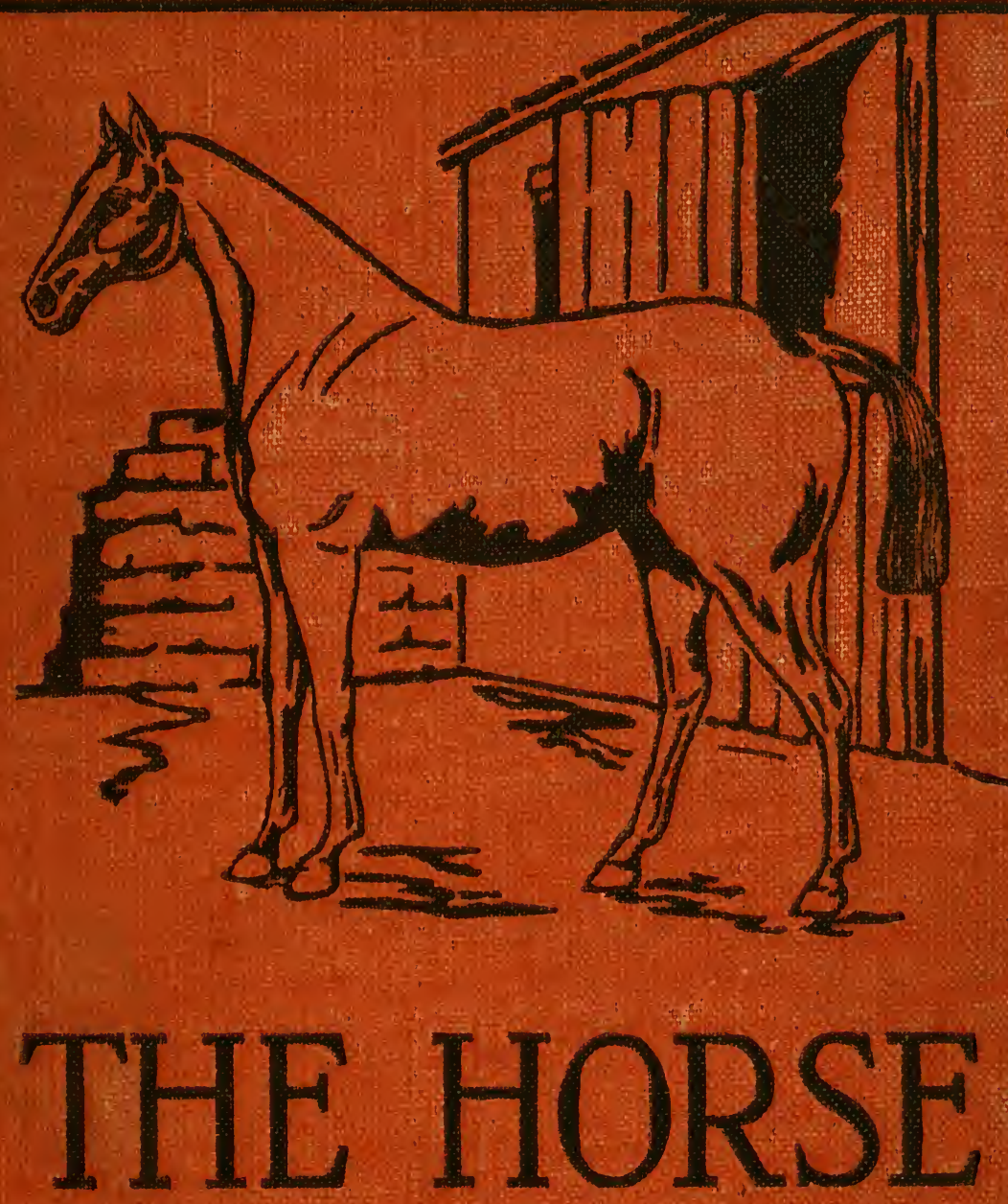

$$
\begin{aligned}
& \text { IN HEALTH } \\
& \text { ACCIDENT } \\
& \text { \& DISEASE }
\end{aligned}
$$

"DARLEY MATHESON" 


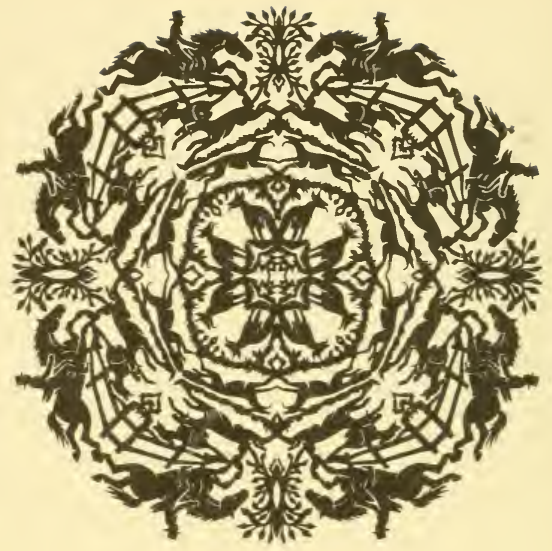

JOHN A.SEAVERNS 




\section{THE HORSE}

IN HEALTH, ACCIDENT AND DISEASE, 




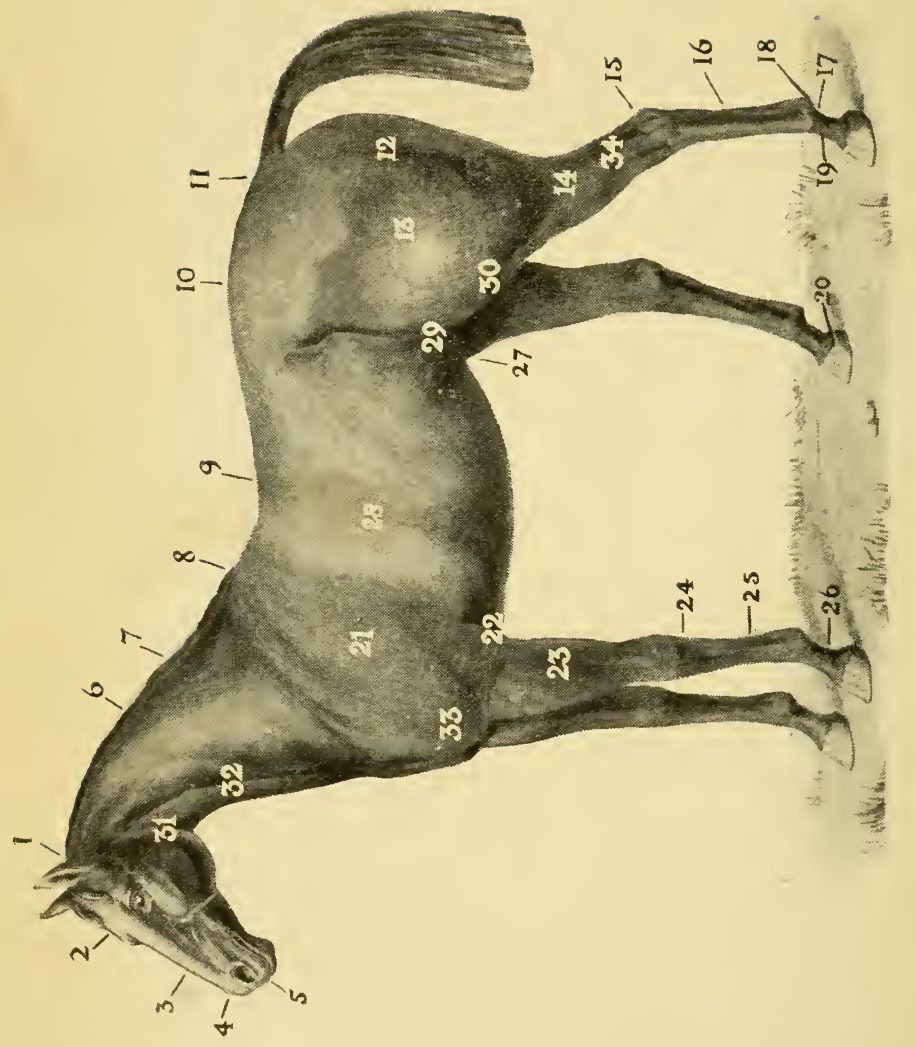

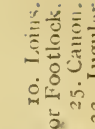

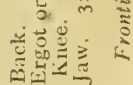

कांने

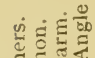

(1)

w

I $\infty^{\circ} \dot{m}$

(I)

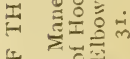

(t)

$\because$ औ

- 5 的

2 ${ }^{-1}$

$\triangleq \quad \dot{a}^{c}$

F

(I) चच चं

उ किं हैं

in लें के

,

$=\div \frac{\dot{x}}{0} \tilde{N}^{\circ}$

0 .

눙

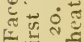

क. एक

m

के त क

تृ

С.

현

诖远

वं तं

.

릉 छ

a

rit记

$\therefore \dot{0}=$ 


\title{
THE HORSE
}

IN HEALTH, ACCIDENT E DISEASE

A THOROUGHLY PRACTICAL GUIDE FOR EVERY HORSE OWNER

\author{
BY \\ "DARLEY MATHESON," \\ M.R.C.V.S. \\ AUTHOR OF "CATTLE AND SHREP," AND NUMRROUS OTHER
WORKS ON LIVE STOCK, BTC.
}

ILLUSTRATED

London

C. Arthur Pearson, Ltd.

Henrietta Street

1921 



\title{
CONTENTS
}

\author{
CHAPTER I
}

STABLE AND STABLE CONSTRUCTION, HYGIENE OF THE STABLE Housing-Sanitation-Flooring-Situation_Construction_Stable PAGE fittings-Water supply-Bedding . . . . • I I

CHAPTER II

GENERAL MANAGEMENT OF HORSES

Grooming-Feeding-Clipping-Washing-Clothing and bandages-Watering-Wintering and Summering horses-Agistment of horses-Forage-Bedding . . . . .

CHAPTER III

HEAVY DRAUGHT HORSES

The Shire and Clydesdale-Percheron and Suffolk-The Packington Blind horse and Weisman's Honest Tom-The Suffolk -The farmer's horse-The vanner and the tradesman's horse $\because$. . . . . . .

CHAPTER IV

HEAVY DRAUGHT HORSES-AGE, SEX, COLOUR, SELECTION, SOUNDNESS, ETC.

Selection-Mating-Conformation-Value of the heavy draught horse-Soundness-Colour-Age-Vice-Buying a horseFeet-Sight and wind-Various diseases . . . .

\section{CHAPTER V}

BREEDING HEAVY HORSES AND THE SELECTION OF THE SIRE AND THE DAM FOR THIS PURPOSE

Breeding heavy horses-Selection-Pedigree . . . . 56

CHAPTER VI

THE CARE OF MARE AND FOAL-THEIR MANAGEMENT FROM SPRING TO WINTER

Period of gestation-Selection-Age at which to breed fromRegistration of brood mares-Disease-Foaling seasonWeather-Weaning-Septic laminitis 


\section{THE HORSE}

\section{CHAPTER VII}

THE SADDLE HORSE OR RIDER

Hacks and hackneys-Manners-Vice-British bred horses- PAGE Height-Colour-Ponies-Plain and showy horses-Soundness - The Cleveland Bay-The light van and tradesman's horse-The hunter.

\section{CHAPTER VIII}

BUYING A LIGHT HORSE AND WHAT TO AVOID IN SELECTING THE SAME

Judgment-Source of purchase-Soundness-Welsh poniesPoints to note-Vice-Common afflictions *. . .

\section{CHAPTER IX}

THE AGE OF THE HORSE AS INDICATED BY THE TEETH, ETC.

How to distinguish horses of different ages-Physical signs of age-Teeth-Gums-Method of approximating age in horses

CHAPTER $\mathrm{X}$ VICE

Vice

\section{CHAPTER XI \\ LAMENESS IN THE HORSE}

Predisposition-Acute or chronic-Searching for cause-Principal causes-Rheumatic arthritis-Dislocations and fractures

\section{CHAPTER XII}

\section{SHOES AND SHOEING-PREPARATION OF THE FOOT}

Shoeing-The Farrier-Hot and cold fittings-Wear of shoesMachine-made shoes-Preparation of foot-Weights of shoes -Nail holes-Leather soles-Frost nails-Lameness

\section{CHAPTER XIII}

\section{THE FOOT IN HEALTH AND DISEASE}

Sound feet indispensable-Concussion and bad shoeing-Grading of feet-Various features in health and disease-Structure of the feet-Laminitis or founder-General managementand treatment-Navicular disease-Sandcrack-False quarter-Canker of the foot-Thrush-Side-bone-Cutting or brushing-Forging-Bruised heel 


\section{CHAPTER XIV \\ FACTS OF GENERAL INTEREST}

The pulse-The temperature-The breathing-Physicking horses

-Administering medicine to horses-Blistering and firingFomentation-Feeding sick horses-Castration of coltsHealing ointment-Wound lotion-Lotion for sore backs and saddle gall-Tonic powders-Saline fever powders .

PAGE

\section{CHAPTER XV \\ ANATOMICAL OUTLINES OF THE CONSTRUCTION OF THE HORSE}

The skeleton-The muscular system-The internal structure of a horse-The respiratory system-The digestive systemThe urinary and genitive organs

\section{CHAPTER XVI}

\section{SPECIFIC INFECTIVE DISEASES}

Catarrh-Chronic catarrh-Strangles - Influenza-Epizootic cellulitis or "pink eye"-Glanders-Farcy or cutaneous glanders-Anthrax-Tetanus-Joint-ill or arthritis in foalsRheumatism-Purpura-Infectious stomatitis - Tuberculosis -Actinomycosis

\section{CHAPTER XVII}

AFFECTIONS OF THE RESPIRATORY AND CIRCULATORY SYSTEMS

Roaring-Thick wind-Broken wind-Chronic cough-Sore throat-Pneumonia-Septic pneumonia-Formalin in pneumonia-Pleurisy-The heart and its functions . . .

\section{CHAPTER XVIII}

SOME COMPLAINTS OF THE DIGESTIVE ORGANS

Shear-mouth-The horse bee-Worms-Colic-Diarrhœa and scour in foals-Lymphangitis or weed . . .

CHAPTER XIX

SOME AFFECTIONS OF URINARY ORGANS

Azoturia Diabetes or excessive urination

CHAPTER XX

THE NERVOUS SYSTEM AND SOME AFFECTIONS OF THE SAME Stringhalt-Shivering-Epilepsy or vertigo . . . . I83 


\section{THE HORSE}

\section{CHAPTER XXI}

DISEASES OF BONES, JOINTS, TENDONS AND LIGAMENTS

Slipped shoulder-Splint-Causes of splint-treatment-Ringbone-Open joint-Septic arthritis-Bursal enlargements or wind-galls-Bog-spavin and thoro-pin-Curb-Bone-spavin -Sprained tendons and ligaments-Treatment of same .

PAGE isis 185

\section{CHAPTER XXII}

\section{SOME SKIN AFFECTIONS}

Epizootic lymphangitis-Ulcerative cellulitis-Psoroptic, sarcoptic and symbiotic mange-Causes of mange-Recurrent mange-Parasitic mange order-Treatment of mangeRules to be followed for the prevention and cule of mange in horses-Lice-Ringworm - Causes of ringworm-Collar and saddle gall-Mud rash-Cracked heels-Grease-Nettle rash

\section{CHAPTER XXIII}

\section{THE EYE AND SOME COMMON AFFECTIONS}

Injuries to the eyelids-Ophthalmia-Treatment and management of same-Recurrent or specific ophthalmia-Opacity of the cornea-Cataract .

\section{CHAPTER XXIV}

WOUNDS, FRACTURES AND DISLOCATIONS

Various kinds of wounds-Broken knee-Picked-up nailTreatment of wounds-Fractures-Various kinds of fractures

\section{CHAPTER XXV}

SOMETHING CONCERNING ORGANIC AND INORGANIC POISONS Yew poisoning-Foxglove poisoning-Deadly nightshade-The hemlocks-Arsenic and antimony 


\section{LIST OF ILLUSTRATIONS}

Points of the Horse

Champion Shire Stallion

Shire Gelding

Champion Clydesdale Stallion.

Clydesdale Mare

Suffolk Stallion

Percheron Stallion

Hunter

Polo Pony .

Hackney Stallion .

Shetland Pony
Frontispiece tacing page 34

$\begin{array}{lll}\text {, , } & 37 \\ \text {, } & 38 \\ \text {, } & \text {, } & 40 \\ \text {, } & , & 42 \\ \text {, } & \text { " } & 42 \\ \text {, } & , & 72 \\ \text {, } & , & 72 \\ \text {, } & , & 77 \\ \text {, } & \text {, } & 77\end{array}$

Illustrations of the Teeth of the Horse, showing " temporary" and "permanent" incisors from birth to thirty years

Pedal-bone to illustrate Side-bone

pages 88,89

page 120

Skeleton of the Horse 



\title{
THE HORSE
}

\section{IN HEALTH, ACCIDENT AND DISEASE}

\author{
CHAPTER I \\ STABLES AND STABLE CONSTRUCTION \\ HYGIENE OF THE STABLE
}

THOsE who study the welfare of their horses will endeavour to see that their animals are comfortably housed, though, unfortunately, a large proportion of stables are anything but satisfactory. Some horse owners seem to have an idea that any sort of hovel is good enough to keep a horse in, but there can be no greater mistake, and no man can ever expect an animal to look well or perform its work satisfactorily if it is kept in a cold or a damp stable, without drainage or sanitation of any kind. Every well-constructed stable should have its inlet for pure air and its outlet for impure, be efficiently drained, and provided with proper flooring. Makeshift floors are never any use, and prove to be the most expensive in the long run. Existing stables, deficient in their internal arrangements, can very often be materially improved by slight additional cost. The best site for a stable is one on a gravel soil, with the front of the stable facing the south or south-west. If there is a slight natural elevation of the ground, so much the better. The walls can be constructed of wood, corrugated iron, brick, reinforced concrete, or stone, the last-named being the best of all, unless exception be taken to reinforced 
concrete. All wooden stables, no matter how soundly constructed, are cold in the winter; and so are corrugated iron ones, with the additional disadvantage of being too hot in summer. For temporary stables both these materials may suffice. The roof, if a concrete stable, should either be slated or tiled, preferably the former. The best material for the floor is concrete, or else vitrified stable paving. The latter, or something of a similar nature, is used in all the best stables. A floor set with this kind of paving is almost indestructible and certainly the cleanest. Ordinary bricks, "asphalt, and wood are not suitable for stable floors or, at any rate, should never form permanent stable flooring. In laying the floor, the drainage should be on the surface and slope towards a surface drain at the foot of the stall, which conveys the liquid into a well-trapped drain outside the stable. The drain inside the building may either be open or closed, with a surface grating, for preference the latter. A great deal of care should be bestowed upon the construction of the floor, otherwise it will never be satisfactory. For instance, if there is too much of a gradient in the stalls, fluid excreta runs away too quickly and leaves particles of solid matter behind. If, on the other hand, the fall is insufficient, the drainage becomes inefficient. The author likes to see good roomy stalls in a stable, and not only roomy, but lengthy, say eight feet from the head to the foot of the stall. Half the stalls one sees in stables are much too short and too narrow, and quite incapable of accommodating a heavy draught horse. The width of each stall should be not less than six feet six inches. Given these dimensions, a horse can lie down comfortably and rise properly, whereas in a narrow stall it will sometimes be cast and unable to rise. The space available will, of course, have all the bearing upon the size and arrangement of stalls, loose boxes, etc. Neither the harness room nor the coach house should communicate directly with the stable, as the vapour from the latter is detrimental to 
harness and carriage appointments. A loose box or two forms a valuable addition to any stable, detached loose boxes being the best. Many stables are fitted with one or more loose boxes at each end of the stable, or somewhere in the building. These are useful for the " segregation " of a horse, but when the loose boxes are detached from the main building a sick animal can be isolated. The inlet for fresh air should be by means of ventilating windows, i.e. the lower portion closed and the upper open, so that there is a constant current of pure air passing into the stable, and foul air passing out through a ventilating shaft in the roof. The stable should be neither too cold nor overheated; a temperature of $50^{\circ}$ to $55^{\circ} \mathrm{Fahr}$. is about right.

The best stable fittings are made of iron, but, in the case of a temporary stable, wood answers the purpose perfectly well. Iron mangers are by far the most durable, and we recommend these in preference to all others. There are quite a number of manufacturers of stable fittings, and anyone contemplating erecting a stable could not do better than to apply to some of these firms for their catalogues. A plentiful supply of water should be at hand in every stable, as cleanliness of the stable is necessary to the well-being of the occupants of the stable. There are quite a number of details to be worked out in stable construction, but the space at the author's disposal prohibits him from entering into consideration of these. The stable floor, during the summer, should be washed down daily, say every morning after the bedding has been lifted, and during the time that the animal is out at exercise, i.e. if there is sufficient help in the stable for this purpose. Plenty of water, a stiff broom, and a large amount of energy are the necessaries for cleansing a stable floor. The bedding should be taken outside the stable and exposed to the air, which should be admitted freely to the interior of the stable. A dirty and untidy stable is a disgrace to anyone, and certainly indicates the 
slovenly habits of its proprietor. If horses are worth keeping, either for business or pleasure, it is surely not too much trouble to keep them as they ought to be kept, there being " a place for everything, and everything in its place." 


\section{CHAPTER II}

\section{GENERAL MANAGEMENT OF HORSES}

\section{INTRODUCTION}

In the succeeding paragraphs the author will deal with matters such as grooming, feeding, clipping, etc., which appertain to the welfare of all classes of horses working in both town and country, likewise those which are turned out at pasture. Before, however, entering into a brief consideration of these it may be worth while to say a few words concerning certain minor features associated with those who have to look after their horses. To begin with, it is absolutely necessary that all horse-masters, horse-keepers, coachmen, and grooms should be early risers, be keen observers, and be capable of exercising a reasonable degree of intelligence : likewise, when necessary, to act on their own initiative. Every horse, no matter whether in the stable or out of it, has its own individuality; its likes and its dislikes; its preference for particular kinds of forage, and its hours for drinking and for abstaining from drinking. All horses should drink freely, and those which do so are usually the best thrivers. All horses should be good resters, which is also conducive to thriftiness. There is a special arrangement in connection with the mechanism of the fore limbs to enable a horse to sleep in a standing attitude, nevertheless, those which lie down thrive the best. In the management of horses regularity of feeding is very necessary. Animals are able to judge when feeding time arrives almost as well as their attendants, and this remark applies equally 
to watering them. The comparatively small size of a horse's stomach, and the short time that food remains within it, clearly indicate that this animal requires to be fed at fairly short intervals, but it should not be fed whilst it is at work. The nose-bag system of feeding is a most pernicious one as practised by the uninitiated. To fix on the nose-bag every time a horse stops is one of the most idiotic ideas ever established. If a horse is worked, fed from the nose-bag, and then allowed an hour or two's rest the matter is quite all right, so far as feeding is concerned. Horses should not be fed on journeys when the body is overheated, but they can always be safely watered, provided that they are not allowed too much water. Anything from half to one gallon will be sufficient under these circumstances. Another fallacious notion in the watering of sick horses is that of supplying them with chilled water, which they hardly ever appreciate. For the reduction of temperature, as in certain fevers, cold water is an invaluable medium, and ought always to be allowed. Another matter which should never be lost sight of by attendants on horses is that of refraining from giving an excessive amount of forage after a prolonged fast. This is a waste of food, as the extra grub will not compensate for the additional loss of muscular energy through prolonged abstinence. The best forage is the most economical, and it is far better to pay more money for a good article than to waste it on inferior or damaged food. A good horse-master will keep a watchful eye on everything appertaining to the general welfare of his charges ; in fact, it is the horse-keeper's eye which makes the animals thrive. Whenever horses are troubled with colic and various other ailments it is a sure sign that the stable management is at fault, and the matter should be looked into accordingly. Every class of the community has its unscrupulous persons, and such unscrupulousness may be at the expense of the animals, although they are unable to record it in black and white. It is impossible to 
pay too much attention to all matters connected with horses ; their grooming, their housing, and their management in various other ways. A conscientious horse keeper will spare neither time nor labour, within reasonable limits, upon the animals placed under his care, and he should always be present when horses are being fed and watered, to see that each member of the stud receives its proper share of forage and water. It is quite an easy matter to see whether horses are thriving or otherwise. Never purchase forage already mixed, i.e. corn and chaff, bran, etc., combined, because it so often happens that the individual components of a forage mixture are distinctly inferior in quality, or at any rate good, bad, and indifferent materials are frequently used in this manner.

\section{GROOMING}

The grooming appliances, plus the elbow grease supplied by the strapper, plus the condition of a horse in relationship to physical vigour, constitute the skin food of this animal for the essentials of grooming. There are grooms and those which call themselves grooms, but there is a vast difference between the two. One can make a horse look well, but the other never. It is quite an easy matter, both by sense of touch and by eyesight, to note whether a horse is groomed, indifferently groomed, or not groomed at all. Want of energy and a dread of work are the chief causes of the two last named. A groom must be energetic and ambitious, active and willing, conscientious and painstaking, and have a special love for horses. Under these circumstances he is bound to succeed and, as already stated, he is a groom, as opposed to the fictitious article. There is a popular notion that any man can groom a horse and can take up the work at a moment's notice. Those who had any experience with horses in the Army during the recent war know perfectly well how ludicrous this is. A groom must 
be trained, and his training to be thorough must be that under a careful master. Organisation in the stable is just as important as it is elsewhere. An unmethodical groom is not a desirable asset in any establishment; in fact, the place is better without him. The grooming appliances comprise the body and the dandy brushes, a wisp of straw or hay, the curry comb, the mane and the tail combs, stable rubbers, trimming scissors, the singeing lamp, and the foot picker, along with a stout arm, strong hands, and plenty of energy. These appliances and their accessories require to be kept clean and in proper order. In the stable of the sluggard they will often be found thrown in odd corners, filled with dirt, and wholly unfit for use-a most unwholesome picture, and one that no self-respecting horse keeper should for a moment tolerate. The body and the dandy brush must be kept clean with the curry comb, which is the use of the last named. Directly a horse comes off work, no matter whether it is summer or winter, wet or fine, sleet or snow, the feet should be washed, and this without wetting the hollows of the heels.

There is an art in even doing a simple affair like this, and it is quite an easy matter to make a bungling mess of the job. First of all get the pail and the water brush, pick up the near fore foot and support it with the left hand, with the brush in the right. Hold the foot so that the toe points downwards, and proceed to use the brush on the sole and round the wall. Treat the hind foot the same, and repeat on the off side. Horses soon become used to having their feet washed immediately they come in from work and readily accept the suggestion when the groom comes with his brush and pail.

The feet washed, if the animal is sweating freely it should be allowed to cool by walking it about for a short time. The majority of grooms put it straight away into its stall and then give the body a vigorous shampooing with a wisp-a most excellent practice, The latter also 
applies when the animal has been out in the rain, but a straw wisp will be found superior to hay for drying the coat under these circumstances. Before using the wisp excess of water should be removed with the body scraper exactly in the same manner in which this appliance is employed after a horse has been washed. The heat of the body and that of the surrounding temperature soon helps to dry the coat, but this process can be assisted by putting on a rug with a packing of straw between this and the body. Under ordinary circumstances when the coat is wet a rug should not be put on until such time as the animal is dry. Many horses begin to sweat after they get into the stable, usually in the form of patches, but this patchy sweating can generally be avoided by vigorous shampooing with a dry wisp of straw. Some grooms partially wash their horses in the summer immediately they come in from work, but it is better to avoid this whenever possible, as a sudden cooling of the skin, especially on the shoulders and saddle, is decidedly pernicious. All parts where the skin is thin, such as around the nostrils, on the face, beneath the tail, etc., should be sponged lightly and thoroughly dried afterwards, otherwise it is far better to avoid this portion of the animal's toilet. As soon as the body is dry, dust and mud should be removed from the limbs with the dandy brush, followed by a vigorous application of the body brush on every square inch of the body, more especially below the belly and inside the thighs. If a horse comes in all covered with mud the latter can either be washed off immediately or allowed to dry on. It is a matter of opinion which is the better method, but all things considered, the latter-named should have preference. The mane, the fetlock, and the tail are just as important as other portions of the body, though unfortunately these are too often neglected. The season of the year, the condition of the animal, and the length of the coat are all factors to be reckoned with, and constitute part of the 
stable calendar. It is surprising what a number of men there are up and down the country, sometimes the masters themselves, and sometimes the hireling, who are content to work their horses until they nearly drop, and then after taking them out of harness or the saddle merely let the animal go into its stall, tie it up, feed it, and leave nature to do the rest. Honest work deserves honest reward, but surely to treat a horse in this fashion does not constitute the latter. A well-groomed horse should be a constant source of pleasure, a dirty or neglected one a continual eye-sore.

The chamois leather and the stable rubber require free application for putting on the finishing touches. After a horse has been thoroughly cleaned and dried the clothing and bandages should be put on. Flannel bandages require to be carefully adjusted, and whilst these are intended for keeping up a good circulation in the legs at the lower parts, and also for maintaining the tendons in a fine condition, they, the bandages, must never be applied tightly.

\section{CIIPPING}

Horses can be clipped at any season of the year, and this without causing them any inconvenience, provided that the body is suitably clothed afterwards. If a horse is kept in a stable all the winter and suitably clothed it will not require clipping, provided that the animal has not been clipped before, but once it is clipped it will require repeating, i.e. if the owner wishes the animal to look well. The winter coat is much longer than the summer one, likewise the texture of the hair coarser. Clipping by hand machines is almost a thing of the past; wheel machines and those which are worked by electricity are almost exclusively used. Two men with a hand-power machine can clip from five to ten horses per day, and do the work thoroughly. In exceptional instances horses are troublesome to clip, whilst certain animals have to be 
either " doped " or " thrown " before they will allow the clipping machine to touch them. When the coat is being shed, viz. in the spring and the autumn, it is not advisable to clip, but to leave it for the time being. All classes of horses are clipped, but horse owners differ in their views as to the manner in which to clip; moreover, there are different views in different localities. Some prefer to clip the whole of the body and the limbs; others will remove the hair only " trace-high," leaving the whole of the hair on the limbs and lower portion of the belly, believing that the hairy covering thus left on affords protection against mud rash, grease, and cracked heel. That it may do so against the last-named is a reasonable assumption, but to leave the hair on above the fetlock is, in the author's opinion, quite a useless procedure. There is nothing to be gained by it, and a great deal to lose in the economy of labour. A clipped horse can be groomed in one fourth the time as compared with that of an unclipped one, excepting in the case of horses which have never been clipped, and whose coats are in a short and fine condition through being clothed and stabled all the year round. When the hairy covering is long it causes a horse to sweat too freely, and the result is that it loses flesh. It is much more economical to forage a clipped horse than one with a long coat. No man can properly groom a horse with a superabundance of hair upon it, and nothing can be more disheartening to the groom than seeing his labour wasted. Hand in hand with clipping should be singeing, and the singeing lamp, when properly applied, is an invaluable aid to the toilet. All the long hair beneath the jaw, around the throat, the back of the jaw, inside the forearms, on the brisket, along the floor of the belly, between the thighs, etc., should be removed with the aid of the singeing lamp. For the removal of the nits of lice and the eggs of the warble fly the singeing lamp is invaluable, and it also can be made to play a significant part when dealing with cases of mange. 


\section{WASHING}

Horses which are properly groomed seldom require washing, but circumstances may render this operation necessary, and it can be done at any season of the year. It is a good plan to wash a horse after it has been clipped, a single washing for this purpose being sufficient. In cases of mange it is absolutely necessary to give the skin a thorough cleansing through the use of soap and water. If an oily dressing has been used this should be washed off at intervals of three or four days. In the summer an occasional bath is beneficial to the skin, and the animal feels reinvigorated through its use.

\section{Clothing AND Bandages}

All light horses, especially during the winter, require the use of a rug, preferably a woollen one, and the owner should see that the clothing is taken proper care of and not thrown in any odd corner of the stable, as so often happens amongst the negligent. There should be a clothing box in every well-regulated stable where the rugs, bandages, etc., can be kept. For summer a light woollen rug is required, and in the winter a heavier one. In a well-appointed stable all the horses wear clothing, and it greatly improves the appearance of the stud. One or more sets of flannel bandages are requisite and, like the clothing, must be taken proper care of.

\section{WATERING}

It is impossible to overestimate the value of a good supply of water for horses, as this fluid is practically food for the horse. Whenever there is a shortage of water for horses it will soon render itself apparent in the loss of condition. When horses are grazing, especially in the spring and early summer, they can do with less water than when the herbage is dry, or the animals are fed in the 
stable ; nevertheless, a liberal supply of water is essential for the well-being of these animals. In some stables a constant supply of fresh water is kept in front of the horses, the manger being fitted with a water trough. This is an excellent plan and one which should be borne in mind by anyone contemplating building a stable. All horses should be watered three times a day, and four when convenient. During the winter the early morning watering of horses, more particularly when the weather is severe, is not necessary, as the animals will seldom drink. If horses are watered at 8 a.m., I2 noon, and 4 p.m., being fed one hour later, the arrangement will usually be found satisfactory. In summer feed and water an hour earlier, but regularity in feeding and watering is a sine qua non. It is a bad practice to feed and water horses only twice a day. It is considered a good plan always to water your horses a short time before they are fed in order that their stomachs may be given the opportunity of dealing to their fullest extent with the corn supplied. Where several horses are watered at the same trough it is a most important matter not to take the animals away from the trough until all have drank freely. Some horses will drink freely immediately they get to the trough, whereas others require to be given time to think the matter over, and if those which have had their fill of water are taken away immediately, the others usually want to follow suit, although they may have drunk little or no water. The result is some members of a stud are properly watered, and the rest improperly so. A horse will drink from half to three gallons of water at one time. If the body is overheated about half a gallon of water will be sufficient for the time being. Horses which are poor drinkers never thrive as well as those which drink freely. Drinking water at public troughs is a most pernicious practice, and carters and vanmen shoud be warned against the dangers of allowing this. The greatest offenders in the watering of horses are farmers, many of whom, and their 
carters, water their horses at the farm pond, the water in which is usually of a most stagnant nature and totally unfitted for drinking purposes. This offence is greatly aggravated by the horses walking into the pond and stirring up the mud or sand. Large quantities of sand must necessarily be taken into the stomach and intestines, where it acts as an irritant. Later on it will lead to the production of sand colic and ultimately the death of the animal. Horses which are fed off the ground are liable to suffer in a similar manner. Greasy legs and cracked heels are very liable to follow when horses are continually going into the water of a pond. Doubtless many readers will argue that their animals have been watered in this way for years and never yet given any trouble, the answer to which is that the risk still remains and the evil resulting therefrom is bound to come sooner or later. Many of these farm ponds contain an excess of nitrates, and these alone may be the cause of loss of condition. The watering pail should be kept exclusively for this purpose, and those which are made of zinc are preferable to wooden ones.

\section{Wintering AND Summering Horses}

There are some horse owners, although these are certainly in the minority, who allow their horses, excepting when required for work, to remain out throughout the winter and summer, both during the day and during the night, believing in the "open air system" of treating horses. In the summer there is nothing better, but in the winter it is a plan which cannot and should not be generally adopted. With mountain and moorland ponies the matter is quite different, but once a horse has been stabled it is not right to allow it to remain at pasture throughout the winter, unless it is provided with a reasonable amount of shelter and a certain amount of corn daily. At the end of the hunting season it is a general custom to turn hunters out for the following four or five 
months, when they usually become " grass fat," but all this superfluous flesh has to be got rid of by about the end of October, being substituted by hard muscles for soft ones-i.e. by condition. Unquestionably this plan has a beneficial effect upon the joints, tendons, and ligaments, and improves the general tone of the circulation. Moreover, grass is a necessary aperient and "Dr. Green" will often work wonders. A free supply of water should always be kept handy when horses are turned out to graze, especially if the grass is very dry and the herbage scanty. As opposed to summering horses the " soiling" system is sometimes adopted. It comprises keeping a hunter or a thoroughbred in a roomy loose box during the summer, and feeding it upon green food, along with hay, with little or no corn. It is not to be compared to the summering system in the writer's opinion, there being so many disadvantages. When horses are turned out to graze always remove the hind shoes and be careful to see that the fore shoes are regularly removed, the feet trimmed, and the shoes replaced.

\section{The Agistment of Horses}

Some owners of grazing pastures make a regular practice of taking horses in for grazing purposes at so much per head per week, the proprietor being known as the Agister. All sorts and conditions of horses are commonly turned out, more especially for the week-end, in places of this kind. To prevent injury to or from other horses the hind shoes should always be removed, but a person who takes in horses does not, like an innkeeper, insure their safety, yet he is obliged to take all reasonable care. The Agister is liable for particular negligence, i.e. he must make good a horse which is lost or stolen through reasons which he could have prevented. The fences and the gates must be kept in proper order, and nothing must be left about liable to cause damage to the animals taken 
in for agistment. It is reasonable to assume that the Agister would be liable for the death of a horse through eating yew, provided that these shrubs form part of his hedges, but the onus of proof, in order to recover damages, would rest with the owner of the horse to show that the Agister must have been aware of the deadly nature of the shrub referred to.

Mares and foals should not be turned out to graze with other horses, as many of the former become vicious when they have a foal running by their side.

\section{THE HORSE AND ITS FORAGE}

As food represents the fuel of animal mechanism it is indispensable that regularity of supply and quality of food constitute the basis of its existence. Domestication has rendered it necessary to supply the horse with a liberal amount of corn.in order that it may perform, in a satisfactory manner, the work demanded of this animal. Horses can live and thrive on grass, but no grass-fed horse will continue to do hard work. Grass is a horse's natural food, but as previously stated the domestication of this animal has rendered supplementary feeding an indispensable feature of its life. Horses, like human beings, vary considerably in their thriftiness or otherwise upon a given amount of food. In other words, some horses will thrive where others will practically starve. A voracious appetite is often associated with an unthrifty condition, and no amount of fodder will make an animal of this kind look well. The amount of food supplied should always be proportionate to the condition of the animal and to the nature of the work which it has to perform. Horses of soft and sluggish temperaments are usually slow workers and get fat on a small amount of food. It is the pace and the expenditure of energy in various other ways which leads to loss of flesh under ordinary conditions. It may be accepted as correct that 
horses foraged on a mixed diet thrive better than when an unmixed one is given, nevertheless, all horses will do well on oats and hay, the latter either as hay or as chaff, i.e. a mixture of cut straw and cut hay or either of these grasses separately. Age, sex, breed, work to be performed, condition of the animal are all important factors in determining the amount and nature of the fodder to be supplied. Elsewhere in this work we have warned horse feeders against the purchase of mixed forage, owing to the inferior nature of some of its constituents, and now repeat the statement just as emphatically. The great secret in feeding both healthy and sick horses is embodied in the phrase " little and often." We have known horse owners feed their animals five times a day, but four times is quite sufficent, and if the exigencies of circumstances demand it, horses will thrive quite well on three feeds per day, but this statement does not disturb the maxim already laid down.

Forage for the horse comprises oats, maize, barley, beans, peas, lentils, bran, gram, hay, linseed, together with certain auxiliary feeding stuffs, such as cake, locust beans, carrots, swedes, ensilage, etc., but the usual forage employed consists of oats or barley, bran and hay, with or without beans, maize, and linseed.

All the foregoing kinds of forage vary greatly in their quality, and it is very necessary for anyone having anything to do with the foraging of horses to acquire a knowledge as to what constitutes good, bad, or indifferent forage No price of forage can be quoted, as the market price must be the price at the time of purchase. Under normal conditions good hay can be bought for $£ 4$ Ios. or $£ 5$ a ton, but the last war has altered all conditions of purchase, as well as prices. Huge quantities of forage are brought into Great Britain from the Colonies and United States, and nearly all the hay coming from the United States consists of one grass only, viz. "Timothy " (phleum pratensa). In that country this grass attain 
three or four feet in height and grows luxuriantly. The following résumé of the various kinds of fodder employed in the feeding of horses should prove of interest to readers.

Hay is divisible into English, Scottish, and Irish, but Scottish and English are by far the best. Hay should be at least one year old before it is used, have a pleasant and fragrant odour, and contain such grasses as rye, Timothy, crested dog's-tail, meadow fox-tail, and sweet-scented vernal grass, as this grass is grown chiefly for the pleasant odour which it confers on the hay crop. Samples of hay vary remarkably in their quality. Two other grasses, viz. the meadow fescue and rough cock's-foot grass are also contained in the best samples of hay. It should neither be mow-burned or musty, but thousands of tons of damaged hay must have been consumed by horses in the army during the recent war. Nevertheless, no sane person would ever wittingly purchase forage damaged in the manner referred to. "Weathered hay," i.e. hay which has been repeatedly soaked and dried loses much of its value, and if hay of this kind is bought it can be improved as forage for horses by mixing with it, in its cut state, a small quantity of salt. The chief difference between good hay and bad hay commonly results from too little or too much heat being evolved in the stack. Overheating hay to the extent of blackening or charring it causes it to become sour, owing to the formation of acetic acid. It requires about $388 \mathrm{lb}$. of grass to make Ioo $\mathrm{lb}$. of hay, the loss in weight being chiefly due to water. The loss of nutritious ingredients is attributable to the process of fermentation carried on in the stack. The sugar has been largely converted into alcohol and carbon dioxide, through which chemical change a certain amount of waste must take place, but there is compensation in return, as the fermentation in the stack breaks down the woody fibres of the grass stems. Horses should be allowed from 5 to $20 \mathrm{lb}$. of hay per diem. 
After grass is cut for hay it parts with about threefourths of its weight by evaporation, but whilst it is lying on the field it undergoes no chemical changes. When it is in the stack the starch contained in the grass is, by the action of the heat, converted into sugar. In making hay early mowing should be practised, i.e. when the grass is young and before the seeds have formed in the flower heads.

If the hay is cut when it is young it is more digestible and of higher quality. If the weather continues to be wet when hay has been cut allow it to lie on the ground without disturbing it, otherwise the grass stems are very liable to be broken. The stems of all grasses are protected by silica, which forms a protective mantle for them, and if this is broken by tossing the grass about wet enters the stems and irreparable damage is done. The most economical method of feeding hay to horses consists in cutting it up, but horses require the use of a bulky food, so that a certain amount of hay should be given uncut. Most of the samples of Scottish hay consist of perennial rye grass, which flowers in May and June. The stems of this grass grow to one or two feet in height, and either alone or in combination with other grasses it makes a first-class hay. It differs from the Italian rye grass by the fact that the latter has long awns to its flower in bloom, whereas the awn is practically absent in the perennial rye grass. One of the worst grasses, and certainly one of the least nutritious, is that known as Yorkshire fog, and its presence in a pasture is an indication of the poor condition of the soil. The smooth stalk meadow grass flowers in June and early in July, and it adds to the value of hay considerably, a remark which is equally applicable to the cock's-foot, provided that the latter is cut before it is allowed to grow too coarse. A sparing amount of clover adds to the value of hay, and horses relish it all the more when it contains this. Sainfoin hay and clover hay are generally on the market, and 
it is always a good plan to purchase a small quantity as an addition to the ordinary hay.

There are many varieties of clover, but giant clovers are much too coarse for horses unless cut up. The white, the red, the pink, and the hybrid clovers are all excellent forage for horses, either green or as hay, and these animals are remarkably fond of them, a remark which applies with equal truth to sainfoin and vetches. No horse should ever be allowed to graze on such succulent herbage as clover before the dew has been evaporated from it by the sun, otherwise the fermentative changes which are liable to occur in the stomach may cause such rapid liberation of gas as to produce death within a short time. Frosted grass and frosted roots are also bad for horses and particularly so for "in-foal" mares. To assist the reader in recognising several of the best grasses which should form part of a good sample of hay, it is a good plan to obtain specimens of these from some seedsman.

Concerning oats and barley both these cereals should be a year old at least, and whichever has the lowest market price may be used, but oats are always preferable to barley, provided that they are of good quality. The average weight for oats ranges from 36 to 42 lb. per bushel, but sometimes a few pounds more-more often, though, a few pounds less. If so, their feeding value is proportionately decreased. Oats constitute a food par excellence for the horse, and many farmers rely exclusively upon oats and hay for feeding all their horses. The farmer is not, however, as a rule a great horse master, and the management of his stud is commonly left in the hands of certain of his dependents, some of whom possess more knowledge than others, and it is fortunate for the horse that this is so. All sorts and conditions of oats are thrust upon the market and imported into Great Britain from various countries. A good sample of oats will have very little husk but plenty of kernel, a shiny outer shell, be free from any musty odour, and neither bleached 
nor kiln dried, although it is hardly likely that the inexperienced would detect signs of either of these features. The same remarks are applicable to barley. Oats and barley may be given either whole or crushed. For old horses they should always be given crushed, likewise both cereals can be fed to horses either dry or moistened. Some horses like them one way, some another. It is a matter of indifference which way they are given. From 5 to $18 \mathrm{lb}$. of oats per day is the right amount for each horse. Both oats and barley should be stored in a dry place, otherwise they are liable to become musty or get over-heated and begin to sprout, in which state they are extremely bad for horses.

A cereal which is used in a good many stables is maize, given in its bruised state. It is properly known as Indian corn, and it has ingredients in it of a very fattening nature ; therefore, if a horse is poor, maize of first-class quality should constitute a component part of the stable menu. As a staple fodder it is vastly inferior to either oats or barley, though we have known some horse owners who have used nothing else but this and hay, and who were apparently quite satisfied with its feeding value. Instead of being flesh-forming it is fat-forming, more especially internally, and fat is no use for work. It helps to keep the body warm, but this can be more satisfactorily attained by work. From 2 to $4 \mathrm{lb}$. maize per horse daily is quite sufficient for all purposes, provided that it is given along with other food. If employed alone, from 5 to $\mathrm{I}_{4} \mathrm{lb}$. of maize would be required daily.

Beans, peas, and lentils are given either bruised or split up along with oats, bran, and chaff. They are all excellent for bringing horses into good, hard condition, and used in this manner from 2 to $4 \mathrm{lb}$. per day will be sufficient. They are very rich in nitrogeneous matter, and their heatgiving qualities are considerable. They are specially valuable during the winter. The author strongly recommends all horse owners to add a proportion of beans to 
their forage, as it will certainly pay them for any additional expense. Beans will replace an equivalent quantity of oats, so that there need be no difficulty if beans are procurable. Peas and lentils are a good substitute and their properties very similar.

Bran is extensively employed; in fact, nearly every stable has a compartment in the corn bin for its bran. It is the coarser offal of the wheat, but its nutritive value is comparatively small. When given as a mash alone or in conjunction with scalded oats it has marked laxative properties. Horses seem to like it along with their food, but some are fonder of it than others. Good bran should have a pleasant odour, leave a mealy mark when rubbed on the palm of the hand, and be in moderately large flakes. Old bran has a brownish tint, the flakes are small, and it loses nearly all its floury touch. It is more used for poultices than anything else, but even for this purpose there is a lot to be said against it, and very little to be said for it. The days of the bran poultice are over, or at any rate should be. From I to $2 \mathrm{lb}$. of bran a day is quite enough as an addition to the forage. Linseed, on the other hand, is a most invaluable adjunct, as its nutritive properties stand well in the list. It requires well cooking so as to swell the seeds in order to obtain its mucilaginous qualities. It is also rich in oil, and from it linseed oil is derived. In France linseed, or flax, is grown to a considerable extent, but most of the linseed imported into Great Britain used to come from Russia. A pound of linseed may be allowed to displace $2 \mathrm{lb}$. of oats in the forage ration, provided that the linseed is properly cooked. It has a most beneficial effect on the coat and skin, and horses improve greatly on this substance.

For sick horses linseed is simply invaluable, for which purpose it is most extensively employed. It requires careful cooking, and the best method of dealing with it is to boil it in a steam-jacketed cooker, otherwise it is inclined to stick to the bottom of the copper and get 
burned. Constant stirring would prevent this. Linseed was largely used in the army for the horses, more especially in the veterinary hospitals, and it proved its value beyond all question of doubt, at home, in France, and other theatres of war.

Locust beans were a good deal used, the steamed beans being mixed with the forage. The locust beans contain a large amount of sugar, and the majority of horses became very fond of them. Carrots, swedes, turnips, etc., form useful auxiliaries in the feeding of horses, more especially carrots for sick animals. There are very few horses that would refuse carrots, even when seriously ill. It is a poor man's stable that cannot afford a sack or two of carrots in the year. They should be washed and given whole, and this remark applies to turnips and swedes. For working horses boiled food does not commend itself to the writer as he believes that it is inclined to make horses soft in flesh, just the very reverse of what occurs when beans are given, to counteract the effects of which an occasional swede or two is useful.

\section{BEDDING}

The best bedding material is straw, either oat, wheat, or rye, the last named being perhaps the best of all. There is very little rye straw about, so it is hardly likely to be used for bedding purposes. Moss litter, bracken, and no bedding at all, excepting the hard, hard floor are the remaining materials. There is nothing to supersede a deep bed of clean wheat straw. To economise stable expenditure this can be lifted in the daytime, all soiled particles removed, and the bedding relaid between four and six o'clock. If a horse is given a good bed it does at least afford it the opportunity of lying down and resting. Some horses apparently never lie down, but a wellearned rest is always a great restorative. In some localities straw is plentiful, whereas in others it can hardly 
be obtained at any price. In all the best-appointed stables straw bedding is employed, as it looks the best, makes the best bed, and subsequently turns into excellent manure, but it is not supposed to have the manurial value of moss litter. If moss litter is used it should be well broken up, frequently raked over, and the saturated portions of it removed from the stall with the shovel. It is a very good absorbent and has slight antiseptic properties, but it gets into the coat and makes both horse and stable untidy. Sawdust is a powerful absorbent, but much too dry for horses' feet. Bracken makes a very good bedding, provided that the animals do not put their beds inside them through the consumption of the bracken. It is an extremely bad plan to allow horses to lie on bare or hard flooring, as they do considerable damage to the fetlocks, the knees, and to the points of the hocks by continual bruising of these particular parts. Moreover, they get extremely dirty and are difficult to clean. A good bed after a hard day's work, a good strapping, and a liberal feed may be said to constitute the three ideal factors in the daily life of a horse. 


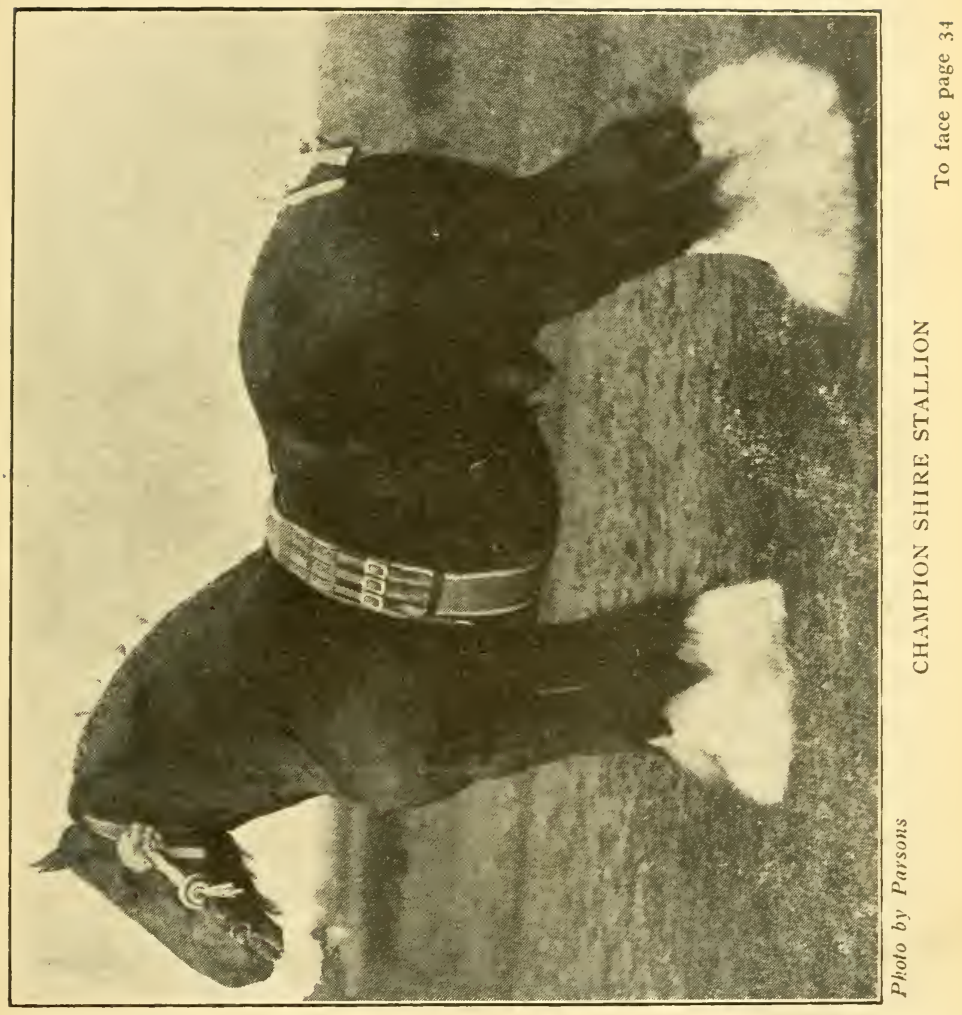





\section{CHAPTER III}

\section{HEAVY DRAUGHT HORSES}

UNDER the heading of this chapter the author has considered it advisable to place those horses which are capable of performing the heaviest class of haulage, and which constitute horses derived from not only the British Isles, but from the United Sates, Canada, and from the Continent. During the last few years huge quantities of horses have been brought into Great Britain from Canada and the States, many of which animals are of a very useful type, but certainly very few indeed are equal to the class of heavy draught horses bred in Great Britain. The writer has examined thousands of these horses, and it is surprising the small percentage that can be classified as being of real good conformation, to say nothing of their slovenly action and bad manners.

Horses which have played a significant part in making the breeds of heavy draught horses, both in the United States and in Canada, are the Shire and the Clydesdale, the Percheron and the Suffolk, all of which are directly or indirectly responsible for the heavy draught horses imported into the British Isles from the United States and Canada. A great many of the best sires have been exported by enthusiastic breeders, but the indiscriminate mating of animals is largely responsible for the production of the indifferent specimens which have been brought into Great Britain from overseas.

\section{THE SHIRE}

This is the heaviest type of cart horse, and one that is largely employed for the heaviest class of haulage. It is 
a breed which originated in the shires, having been derived from the introduction of a Flemish sire into the North Leicestershire and Derbyshire districts, and mating this animal with the mares in the various districts, somewhere between I726 to I793. Mr. Bakewell, of Dishley, has always been regarded as one who did a great deal towards the improvement or manufacture of the Shire horse.

Two animals, viz. the Packington blind horse and Weisman's Honest Tom are looked upon as having played a significant part in the production of the Shire, and it would appear that the county of Derbyshire was the home where the best Shire horses were bred. The old English war horse, from the days of King Henry II to the time of Queen Elizabeth, really represents the foundation stone of the Shire. The Shire Horse Society has, of course, played a most prominent part in making the breed up to its present high standard of excellence. The only serious rival to the Shire is the Clydesdale, and whilst the latter horse has competed with the Shire from a utilitarian standpoint, there always has been and will continue to be those who favour the respective breeds. It is of interest to note that the Shire and the Clydesdale are now mated together for the production of the so-called Clydesdale Shire Horse, and there is no reason why the combined qualities of both should not be reproduced in the manufactured article. For a long time there was a certain amount of prejudice against the mating of these two breeds, but in all probability there was no valid reason why such should not take place. It is hardly fair to compare the respective merits of the two breeds, because both have their good points as well their bad, but if a critical analysis were made so far as good points are concerned the probability is that the scale would turn in favour of the Clydesdale.

In colour the Shire varies, but bay, brown, and grey are frequent, though, like any other horse, a good Shire can 



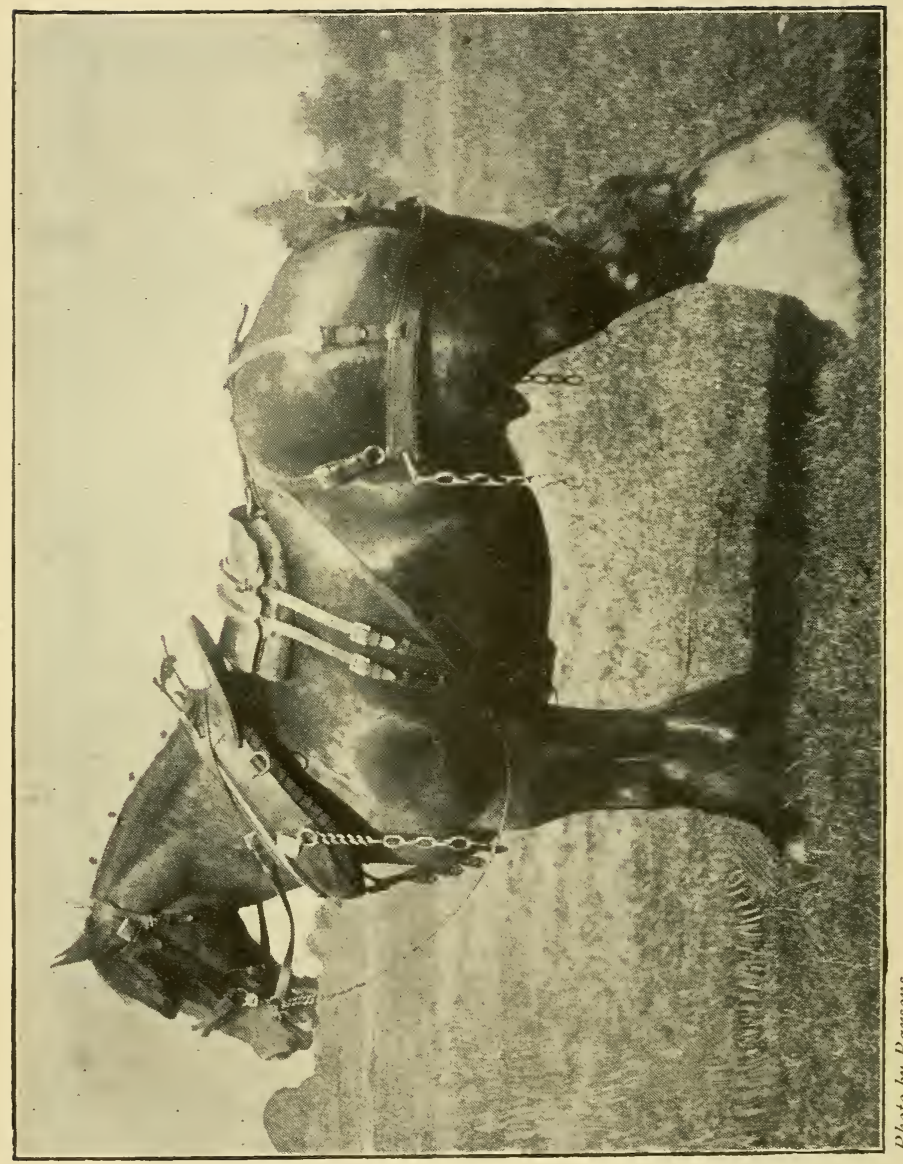


be almost any colour. One of the most distinctive features of the breed is the shortness of the limbs and the ponderous body, the latter rather a disadvantage than otherwise. To be typical a good Shire should have plenty of bone and substance throughout, and an abundance of hair of a soft, silky texture, extending from below the knees and hocks, and encircling the pasterns and coronets. If the hair is coarse in the regions alluded to and the skin thick it indicates that the animal is of coarse breeding and predisposed to a sluggish circulation. Some people object to a superabundance of hair at the parts referred to, and there is no doubt that for horses working on heavy land it does give a certain amount of extra trouble in grooming the animal, but at the same time this long hair is most decidedly protective to the skin, preventing cracked heels, etc.

A well-developed crest, moderately high withers, wellsprung ribs, a strong back and loins, and powerful quarters are points of importance, and as such should never be overlooked when purchasing a horse of this class. A good Shire should have the best of feet and be free from both ring-bone and side-bone-two of the commonest defects. There should be a general compactness of form, and above all good action, and such action should mainly come from the knees and hocks. Faulty action is quite common, but it is always distinctly detrimental. In buying a Shire the intending purchaser should see that the animal is examined prior to purchase for soundness, tried in harness, prove its suitability for the work required, and be sure that it is representative of the breed to which it belongs. Six years is a good age to purchase, whilst the price may range from 80 to 250 guineas, striking the average at I20, when horses have assumed their normal market value. The last-named price does not, of course include horses required for show purposes, the prices for which range up to several thousands of pounds. 


\section{The Clydesdale}

The Scottish horse is an extremely useful type of animal for the heaviest haulage, and it is a breed that has attained universal popularity on account of its soundness of constitution, ability to shift heavy weights of tonnage, its handsome appearance, and remarkable powers of endurance, all of which features render the Clydesdale a valuable animal for work either in town or upon the land. Durability is one of the combined qualities of this breed, so that if a really good stamp of horse is purchased say at six years old it can, with ordinary luck, be relied upon to perform satisfactory labour for the next fifteen or twenty years.

The only really serious rival to this breed has been the Shire, but, as stated in the preceding paragraph, there is plenty of room, both at home and abroad, for both varieties. The origin of the Clydesdale, like that of the Shire, is somewhat speculative, but the county of Lanarkshire appears to be intimately associated with the early history of the breed. It is reasonable to assume that the heavy draught mares of Scotland, several centuries since, were mated with horses imported from Flanders, animals being specially selected for this purpose. Breeders in the Vale of Lanark are usually credited with the production of the Clydesdale, and records prove that the county referred to played a significant part in the early history of the Clydesdale.

The Clydesdale Horse Society, whose head-quarters are in Glasgow, was founded in 1877 , and its first Stud Book was published in 1878 , since which time there has been a systematic registration of pedigrees. The average weight of a typical Clydesdale gelding is about I80o lb., but some Clydesdales have weighed as much as $2000 \mathrm{lb}$., or slightly over this weight. The Scottish horse now under consideration is an extremely useful animal for crossing with the Shire for the production of a good class of agricul- 


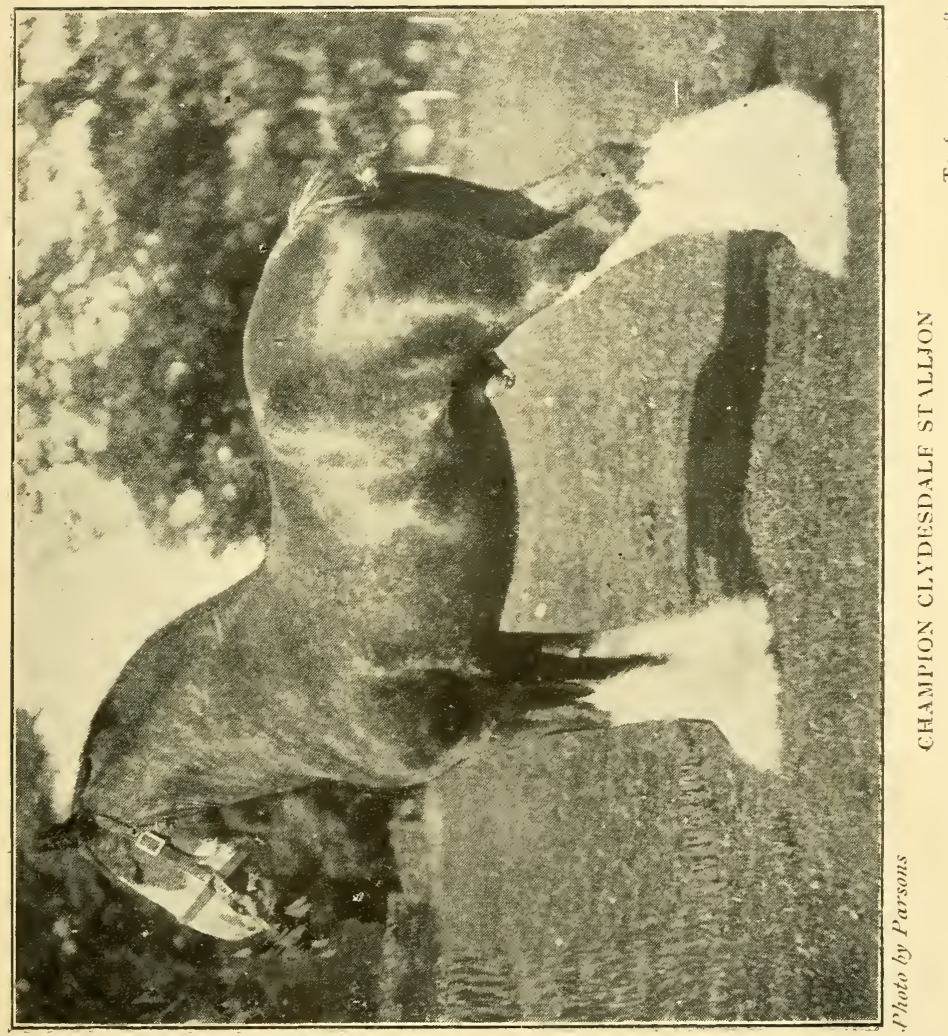



tural horse. In fact, we should prefer to employ a Clydesdale sire in preference to a Shire sire for the purpose just alluded to.

All Clydesdale horses are particularly active and can perform work of the heaviest class with more freedom of movement than the Shire or horses derived from the Shire cross.

The typical colours are bay, brown, or black, with a ratch upon the face, and usually with an abundance of white hair from below the knee and hock to the coronet. Other colours than those referred to are not favoured by Clydesdale breeders, but some good specimens of this breed have been grey, chestnut, etc.

In general conformation the Clydesdale is a cleanlimbed, broad-jointed, strong-loined, stout-necked, powerfully-quartered horse. In proportion to the size of the animal the head is on the small side, the crest well developed, the chest deep-great depth of chest being an additional recommendation. The ribs should be well sprung, the back of the loins well clothed with powerful muscles, and of medium length. The muscles of the quarters and first and second thighs ought to be particularly well developed. Powerful arms and forearms necessarily represent indispensable features.

In selecting a horse of this class the reader should pay particular attention to the regions last mentioned, as many horses are deficient in strength about this part. As previously stated, the Clydesdale should be broadjointed, with great freedom of movement in these joints; but the Clydesdale is a horse, as a rule, with very good action, both at the knees and hocks, giving it a quick, active step with the feet lifted well off the ground. Freedom from disease, such as bone-spavin and side-bone, is of course desirable, though there are plenty of horses, having both the diseases named, which continue to work without any sign of labouring.

Granting that a Clydesdale has either, or both, of the 
troubles referred to, and is five or six years old, with good action and free from lameness, the writer would certainly advise the purchase of such, with or without a modification of price.

So far no mention has been made of the feet, but the old moral, "No foot, no horse," is as applicable to Clydesdales as to any other horse. The feet must be proportionate, sound in the wall and sound in the sole, with the heels well open, strong bars, and a well-developed foot-pad, or frog. As a rule the Clydesdale has good feet, but exceptions are by no means uncommon. Anyone wishing to purchase a Clydesdale of good breeding should make application to a breeder of repute, or else advertise his requirements in some agricultural journal, such as, for instance, the North British Agriculturist, or the Scottish Farmer. It is not at all a bad plan to visit some of the principal Scottish agricultural shows and confer with breeders and exhibitors as to any animals which they may have for sale, or else purchase a colt, say a two-year-old, which has been exhibited at the show, not necessarily one that has been in the prize list, as the competition at many of the Scottish shows in the Clydesdale classes is often very keen, and good animals may easily be kept out of the prize list. The prices of Clydesdales range from Ioo guineas up to several thousands, but a fairly good specimen of this breed can be bought at the average price of $1_{50-250}$ guineas.

\section{THE SUFFOLK}

The Suffolk, formerly known as the Suffolk Punch, is a most excellent breed, and one that has always been popular, but its popularity has been gradually increasing during these last twenty years, and there is every prospect of its further increase, although it has got a closely allied rival in the form of the French horse-the Percheronto which it bears a close resemblance.

The Suffolk has been largely exported to the United 


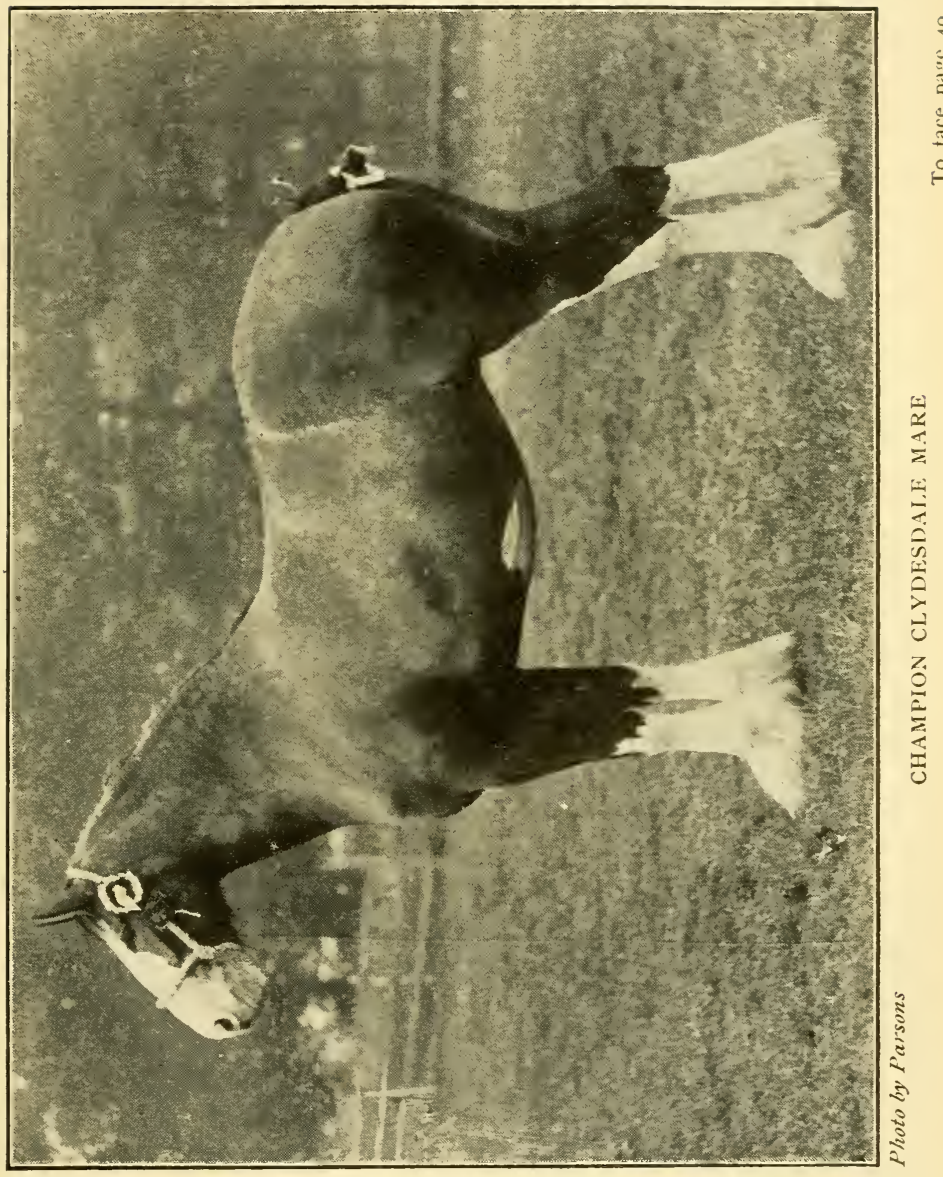



States, where, we believe, it has given every satisfaction. As a heavy draught horse it is particularly valuable for artillery purposes, and it has been in considerable demand during the recent war. In a gun team the Suffolk materially added to the utility and the appearance of the team, and very rarely failed to satisfy the requirements.

It is an invaluable horse for working on the land. For quick work with moderately heavy draught in town it has no superior, and certainly very few equals, consequently we find this breed of horse taking its place in some of the finest cart studs in England. There are many enthusiastic breeders of Suffolk, and excellent prices have been obtained within recent years for animals sold at the various dispersal sales.

As the name implies the Suffolk originated in the county of its name several centuries since, and has always been famous for its remarkable powers of draught, activity, cleanness of limb, and soundness of constitution. As a rule they are good-tempered animals, but there are exceptions as in every other breed. The typical colour is chestnut, with or without silver hair in the mane and tail, but this must not be sufficient to give the animal a roan appearance. Commonly the pasterns and lower part of the legs are white, with blaze on the face. The correct height is about I6.I. The Suffolk Horse Society has done a great deal towards the improvement of this breed through the registration of pedigrees, and the various strains of Suffolks have, for many years, been kept in a state of purity. One of the outstanding features of the breed is the low position of the shoulders, the highly developed muscles in this region, and the great depth of the chest.

The Suffolk is a heavy-bodied horse, but exceptionally clean limbed; in fact the latter characteristic is only observed in the Percheron, the Boulonnaise, and the breed now under consideration.

It is a variety of horse that commends itself to the 
majority of horse masters in search of an animal moulded upon lines which render it specially suitable for shifting anything up to three-quarters of a ton at a slow trot.

As an agricultural horse for working on light land the breed is pre-eminently suitable, but on hill farms, or especially if the land is heavy, the Clydesdale is a much more suitable horse.

The Suffolk is a good thriver, durable, remains workably sound under ordinary conditions as well as any other variety, and for the lighter work of a contractor it would be impossible to suggest the purchase of any better breed. Select a gelding at six or seven years old, and get the animal whenever possible direct from a good stud, there being many of these in the county of Suffolk, from which county most of the best specimens have been derived.

Prices of Suffolks vary, but a good one can be bought for about I50 guineas.

\section{THE PERCHERON}

This is a continental variety of horse and exists in three grades, namely, the light, the medium, and the heavy, and, as stated in the previous page, it bears a strong resemblance to the Suffolk and the Boulonnaise.

The Percheron horse is, however, chiefly bred up to one standard, namely, that suitable as a vanner or gunner horse, resembling in all particulars our own Suffolk.

The French horse has received a great deal of notice since I9I4 by British horse masters, but for generations prior to this time the United States, Great Britain, and, maybe, certain Colonies kept these horses, bred from them, and used them also for mating with the native horses of their countries. This is one reason why so many of the light draught horses (Army classification) possessed a good deal of the Percheron conformation combined with some of the poor qualities of the Colonial horses.

The British Percheron Horse Society was recently founded for the purpose of introducing into the United 


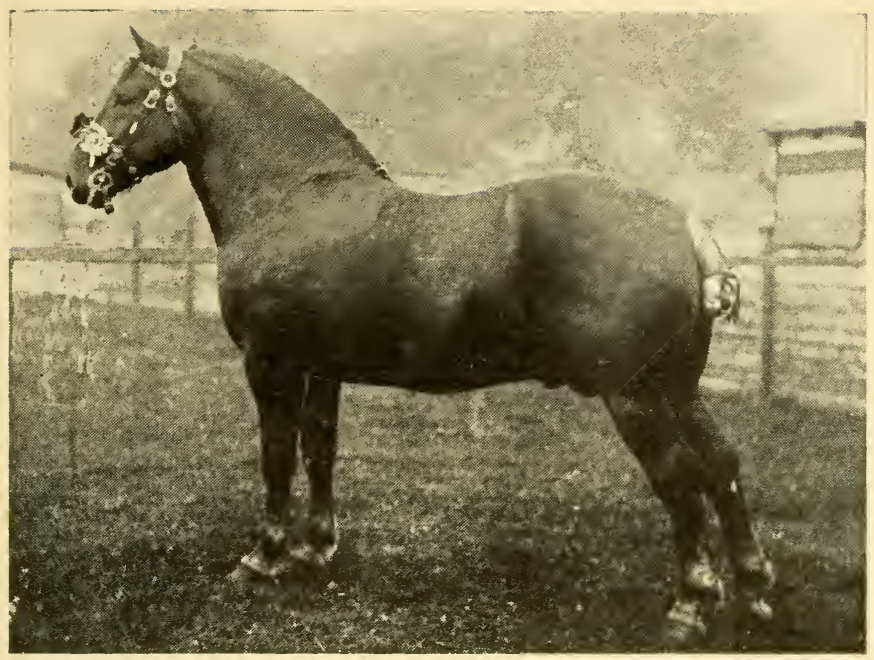

SUFFOLK STALLION

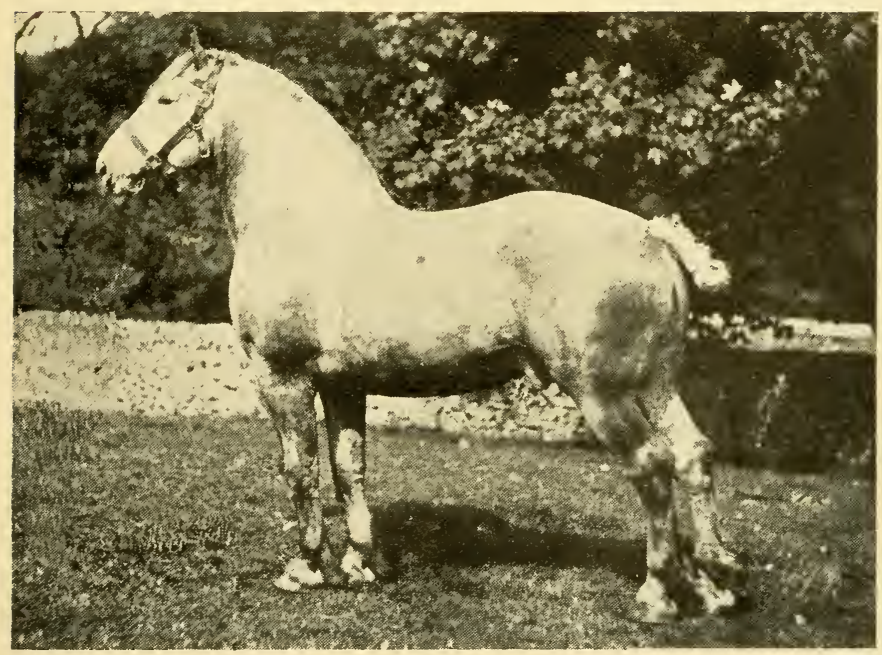

Pholos by Parsons 

Kingdom the Percheron draught horse, a breed indigenous to the Perche districts of France. The Society referred to has its head-quarters in London, and anyone anxious to become a member of it should make application to its Secretary, Mr. A. W. Hewett. Like all other horse societies the general welfare of the breed receives every consideration, and its interests are promoted at every opportunity.

The typical colour for the Percheron is grey, and if the reader will refer to the accompanying illustration he will at once see the striking resemblance which the breed bears to our own Suffolk. Enthusiastic breeders proclaim that it is a better horse than the Suffolk. This is not correct; in fact, if it comes to a critical examination of two typical representatives of each breed, an analysis of points will certainly be in favour of the Suffolk horse. Those who advocate that it is superior to the latter as regards soundness, etc., certainly display a strange want of knowledge upon the subject.

The Percheron is, in relationship to its size, a smallheaded horse with a very short neck, thick in all proportions, heavy-shouldered, but deep in the chest and very round in the body. It is a type of conformation that many connoisseurs would object to, being ugly about the head and the neck, more especially the set-on of the head. The Percheron, like the Suffolk, has advantages over the Shire and the Clydesdale, likewise the agricultural horse in general, in having no long hair upon the lower parts of the limbs, whilst in horses of good breeding the legs are usually clean throughout and as a rule free from diseases.

Quite a number of Percheron horses have recently been imported into Great Britain, and some extraordinary prices-as much as 5000 guineas-have been paid on one or two occasions for the best specimens. It is a breed that ought to cross very well with the Suffolk, though whatever advantages would be gained by such a cross it is difficult to conceive. 


\section{THE FARMER's HoRse}

It is not necessary to say very much about the farmer's horse, which is usually a cross-bred animal derived from, directly or indirectly, any of the preceding breeds of horses. Unfortunately it is commonly the product of indiscriminate breeding, and the result is that many of these horses are of a nondescript class, yet they are always marketable, sometimes so much so that the price is far beyond any intrinsic merits possessed by the animal.

There are farmers' horses and horses working on the farm of a good, bad, and indifferent type, but the word " indifferent" certainly answers for fully 50 per cent of these animals. There is no reason why the agricultural horse should not be bred up to a better standard of excellence than it has been in the past, but recent efforts in the selection of horses for certain districts constitutes a solid step in the right direction. Doubtless the tractor will limit the use of the farm horse; nevertheless, this animal will be required to perform its share of the farm work.

The majority of the farmer's horses are derived from the Shire or Clydesdale, but on quite a number of farms in the shires, and possibly elsewhere, many typical specimens of the respective breeds do their share of the work, excepting when required for show or stud purposes. When a farmer is buying a horse for ploughing, carting, etc., he can sometimes purchase an animal for the matter of a few pounds, owing to some infirmity which renders it unsuitable for town work. The writer has seen in prewar times $£ 5$ horses bought by farmers, placed on the land and worked regularly, which, after a time, have made such remarkable improvement as to become as useful as a horse for which ten times that amount has been paid.

There are certain diseases affecting the horse which show considerable amelioration after the animal has been worked on soft and moist land for a few months. It is 
reasonable to assume that the average price a farmer pays for a horse, barring war conditions, is 70 guineas, and a fairly good type of horse should be obtained, but very often it is quite the converse. A poorly built horse, that is one which is flat-sided, weak in the forearm, narrow and slack in the loins, light on the body, weedy about the neck, and deficient in bone will never, no matter how good the horse mastership, make up into a decent type of animal. A badly built horse always remains so, but a horse in poor condition, provided that Nature has been kind enough to construct it upon good lines, will, with few exceptions, soon repay the farmer or the owner for the extra attention which it is necessary to bestow upon it. It is not every farmer that knows a good horse when he sees one, yet there are plenty who do, and it is fortunate that this is so. The degeneracy of the farm horse has been an ever-present drawback, but by careful selection and an increasing interest in the general welfare of the work horse upon the farm there is good prospect of a steady improvement taking place.

\section{The Vanner and the Tradesman's Horse}

Van horses are divisible into those required for work in light vans and those which are employed in the heavier work of ordinary railway vans. Both classes of horses should be constructed upon sound lines, stoutly built, have fairly good action, good feet, and above all good manners. The qualification last named is very essential, because the majority of horses required for this work have frequently to be left wholly unattended, a remark which applies with equal force to the tradesman's horse. The butcher, the baker, the corn chandler, the dairyman, the grocer, and others delivering their goods by cart or van require an animal which can do its work and remain sound at any odd time, and it may be for twelve hours or more with little or no rest meanwhile. The tradesman's horse ranges from a pony of $I 2$ or I3 hands up to an animal 
I6. 2 or thereabouts and capable of performing its work at a slow trot, though the butcher seems to be one of the principal offenders in working his horse at the fastest pace possible. There is no surer method of wearing the animal out. It is the pace which kills, and when it does not kill its effects are detrimental in some other way. If tradesmen would conserve the energy of their horses by exacting a moderate amount of work within a limited number of hours they would find it much more economical in the long run ; many a veterinary surgeon's bills would be saved, to say nothing of the annoyance and inconvenience caused through enforced idleness in consequence of lameness or some other injury. A good horse master will always take particular care that his horses are regularly fed, regularly watered, regularly groomed, and consistently worked; but a bad horse master will violate all the foregoing principles and then wonder why the animals placed under his charge are so unsatisfactory, both in the stable and out of it.

Both vanners and tradesmen's horses comprise Suffolks, Percherons, Hackneys, Galloways, Russian ponies, Welsh ponies, Dale and Fell ponies, Highland ponies, and crosses derived from any of the foregoing. There is just as wide a range in the prices of these animals as there is in the quality of them and the breeds from which they have been derived. If a tradesman is purchasing a horse the cheapest guinea's worth that he can obtain will be that of having the animal examined by a qualified veterinary surgeon as to its soundness and, if necessary, suitability for the purpose for which it is required. But price and suitability are matters which chiefly concern the intending purchaser.

Horses of this class can be bought at the various horse repositories, at fairs, markets, or from private vendors, and various other sources. A cob or a pony suitable for a tradesman can usually be got at prices ranging from $£ I 5-£ 35$ or $£ 40$, whilst a van horse will probably cost 55 or 60 guineas, sometimes more, seldom rather less. 


\section{CHAPTER IV}

HEAVY DRAUGHT HORSES-AGE, SEX, COLOUR, SELECTION SOUNDNESS, ETC.

AcCording to the classification as adopted by the British Army the heavier type of horses are divisable into heavy draught and light draught in accordance with the duties assigned to these animals.

For the heaviest class of haulage, horses of the Clydesdale, Shire, or a cross derived from these, are those which are usually selected, whilst for artillery work with the lighter guns, stocky horses of the light draught or Suffolk type are required.

Both the Percheron and the Boulonnaise make excellent gunners.

The light draught horse is merely the ordinary type of vanner, as used by Carter Paterson, Pickford, etc. When a large number of horses are collected together, as in the various Remount Depots, and immediately required for service, it follows that a certain amount of discrimination is required in selecting horses according to the classification allocated; hence one often finds some departure from the strictly recognised type of animal required for the purpose. The indiscriminate mating of stallions and mares has always been, and still is to a great extent, one of the most baneful influences in horse breeding.

It is astonishing to note how very few people, professing to know, and with a large amount of experience in addition, really understand "Horse Conformation" either at rest, or in action, and the relationship the 
latter bears as a predisposing factor in the production of disease.

The heavy draught horse will always be required for use in commercial life, but particularly so in the army and in agricultural husbandry.

Motor traction has supplanted, in a great measure, horse traction, but it can never, either efficiently or economically, entirely supplant the latter.

The value of the heavy draught horse in warfare, as proved in the Allies war with Germany, has been amply demonstrated. The heavy draught horses comprise the Clydesdale, the Shire, the Suffolk, and the two continental breeds, viz. the Percheron and the Boulonnaise, the larger breed of the latter being the chief draught horse employed about Boulogne, Calais, St. Omer, etc. The short, powerful neck and the large head are very characteristic of the breed last named.

In the selection of a horse for the heaviest class of haulage two breeds stand pre-eminent, viz. the Shire and the Clydesdale. It matters very little which is selected, provided that a good class of animal is chosen, concerning which there need be no difficulty, if the instructions laid down in this chapter, are diligently read and digested: The majority of the devotees of the Scottish horse will naturally prefer to select a horse of this breed, nevertheless when the heaviest class of work has been done, the author thinks that the Shire takes precedence. All things considered, the Shire is more massive in general build, but not quite so agile as the Clydesdale. This is due, in a great measure, to the middle piece or body of the former being more cumbersome. In other words, the Scottish horse has a more economical distribution of material, in relation to working capacity, and consequently is able to employ this to greater advantage.

Doubtless good horses can be produced by mating the Shire and Clydesdale, and there is evidence that in future this cross will be vigorously pursued by breeders. 
The Shire horse of fashionable strain is an exceedingly handsome animal, short on the legs and with abundance of feather below the knees, over the pasterns and fetlock joints ; but for work on the land, this is rather detrimental than otherwise.

Too much feather or hair about the fetlock causes a lot of mud and wet to adhere to it, finally resulting in cracked and greasy heels, therefore the farmer should bear this in mind when contemplating purchase. Fully 75 per cent of the horses working as cart horses and vanners are either half or three-quarter-bred Shires, whilst a great many of the imported Canadian horses have some Percheron blood in them.

Quite recently we have heard a lot of rubbish talked about the Percheron in relationship to soundness, and the merits of this as compared to the Suffolk. There is plenty of room for both varieties, but when an analysis is made of conformation and soundness, it will be found that the Suffolk is an easy first.

The writer has examined Percheron and Boulonnaise horses in France for this purpose, with the results as above stated. No lay mind can appreciate these comparisons in relationship to soundness. The Suffolk is an exceptionally valuable horse for all van work, for light dray work of brewers ; for carting work on the farm-in other words, for draught up to half a ton, either at a fast walk, or slow trot.

The colour of the Suffolk is either chestnut or sorrel. A half or three-quarter-bred Suffolk is distinctly inferior to the pure-bred animal, hence in purchasing a horse of this breed it is better to get into direct communication with a breeder of repute. This can easily be done by reference to the announcements in some of the Live Stock Journals.

The best age to buy a cart horse is between 6 and 9 years, but if required for work on the land, such as harrowing, etc., 4 or 5 years is a suitable age, so that by 
the time the animal reaches 7 years, the proprietor will have had 3 years' work out of it, and an animal of increased value for sale. This is a very economical method of purchasing horses for farm work, provided that the farmer is a good horse master, and delivers his instructions to his dependents accordingly.

At 6 years a horse is fully matured, and its bones, ligaments, and tendons capable of standing a maximum degree of strain with a minimum of liability to injury. It is perfectly ruinous to work a horse in town at 4 or 5 years, as the constant concussion on the hard roads leads to the joints, tendons, etc., becoming prematurely and permanently damaged. The height should range from $I 6 \frac{1}{2}$ to $I 7 \frac{1}{2}$ hands.

Sellers of young horses $(3,4$, and 5 years) quite commonly offer these as being ( 4 and 5 in particular) 6 years old, therefore care should be exercised (see chapter on age) when buying.

In one way it is better to buy a horse a little older, or seasoned animal, than purchase one too young for immediate work in town. Geldings are usually a little higher in price than mares or fillies, there being more demand for them, nevertheless the writer would not allow sex to stand in the way, provided the animal is suitable in other respects. Temperament is a most important matter, and certainly should receive every consideration. A vicious horse is always a source of danger, the latter being proportionate to the degree and form of vice. Some horses are vicious in the stable only, others both in and out of the stable or in the harness.

A common vice is kicking and biting other horses, especially during feeding time. Kicking and biting are most dangerous, and usually finish in some kind of trouble for the owner. Muzzling is the only preventive of the latter, and this is a nuisance, and often inconvenient to both horse and proprietor.

Stamping the feet, rubbing the legs, and kicking the 
stall posts, are often due to skin irritation (symbiotic mange). This annoyance leads to thickening of the skin, capped hocks, and certain other pernicious effects gradual in onset, but a permanent legacy when established. Vices, objectionable habits, or whatever one chooses to call such, are of infinite variety (see chapter on vice), and the possibility of the existence of these ought not to be overlooked.

Concerning the colour of draught horses we have considerable variety to choose from, such as light and dark bay, golden chestnut, sorrel, dun, brown, grey, white, strawberry roan, blue roan, and black.

There is an old saying that a good horse may be any colour, which is quite true; nevertheless, bay, brown, chestnut, and grey take precedence in the order named in the degree of popularity, and rightly so. The majority of Shire-bred horses are bay or brown, but other colours are quite common.

Bay, brown, and black are the usual Clydesdale colours, and certainly the most favoured by breeders of them.

By far the commonest colours (irrespective of breed) are bay, either light or dark, and brown.

Both harmonise with any surroundings, look well, and wear well.

In closing the remarks on colour, we should say that it is not necessary to attach too much importance to it, provided that a really good animal, proving suitable on trial, and sound, is offered for sale.

In giving a candid opinion as to the, selection of a horse, nothing short of life-long experience will enable the amateur buyer to be certain of the quality and qualifications of his purchase.

Horse-flesh can only be judged with advantage to the buyer by keen observation, coupled, in a great measure, by the aforesaid experience.

It is necessary to point out that there is considerable difference between defects of conformation and the 
soundness or unsoundness of a horse. Defective conformation is very common, and may be observed either when the animal is at rest, or, and very often is, only noticed during its movement, viz. the walk or the trot.

Many cart horses cross their front feet when they walk -hand over hand-and may, in this manner, easily tread on the coronet-always a nasty injury, producing severe lameness.

Defective action of this nature does not warrant the author to recommend purchase, no matter how excellent the animal in other respects. There is also another defect of action, the converse of this, viz. feet turned outwards - splay feet. A heavy draught horse should bend both knees and hocks freely, and lift the feet well off the ground both when walking and trotting, although the former is the pace for this class of animal. It is wonderful what differences exist in action of horses, although the ordinary observer may not notice such.

Sometimes a cart horse has good action in front and poor action behind; more rarely the converse applies. Far too little attention is paid by breeders of heavy draught horses towards the improvement of action.

Buyers seldom study this when selecting. The author insists that good action is just as important in this class of horse as in any other breed.

The intending buyer should select a horse with bone and substance, i.e. strong and broad forearms, broad knees with thin skin covering the short and broad cannons. Commonly cart horses are very deficient in bone below the knees. A great deal of importance should be attached to this statement. A super-abundance of fine silky hair in the latter region is indicative of good breeding, but a moderate amount of it is preferable. Good feet are a sine qua non-old saying, no foot, no horse, is an absolute truism. The feet demand special attention, and the most critical inspection is expedient.

The normal slope of the wall is from 45 to 50 or 55 
degrees. We merely mention this as indicating that the wall of the hoof should be of a moderate degree of obliquity, free from indents and cracks, healthy in appearance, and the heels well opened out. A concave sole (never flat) and sound well-developed frogs are most essential.

Fully 25 per cent of horses have faulty feet, hence the reason why the buyer cannot be too particular. Always have both fore shoes removed when examining the feet, otherwise some serious defect such as separation of the wall and seedy toe may be hidden.

The fore feet are more liable to disease than the hind ones. Brittle hoof, flat feet, contracted heels, sandcrack, false quarter, corn, canker, thrust, seedy toe, and side-bone are some of the principal troubles to be looked for in connection with the feet, all of which are regarded as a sufficient cause for the rejection of a horse when examined by a veterinary surgeon.

Feet may be classified as good, bad, and indifferent. Feet of the first category may easily be ruined through bad shoeing, and bad feet made still worse through the same cause, hence the expediency of attending to details of shoeing, both in summer and winter, likewise to the feet of unshod colts. The periodical examinations of the feet of the last-named should be religiously insisted upon, thereby preventing many troubles arising out of unequal distribution of pressure.

If the feet are muddy, always wash them before proceeding to inspect them, as many defects are sometimes hidden in this manner.

Heavy horses and vanners are very liable to be troubled with sub-acute (sometimes acute) laminitis or foot founder, which usually causes the sole to drop or become more or less flattened-an irreparable defect. The wall of the hoof also becomes malformed and irregularly ringed (laminitic rings).

Sandcrack, usually seen at the inner quarters of the 
fore feet and toes, in the hind ones consists of a split in the wall of the hoof, and is due to an imperfect secretion of horn from the horn-forming structures at the coronary band. It always starts from above and extends downwards. It may cause acute lameness, or this may be absent. These cracks are sometimes filled in for the purpose of deception, and their presence may easily be overlooked.

It is equally important to have sound sight and sound wind. The eyes require critical inspection (see diseases of eye). The two chief defects of wind are (a) roaring, (b) broken wind. The former is an affection (in 90 per cent of instances at least) of the larynx and the latter one implicating the lungs. They are both fairly common complaints in heavy draught horses, and materially interfere with the commercial value of the affected animal (see chapter dealing with these troubles), though not necessarily rendering it less useful to the owner.

Thus detection, prior to concluding purchase, is of vital importance to the buyer, otherwise a considerable sum of money may be dropped.

There are quite a number of diseases affecting the various structures of the limbs, but the chief ones of interest to the buyer of heavy horses are :

Side-bone, shivering, ring-bone, bone-spavin, windgalls, and other bursal swellings, contraction of the tendons, curb, thoro-pin, sprung-hock, and capped-hock (see these diseases). In addition to the troubles already enumerated, horses of all kinds are liable to be affected with various obscure affections such as colic, worms, strangles, cramp, staggers, any of which may be easily overlooked at the time of purchase.

Failure to detect any obscure maladies implies no liability in damages against the professional examiner, unless neglect of proper skill can be proved.

Veterinary surgeons, like the rest of human beings, have no pretence to infallibility, but given a good man for the 
purpose, the buyer may be saved pounds for the modest fee usually demanded of, from half to one, or two guineas.

Apart from such professional examination, the buyer can to a great extent protect himself in various ways.

$\mathrm{He}$ can insist on having a warranty with the animal, a general warranty of soundness and fitness for the work required. A written warranty is preferable to a verbal one, but the latter holds good when it can be substantiated.

Horses purchased at certain public auctions-horse repositories-are warranted sound in particular respects, which, if not complied with, and the animal returned within the specified time, renders the sale void.

Buying from a private source, or a dealer of repute, is often very satisfactory, sometimes unsatisfactory. Whenever possible have the animal on a week or ten days' trial. This gives one time to note most faults and the good qualities possessed by the animal.

The majority of dealers of repute will never hesitate to allow a responsible buyer to have a horse on trial as above, or sometimes even longer. 


\section{CHAPTER V}

BREEDING HEAVY HORSES AND THE SELECTION OF THE SIRE AND THE DAM FOR THIS PURPOSE

THE breeding of heavy horses is likely to prove more remunerative than that of breeding those of a lighter class, unless it be hunters and polo ponies, both of which are certain to be in demand for an indefinite period. The heavy draught horse has been, still is, and is likely to be for generations a marketable asset, provided that the right stamp of animals are produced. The farmer's horse has been produced without the care which should have been bestowed upon its production. Most of the best Clydesdales, Shires, and Suffolks produced by breeders do not find their way into the hands of the general farming community, but are exported or else sold to the largest contractors. The average type of agricultural horse, bred on the farm, and worked on the land up to four or five years of age, is not, as a rule, of the best type of conformation, owing to the fact that the mare has not been bred from the right class of stock in order to breed a good type. We have the Clydesdale, the Shire, the Suffolk, and the Percheron to breed heavy horses from. The two first-named are those to select for the production of animals capable of dealing with the heaviest class of haulage, and the work has to be done at a walking pace. The Clydesdale can be mated with the Clydesdale and the Shire with the Shire for the production of pure-bred stock. A Clydesdale sire and a Shire-bred mare makes an excellent cross, probably better than when this is reversed. As the Clydesdale and the 
Shire have so many affinities there is no reason why the very best of stock should not be produced in the manner named. It is quite another matter to cross the Shire with the Suffolk or with the Percheron. The highest market prices can be obtained for the right class of animals belonging to the breeds named. The Percheron, or French horse, is an animal of fine constitution, of splendid size, power, weight, activity, and courage, consequently for a clean-legged draught horse suitable for either military transport, artillery, agricultural, or commerical work, it is an invaluable breed. The United States and Canada have bred thousands of this class of horse, and are apparently satisfied with its introduction into these countries; nevertheless, as a breed the author does not consider that it possesses the impressive, sterling qualities of the Suffolk. The British Percheron Horse Society's primary and definite object is that of bringing this breed into pre-eminence in Great Britain, although the author fails to see any particular advantage in this when our own breed, the Suffolk, can do everything that the Percheron can do. Some may prefer the colour of the Percheron to that of the Suffolk, but this is of no particular importance. Both breeds are clean-legged and active, deep-chested and well-hearted, and are particularly good in the stoutness of neck and shoulders. The possession of these features makes the breeding of this class of horse desirable for the purposes already named, and anyone establishing a stud of draught horses would do well to consider the advisability of purchasing good stock of either the Suffolk or Percheron breed. Begin by buying two or three five or six-year-old mares and a couple of two-year-old fillies. This will constitute the nucleus of a good stud, provided that a judicious selection is made and the animals selected from studs which have built up a good reputation. To those who contemplate crossing the Suffolk with the Percheron the author would say don't do it. There can be no possible advantage. 
Like the Clydesdale and the Shire the breeds are allied in nearly every feature and of good constitution, which is not always the case with the heavy horses, and the introduction of another breed strengthens any tendency in this direction. The initial outlay in all horse-breeding operations do not necessarily represent either future success as regards sale or the production of high-class animals. Pedigree goes a long way, but it is no good unless the animal can carry it on its back. Some of the poorest horses ever bred have had a right royal pedigree, but they have been as useless animals as one could possibly conceive. To be a successful breeder of horses it is essential that a man should know a good horse when he sees one, be able to find a better, and lastly purchase one that is better still. This constitutes prospective judgment, and it is the initial to success. It seems almost absurd to say that the sire and dam should be sound-theoretically and practically sound-under which circumstances they may be expected to reproduce these features in their offspring. A practical man will probably feel amused at this statement and suggest that the author ought to belong to a Horse Breeding Commission. There is no answer, silence being golden. A keen eye and a tactful hand can detect most of the good and bad points in a horse, and unless these senses are well developed it is better to leave horse breeding alone. 


\section{CHAPTER VI}

\section{THE CARE OF MARE AND FOAL}

\section{THEIR MANAGEMENT FROM SPRING TO WINTER}

"IN-FOAL" mares can, with advantage to them, be worked up to within a week or so of foaling, but during the last month or two of gestation the work should be of a light character. It is a great mistake to put severe strain upon "in-foal" mares later than the period referred to, and it is quite possible that to do so is often accountable for many of the abnormal and difficult presentations met with in mares. Mares which have had one or more foals experience less difficulty in the delivery of the foal than in the case of a mare having a first foal. It is wonderful what a remarkable difference there is in brood mares for maternity purposes. Some mares look after their foals in a most kindly manner, allowing the little creature every facility for sucking, whereas others manifest very little interest in their foals, and not a few are vicious, both to their offspring and to strange attendants. It is not always the best mares which produce the best foals, but given a fairly good mare and a good sire the offspring is usually good. In the selection of a brood mare an animal of a kindly disposition, in other words of good temperament, is of primary consideration, as vicious propensities are usually transmitted from parent to progeny. A good brood mare is an invaluable asset on any farm, as she can help to stock the farm with horses and at the same time participate in her share of the work on the land, or whatever other purposes she is required for. Heavy draught horses will always be in 
demand for agricultural and other uses, and there is no reason why the possession of three or four good brood mares on a farm should not be made to pay their way. It is the indiscriminate breeding from unsuitable mares and sires which commonly causes failure in breeding operations. A mare should not be bred from before she has arrived at her fifth or sixth year, but mares at the ages of twelve and fifteen years, or even more, are specially suitable for breeding purposes. It is reasonable to assume that a mare at eight or ten years old will produce a more vigorous foal than one at eighteen or twenty. The registration of brood mares by the various horse societies has done a great deal of good in laying the foundation stone towards the perpetuation of good stock -stock which is sound and free from the so-called hereditary afflictions. It has been and still is customary to look upon certain equine troubles, such as roaring, bone-spavin, ring bone, curb, splint, side-bone, stringhalt, etc., as capable of being transmitted from either a sire or a dam to their offspring. It is not thought that the actual disease is transmitted, but "predisposition" to the development of any of the foregoing troubles directly an exciting cause comes into operation. In all probability there is a good deal of truth in this, and practical demonstrations are not wanting in support of this theory. Very few mares would be obtainable for breeding purposes, especially of the heavier class, which were free from one or other of the diseases enumerated. Remarks which apply to the dam are equally applicable to the sire. A great deal of rubbish has been written and spoken about hereditary diseases in the horse, and an animal considered sound by one veterinary surgeon may be rejected as unsound by another, therefore it is quite easy to perpetuate many fallacious notions. The great thing in selecting a mare for brood purposes, in addition to the feature already referred to earlier on in this chapter, is that of possessing good conformation and good action, 
without which qualifications it is quite unlikely any really good foals will be produced. The foaling season extends from, or approximately so, February to the end of May or early in June, but the best months for foals to be born are March and April, so that when the grass is just beginning to spring the mare will be able to take full advantage of the succulent herbage, and the foal have the opportunity of outdoor exercise, pure air, and rapid growth. It is customary to fix the date of thoroughbred horses from January Ist, and all other horses from May Ist. The period of gestation, or the time which a mare carries her foal, is eleven months, or within a week of this period. Sometimes a mare will foal a few days before or after the specified time. It is of very little importance, under these circumstances. With some mares it is not an easy matter to ascertain whether they are "in-foal" or otherwise, and the only satisfactory manner of doing this is to make a manual examination. Towards the later phases of gestation, say the eighth or ninth month, the abdominal dimensions increase until within a week or so before foaling; the udder enlarges and the teats begin to wax, followed by milk secretion in the gland. A mare may come into milk without being in foal, but the supply soon passes away. Every "in-foal" mare should be kept in a loose box for several weeks prior to the time she is expected to foal, so that she may become accustomed to her surroundings. Never take any risks by tying a mare up in the stable within a couple of months of her time for foaling, the writer having seen some nasty accidents arising from having done this. Another "don't" is never leave a mare out at pasture at or about foaling time. Seclusion is necessary when a mare is in labour, and the less she is disturbed the better. If all is going on well the foal will be delivered without any assistance, and during delivery the mare may be either standing up or lying down. It makes no difference. In every instance the birth of the foal is immediately 
preceded by the appearance of the water bladder externally, and the rupture of this should immediately be followed by the presentation of the foal in its normal position, viz. both fore limbs with the head lying between and the muzzle directed forwards. Deviations from normal presentations are quite common, and when they do occur it is absolutely essential to send for professional assistance as speedily as possible. Delay in doing so may mean the loss of a foal and complicate matters, whilst interference by the uninitiated will probably lead to the death of the mare. The author cannot too strongly emphasise the importance of having professional assistance. The owner should never allow anyone to interfere with the mare when in this condition. The country is overrun with empirical humbugs, i.e. unqualified men, who are wholly unfitted, except in imagination only, to perform the duties of a duly qualified practitioner. If the public would only make themselves acquainted with a man's qualifications before employing him the general community and the live stock of the country would be a thousand-fold better off. The author has a thorough detestation for those individuals who profess knowledge without possessing it. It is a rank form of charlatanism and should be dealt with in the manner it deserves. This, however, is merely digression from the subject now under consideration. Directly the foal is born the cord should be tied about two inches from the body of the foal -a piece of sterilised catgut or twine can be used. A double ligature about one and a half inches apart on the cord is the best method of application, and then the cord severed between the ligatures. (See "Specific Diseases, re Septic Arthritis in the Foal.") The foal rapidly gains strength after it is born and may begin to suck right away, but a little assistance from the attendant will generally help the matter a good deal. Some foals are very stupid and are several days old before they make any real headway in sucking. In cases of this kind the 
foal can be artificially fed on cow's milk or some other substitute. A well-nourished foal should almost be seen growing and its strength increasing from hour to hour. The mare should be liberally fed, certainly not less than four times per day, on corn, linseed cake, scalded bran and oats, hay, and green food when obtainable. A strong foal is a great drain upon the economy of the mare, consequently the more generously she is fed the better the growth of the foal. During fine weather it is an excellent plan to turn both the mare and the foal out at pasture, but grass alone is insufficient for the mare during the first three months after the foal is born. Sometimes mares " pick their foals," i.e. the foal is born prematurely, say any time after six months. If before this period it constitutes abortion, and there is an infectious form of abortion liable to affect mares in a similiar manner to that trouble amongst dairy cattle. In either case a mare may or may not part with the " cleansing," but this is a matter demanding urgent professional skill, and this fact should never be overlooked, otherwise the owner may have cause to regret it.

As already stated, when the weather is suitable both mare and foal should be allowed out in the paddock. A mare will, during June, July, and August, get three parts of her own living at pasture, and she ought to give a superabundance of good milk for nourishing the foal during the months named. There are plenty of owners who give their mares no corn at all when they are out grazing, but it will be found much more satisfactory for both mare and foal, and to the proprietor, to allow the mare $8 \mathrm{lb}$. of oats per day and I lb. of beans in addition. As soon as the foal is two or three months old it will begin to nibble at the grass, and by September-October the foal should be allowed a small quantity of crushed oats every day. A foal should be weaned when it is six months old, after which period the milk supply usually decreases, and if the foal continues sucking it has a strong 
tendency to weaken the dam. Excepting when the nights are very warm towards the latter end of June and throughout July, both mare and foal are better housed at night. All brood mares should be bred from regularly, and not have one foal and then miss a couple of seasons, as this tends towards sterility.

\section{SEPTIC LAMinitis}

This disease consists of an inflammation or congestion of the blood vessels and sensitive laminæ of both fore, both hind, or all four feet, and it is the result of septic infection, arising from the uterus, the result of septic material such as a portion of cleansing or the whole of that structure being allowed to remain in the uterus until it has undergone decomposition. This is very liable to happen after a mare has " picked her foal," as the cleansing is commonly retained, or some portion of it. Many a valuable mare has been lost for the want of proper attention at this particular time. It is impossible to leave a mare in the same disgusting condition which the writer and others doubtless have also seen after a cow has calved. Septic laminitis is an extremely painful and malignant disease, usually leaving the feet with drop soles as a sequel, and sometimes necessitating the destruction of the animal, as not only being the most merciful, but also the most economical. Prevention is, as we all know, better than cure, and septic laminitis is one of those diseases which, by the exercise of ordinary care, can be prevented. 


\section{CHAPTER VII}

THE SADDLE HORSE OR RIDER

THE word " hack " as opposed to " hackney " is applied to the saddle horse, and it may be worth while to repeat the maxim that " a hack is a horse to ride, but a hackney one that should not be ridden." This is a very trite maxim and implies a good deal more than it expresses. The conformation and action of the hack should be diametrically opposed to that of the hackney, though quite a number of hackneys have been, and still are, sold for hacking purposes. This, however, does not alter the truth of the previous remarks.

Every saddle horse should have good manners, a light mouth, a good temper, and be familiar with all road nusiances, such as tractors, motors, etc. etc. Horses that are troublesome on the road or in traffic are a nuisance and sometimes dangerous. Vice often becomes active when the surroundings are most unsuitable for the rider, and many very nasty accidents have arisen in this manner. If one can purchase manners-which can sometimes be done-it is, in the author's opinion, far more important than absolute soundness. This is particularly necessary in the case of those who like myself are of nervous temperament. Some horses-certainly the exception rather than the rule-have very sweet tempers, will pass anything on the road, and, having good manners, it follows that a light mouth must be a complement. It is quite a difficult matter to buy a really good hack with manners, mouth, action, and pace. The majority disclose some fault-venial in some cases, rotten in others. 
Naturally what may appeal to one man is thoroughly disliked by another one. The "Jack Mytton" type of rider likes one of the " Hell-for-Leather Brigade," but it is just as well that members of that fraternity are not too prevalent.

As a saddle horse the British-bred animal has no equal, no matter whether it be a pony 9 or Io hands, or a horse I6 hands or over. The height of a hack must correspond to the height of the rider. For instance, a man whose height is say five feet seven inches will look much better upon a horse I5 hands than he would upon one over I6 hands. This is a fact that should never be lost sight of when contemplating buying a horse of this class. Sex is unimportant, but a gelding is to be preferred when obtainable, although this must not be allowed to stand in the way if the animal is suitable in other respects. Sometimes mares are a bit of a nuisance in summer. The best age is six or seven years old, but some prefer to buy at four or five years. A well-seasoned hack must be seven or eight years, and if it has been taken proper care of, used but not abused in its youth, it should be good for service during the next ten years-sometimes more, sometimes less. As to colour, the author certainly prefers bay, followed by chestnut (golden), liver ditto, brown, grey, black, and lastly dun to nearly chestnut, roan (red or blue). Piebalds and Skewbalds look better in a circus ring than on the road. Mouth most important. A hard mouth and the animal that "bores" is very objectionable. A saddle horse for a boy of twelve to fifteen years should be well broken and good tempered, and not less than five or six years old. A thoroughbred pony, say I 5 hands, will suit some boys. Hacks suitable for children can be bought as Shetland ponies, Welsh, Exmoor and Highland ponies, but one must take particular care to ascertain that a pony required for this purpose is free from any form of vice. High action, i.e. action coming from the knees or hocks is not a desirable feature 
in a saddle horse, but good shoulder action is indispensable. The ribs must not be too much bent, in fact a slightly flat side is the best type. It is quite impossible to get to know what sort of a rider any particular horse will make without trying the animal thoroughly. Some very plain horses make superb animals for this purpose, and some showy ones quite the reverse-a plain or even ugly-looking animal. Quite a large proportion of hacks are bought at the horse repositories in various parts of the country, and many of these animals are either warranted sound in a general sense or carry with them a specific warranty, such as sound in wind and eyes. The last named is quite valueless, so far as warranty is concerned. Apart from soundness in the regions named a. horse may have a hundred and one defects, any of which may render it " something more than a white elephant" to the purchaser. Defects of wind-roaring and broken wind-defects of eyesight-opacity of the cornea and catarrh, etc., as well as bone-spavin, ring-bone, splints (badly placed), chronic sprains and bursal swelling. along with abnormal or diseased feet and vice should all debar one, if present, from buying a horse for saddle purposes. To be correct, the knees should be broad, the pasterns of moderate slope, the legs clean and well placed in relationship to the body, a well-moulded head and a strong back and loins plus nice quarters, with every sign of animation throughout are some of the chief essentials of beauty.

Prices of hacks vary considerably, but range somewhere between I5 guineas (ponies for children) and several hundred guineas. A good all-round hack should be bought for 70 or 80 guineas, and a boy's hack for 35 or 40 guineas, and occasionally a trifle less.

\section{The Hackney or Harness Horse}

The Hackney, or Roadster, is a very useful type of horse, and one that, prior to the advent of the motor-car, 
was greatly sought after by those who wished to keep either a single horse for trapping purposes or an animal to run in double harness. Some wonderful specimens of the breed have been produced and still are being produced, but it is a variety which can hardly be expected to keep abreast of the times when the motor-car is making such rapid advances all the world over. There are really two distinct types of hackneys, viz. the Yorkshire hackney and the one derived from the Norfolk trotter, which for convenience may be designated the Norfolk type of hackney. Strictly speaking, the Yorkshire type is more allied to the coach horse and a slightly larger animal than the original type of hackney. Irrespective of type the general opnion is that the hackney has been a manufactured article and owes its origin to an Arab horse brought into this country from Aleppo about I706, and the imported animal was introduced into Great Britain by a Yorkshire gentleman - a Mr. Darley. The Arab referred to is usually spoken of as the "Darley, Arabian." A thoroughbred horse, known as " Eclipse," was foaled in I764, which was a great grandson of Mr. Darley's imported horse. During the year I I I5 a chestnut horse, with a white muzzle and four white stockings, known as " Flying Childers," and called after its breeder, Mr. Childers, was foaled. The sire of this horse was the "Darley Arabian," and the dam, "Betty Leeds." "Flying Childers" was said to be of compact form, long in the back and loins, and his height about I5 hands. Like "Eclipse" he is accredited with being a fast horse. He was the sire of "Blaze" which was foaled in I733, and this horse subsequently travelled in Norfolk, where he established the foundation stone of the hackney, then known under the title of "Norfolk Trotter." "Blaze" in his turn was the sire of a horse called "Shales," which was foaled in I755. "There were several horses bearing this name. "Blaze" was also the grandsire of "Driver," a horse which was foaled somewhere about I765. This 
was followed by the "Fireaway" family belonging to Jenkinson, West, and Burgess. Jenkinson's " Fireaway" was foaled in I780, and West's "Fireaway" in I800. The last-named was the sire of Burgess' "Fireaway" foaled in I8I5, which in turn was the sire of a horse called "Wildfire," foaled in I827. Later on we find the names of "Phenomenon," the sire of "Performer," and "Performer" begat "Sir Charles" (I843). " Sir Charles " was the sire of "Denmark," and the latter the sire of Sir Walter Gilbey's " Danegelt," foaled in I879. This horse had a brilliant show and stud career, and a considerable number of the best hackneys have the blood of this horse in their veins. The foregoing is a brief survey as to how the hackney was moulded, so far as descent on the male side is concerned. The mares indigenous to the county of Norfolk were employed for mating to the aforesaid sires. According to authentic information, these animals were well built, being of compact type, durable, fast, but did not possess the extravagant action which many of the modern hackneys possess. The obvious deduction is that the right material was present on the side of the mares, and that all that was required for establishing the hackney was the use of impressive sires-a condition which was duly fulfilled. Almost anyone can recognise a hackney at a glance, either as a 15 or 16 hands horse or as a pony between I2 and I4 hands. The compact form, the remarkable knee and hock action, the clean limbs, the thin skin, and the general ensemble are unmistakable signs of this useful type of horse. As a roadster the breed has certainly no superior and very few equals. Its manners are usually very good, both in and out of harness, whilst for durability, courage, and speed the breed leaves nothing to be desired. We must not forget to mention the splendid work done by the Hackney Horse Society, and the untiring energy displayed on behalf of the breed by their Secretary, Mr. Frank Euran. It is of interest to note 
that the Society has overcome the prohibition as formulated by the Department of Agriculture in the United States (Igr8), forbidding the importation on and after January Ist last of all horses except pure-bred ones, for breeding purposes and racing, from Great Britain. The Hackney Horse Society sent a special representative over to the States, and the order has now been rescinded, excepting that relating to horses from continental Europe, which is still to remain in force. The prices of hackneys vary according to age, sex, pedigree, etc., but a very good horse of this class can be bought for 80 or 90 guineas, and a useful stamp of hackney pony should be obtained, as a sound animal, for 60 guineas. The hackney cob, when in harness, makes about as smart a turn-out as it is possible to conceive, and if anyone prefers a horse in single harness to that of a small car, the hackney is the sort to buy.

\section{The Cleveland Bay}

This is a very handsome variety of horse of the coach horse type, in the manufacture of which breed the Cleveland Bay must have played a significant part. The Vale of Cleveland, in Yorkshire, more especially around Whitby and Pickering, is the land of its nativity, and some of the best specimens come from that district. Somehow or another the Cleveland Bay has never attained any particular degree of popularity, but the reason of this is not very clear unless it be due to the decline of coaching. It certainly deserves to occupy a much better position than it has ever attained, as the conformation is usually of the best. The typical colour is either light or dark bay, with black legs. There is usually a star on the forehead, but no white elsewhere, unless sometimes in the hollow of the heel, the existence of which breeders regard as a sign that some other blood has been introduced into the breed. Most of these horses have exceptionally good legs and feet, the limbs being 


\section{THE CLEVELAND BAY AND VAN HORSE $7 \mathrm{I}$}

clean and the joints of the best. About a hundred years ago three noted families of Cleveland Bay horses are said to have existed, viz. the "Dart," the "Barley Harvest Horse," and the "Hoghill Horse." The two last-named, it is said, were foaled just before the end of the eighteenth century, and these families are usually regarded as the foundation stone of the modern Cleveland. A Cleveland Bay contains a good deal of thoroughbred blood in it, and it resembles the race-horse in its configuration, although it is a much heavier type of animal. In every feature it re-echoes the true type of a coach horse, and this is one reason why the demand for the breed is comparatively small. It is very questionable, so far as Great Britain is concerned, whether the Cleveland Bay will ever occupy a prominent position. In some of the Colonies the breed has been introduced, and we believe with satisfactory results. As regards soundness and durability, everything is in favour of it.

\section{The Light Van and the Tradesman's Horse}

Very few words are necessary when speaking of the light van horse and one suitable for the lighter work of the tradesman. As a rule a nondescript type of horse fills the gap, it being exceptional, certainly not the rule, to find a settled type of horse running in harness and doing the work of the small trader. Cobs and ponies, without any qualification beyond the possession of four limbs and an animated body, very often represent the type of horse now under consideration. One can hardly expect the average tradesman to possess very much knowledge of horse-flesh, and what little is possessed is often more misleading than helpful. Improper treatment and careless handling interlinked with a certain amount of ignorance are mainly responsible for the indifferent class of horse one so frequently sees doing their jobs in town and country. There is no reason why the tradesman 
should not possess a well-groomed horse, a horse that is well harnessed and looks well in harness, and one that is able to give a fair day's return for a fair day's keep. The author would like to see the small trader with a totally different class of horse from those which the majority of them now possess. The type of horse should be a bantamised form of the Suffolk, and animals of this type can, by judicious selection, be bred, and the correct way to breed them will be through using a stoutly built Highland pony sire and a Galloway mare. The small trader requires a horse that can trot with anything up to 4 or 5 cwt. without showing undue effects of fatigue.

The reader will ask what about the soundness of the tradesman's horse. If the animal is practically sound it is not necessary to worry about anything else. Eyesight and wind must be right; the feet must be good; the limbs must be clean, and the joints strong and supple. When buying a horse of this class, flex the knee joints, the fetlock joints, and both hock joints, and if there is any stiffness, don't purchase. Another trouble to avoid is a navicular disease either in one or both fore feet. A horse affected with this has generally a short, catty step; goes groggy, and in horsey vernacular it is called a "grog." Plenty of tradesmen's horses are sold with this trouble, which is always progressive and incurable. Further evidence is afforded by lameness when the animal comes out of stable, but this usually passes off with exercise. (See "Navicular Disease in connection with the Foot and its Diseases.") A tradesman, when contemplating buying a horse, should never purchase without having the animal examined by a qualified veterinary surgeon, and the fee for such examination ranges from half to one guinea. Many a foolish speculator might have saved himself pounds, to say nothing of the annoyance, had he followed the advice which the author now tenders, and which the tradesman would do well to adopt when buying a horse. 


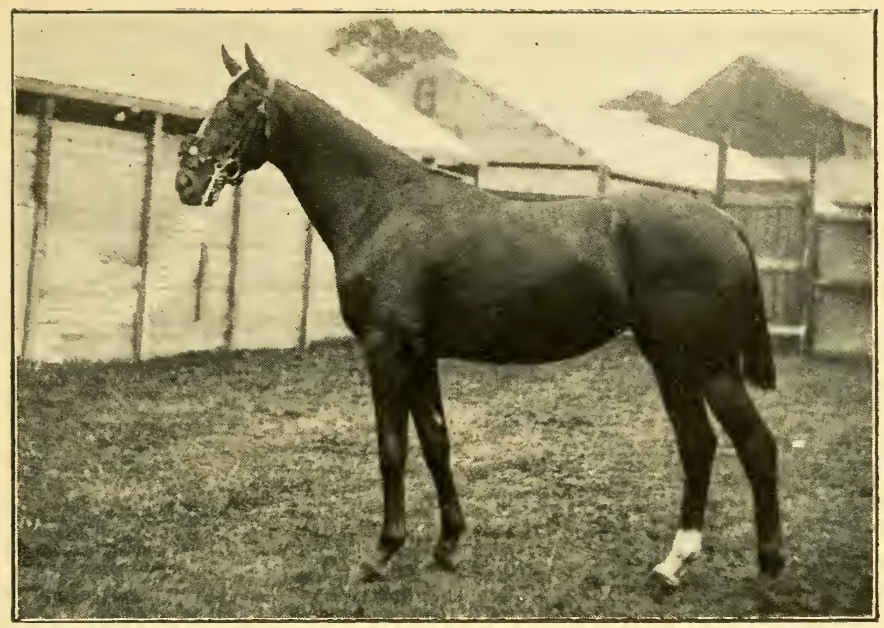

HUNTER : TWO YEAR OLD FILLY

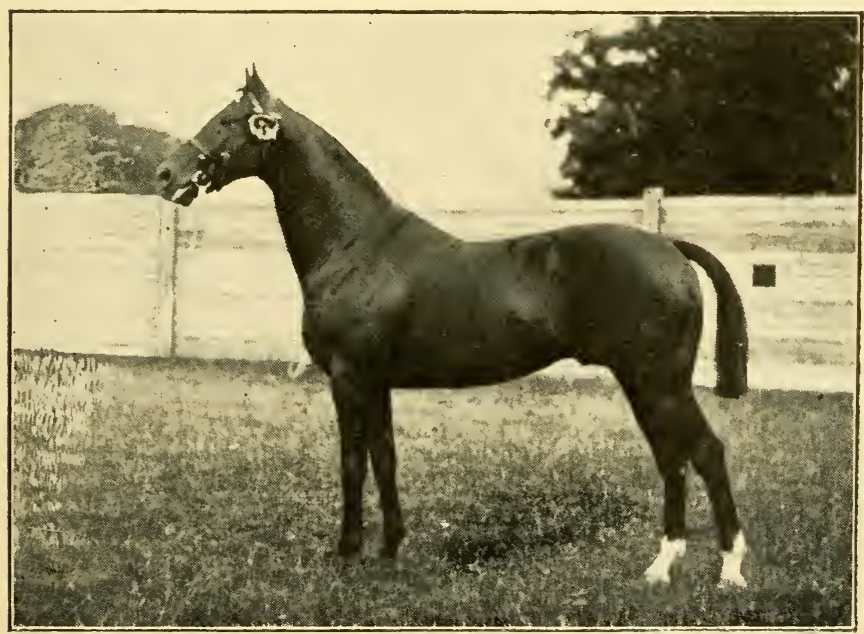

Photos by Parsons

POLO PONY

To face page $7 \cdot 2$ 



\section{THE Hunter}

In the modern type of hunter, the blood horse, or thoroughbred sire, is largely responsible for its production, and the Hunters Improvement Society has paved the way for the production of hunters to meet the requirements of those in search of these animals. All sorts and conditions of hunters are found in stables, at horse repositories, at fairs, at markets, and in the stables of dealers, where they are offered for sale, bought, and not infrequently returned to their vendor. It is reasonable to assume that more hunters are sold at Messrs. Tattersall's Horse Repository in London than in any other sale yard in the kingdom. Some very high-class animals are exposed for sale, and, as in every other horse repository, the converse sometimes applies, in spite of the stringency of the auctioneer's regulations. It is customary to speak of a horse as " the hunter born," and the " hunter made," both of which terms are sufficiently expressive. It is impossible to pay too much attention, in the matter of soundness, when about to purchase a hunter. To judge distance a hunter's eyesight must be perfect. To go the pace, it must have a sound heart, sound lungs, and a sound breathing apparatus, from the top notch to the last air space in the lungs. It must be sound in its joints and sound in tendons, ligaments, and above all be free from stiffness. Moreover, it must possess two very essential features, viz. great freedom of shoulder movement and free flexion of the hocks. If it is wanting in the two last-named it never will jump clear. Condition is also of vital importance. The muscles must be hard. To ascertain whether the latter is present or not run the hand along the upper border of the neck, which should feel like a cord; in fact, it should be as hard as iron. Condition is seldom bought. It has to be made, and the new owner may have to make it. If the animal is required for immediate use this cannot be done at the beginning 
of the season. It is work that should commence in August or September and be carried right on until November, when the animal's work and the owner's sport may be expected to commence. Purchase from a private source, when reasonable facility is given for trial, can be recommended. A week or two's trial is not at all an unreasonable request, provided that the vendor is satisfied that the animal is placed in capable hands. When a horse is on trial, under these conditions, it rests with the intending purchaser to take all reasonable care of the animal, otherwise he becomes responsible in damages to the proprietor should anything go wrong. Nothing but a trial can give complete satisfaction, yet plenty of buyers have to take their chances as to how the animal will turn out. Unmade hunters are bought at three and four years old, particularly at some of the principal fairs in Ireland. Horses which have been regularly hunting for several seasons, say four or five, are usually about ten years old when offered for sale, and this is the class of animal which frequently comes up for auction, and also for sale by private treaty. We should not recommend the purchase of an animal required for use as a hunter after twelve to fifteen years old, although it must not be assumed that a horse is no use for this purpose after the age specified, as there are plenty of hunters doing good work when they have reached a score of years or even more. Space forbids us to enter into details concerning hunters, but we have endeavoured to indicate one or two matters which may be of some interest to the reader. In conclusion, we may say that no hunter should do any real work before it is five years off, otherwise it will be prematurely damaged.

\section{Ponies}

The various breeds of ponies comprise the Shetland, Welsh, Exmoor, New Forest, Irish, Highland, Fell, and Moorland ponies, Thoroughbred and Hackney ponies, 
Russian, Iceland, and Basuto ponies. All these various types of ponies possess certain distinctive features, more conspicuous in some than in others. The thoroughbred or blood pony is, so far as make and shape are concerned, the lightest built animal amongst the whole of the ponies, and next on the list comes the hackney pony, which has, of course, descended from the thoroughbred. The breed first named is a saddle horse pure and simple, consequently we find that it is usually advertised and sold as a boy's hunter. It is practically a replica of its larger prototype, the thoroughbred, and really represents the blood horse. The hackney pony is essentially one employed for harness purposes, and if the reader will trouble to refer to our description of the hackney he will find this pony therein referred to. The Arab pony is closely allied to the thoroughbred and possesses great staying power. It is an extremely handsome animal and commonly bright bay or grey in colour. It makes an excellent saddle pony and has been used both as a sire and for play in polo. All the hill ponies are very hardy, and very sure-footed. They are willing workers when properly broken, and capable of a large amount of endurance. In action, pace, and manners they vary considerably, some being much better than others, and not a few useless for any purpose, unless it be for removing the herbage from some barren mountain-side. The Shetland ponies are hardy little creatures, very suitable for children, either for saddle or harness, and being small they are inexpensive to keep and inexpensive to purchase. We have seen them sold for as little as $£ 4$ apiece, but a good Shetland pony can be bought almost anywhere for $£ \mathrm{I} 2$ or $£ \mathrm{I} 5$, at which price it should have good manners, be five or six years old, and thoroughly broken. Soundness in these ponies is a mere matter of detail. The Welsh ponies are most excellent animals, and being a little larger than the breed last named, are really more useful for work in a small governess car. Some of them can get over the 
ground, but of course do not, as a rule, possess the turn of speed like the thoroughbred or the hackney. Ponies are very handy animals, and can be kept where it would be impossible to keep a large horse. They are easily looked after, not costly to keep, and always a source of pleasure to their owners. The writer is particularly fond of them, and this, irrespective of age, sex, or breed. The colours to be preferred are bay, brown, chestnut, and grey, but like a good horse, a good pony may be any colour. If an unbroken pony is purchased care must be taken to have it properly broken, otherwise it will acquire all sorts of objectionable habits, such as shying at trifling objects on the road, kicking, etc. It is much more ready to adopt vice than virtue, and whilst the former is so easily acquired it is less easily eradicated. Anything up to 14.3 hands may be classified as a pony. Prices range from $f$ Io or fI2 up to several hundreds of guineas, according to quality, but from $£$ I 8 to $£ 25$ may be accepted as a fair average for the ordinary type of pony. 



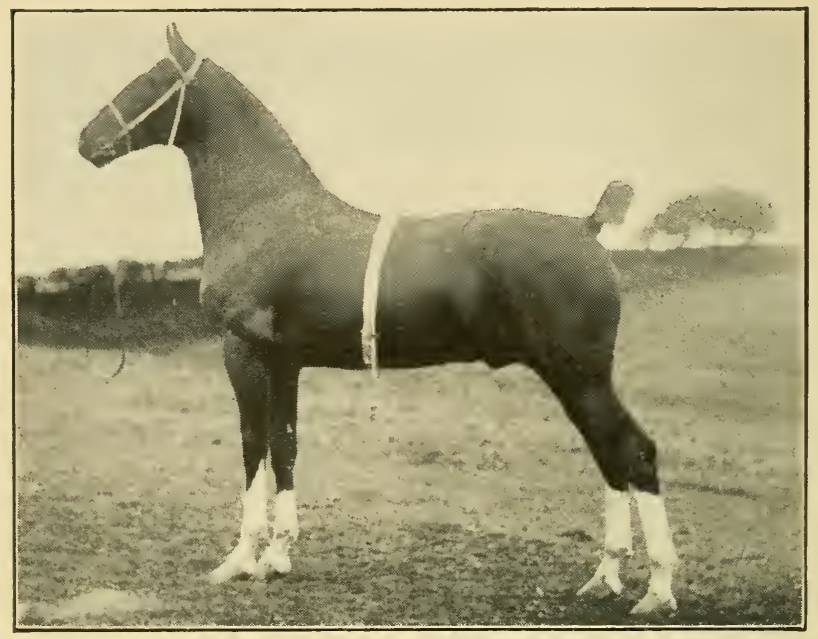

HACKNEY STALLION

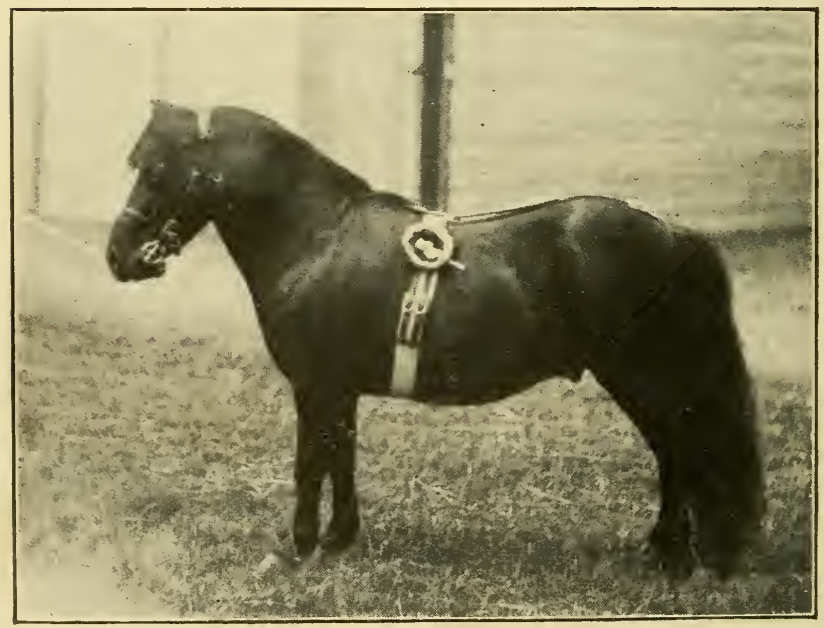

Photos by Pursons

SHETLAND PONY

To face page 77 


\section{CHAPTER VIII}

BUYING A LIGHT HORSE AND WHAT TO AVOID IN SELECTING THE SAME

In the selection of a light horse, i.e. one required for work in single or double harness, a good deal of judgment is necessary, as this class of horse is much more liable to be afflicted with diseases in connection with the tendons and joints than in the case of the heavy draught horse. The roadster or harness horse, the hunter, the trotter, and the light van horse are all placed in this category for selection, but the reader is referred to the chapters on the various breeds for further information respecting these. It is a much more difficult matter to obtain a well-matched pair of horses than a single, and the prices are generally considerably more. There is not, however, the same demand now as formerly for pairs of carriage horses, or even for harness horses of any kind, the motor having largely supplanted the use of these animals. Still, it is quite a reasonable assumption that horses will always be employed both for business and pleasurable occupations, though possibly it will diminish in extent.

To begin with, there are various channels through which purchase can be made, but the dealer, the horse repository, and the private vendor are the usual sources. Whenever possible purchase from the breeder is desirable, but buying in this direct manner is seldom feasible. The horse dealer has, unfortunately, through the motor had to abandon his business in quite a number of instances, consequently, there are fewer dealers of repute than formerly. The horse dealer with a good reputation can 
usually be relied upon to provide the intending purchaser with an animal suitable for his requirements, provided that sufficient time be allowed and an adequate price paid for the animal. Moreover, nearly every dealer will allow a week or ten days' trial, so that the buyer has every opportunity afforded him of judging as to the good and bad points of the animal. In the meantime its soundness or otherwise can be ascertained by submitting it to examination by a qualified and experienced veterinary surgeon. The writer emphasises the word "experienced " because examination of horses and the relationship to soundness can only be acquired after many years of experience. Another word of advice whilst discussing this matter is that of having every animal, prior to purchase, professionally examined, as the modest fee exacted by a veterinary surgeon may be the means of saving many pounds, to say nothing of the trouble and annoyance at some future date. In every instance it is advisable, when purchasing from a source available for the purpose, for the intending buyer to try the animal as to its suitability for his requirements : at the same time, the possibility - in the event of such existingof vice or some objectionable habit or habits may be revealed. The percentage of horses which are sound, more especially the ordinary roadster and draught horses, is, from a legal standpoint, very small, whereas, from a practical point of view, 75 per cent of horses are sound. There would be very few horses at work if this were not so, the mere fact of a horse being legally sound is no criterion as to its utility, in fact, it may even be the reverse. When a horse is classed as "practically" sound the natural inference is, that the animal is capable of performing all the duties required of it, and likely to be required, at the present time, or at any subsequent period within a reasonable limit, as to age, etc. All horses purchased at horse repositories are sold subject to the conditions of the sale regulations, and if a horse is 
bought and afterwards found not to comply with the catalogue description, it can and should be immediately returned, along with the veterinary certificate, to the auctioneers, within the prescribed period. Any misrepresentation should be treated upon these lines, but nothing can be done after the time stipulated by the auctioneers has expired.

Throughout London and the provinces there are numerous horse repositories, and a considerable amount of traffic in horse-flesh takes place through these channels. All classes of horses are obtainable in this manner, but a great deal of circumspection is necessary, otherwise the buyer may become possessed of a highly undesirable animal-as useless to the buyer as it was to the seller.

Apart from purchase from the repository, the horse fairs in various parts of the country afford a ready means for the bartering of horses. Many excellent animals are bought at fairs, and with equal truth it may be said that so are many useless ones. The number of horses offered for sale at horse fairs within recent years has declined, and in the future there is every probability of a further reduction, owing to the continued progress of motor traction. The horse fair of the future will never, so far as quality and number of animals is concerned, reach those of the past, no matter how optimistic one may be as to the future welfare of the horse. At some of the principal horse fairs in Ireland the highest class of animal is bought and sold. A list of these fairs can be obtained by reference to any of the live-stock annuals, a remark which is equally applicable to the horse fairs and markets periodically held throughout England and Wales.

For the purchase of Welsh ponies, the Welsh horse fairs afford undeniable opportunities, and anyone contemplating purchase of these will do well to pay a visit to these fairs. In the latter case, the animals are usually unbroken, coming into the market in droves. The facilities for examination at the horse fairs are, of course, 
only poor, and the buyer has to rely exclusively on his own discrimination, there being no redress in the event of an unfortunate purchase.

Buying a horse from a private source is not always commendable, as many useless animals are sold in this manner, the only advantage being that the buyer may possibly get a general warranty of soundness, or else be given every facility for the examination of the animal. Unless for very special reasons, owners are not willing to part with reliable animals, as these are not easily replaced. Horses are commonly advertised for sale in daily papers, and the wording of the advertisements is sometimes more interesting than the animal, when the intending purchaser views it. It is very necessary for buyers to pay particular attention to the wording of advertisements, no matter whether in catalogue or in a newspaper, because these are often guardedly worded so as to deceive the unwary buyer. As previously stated, whenever and wherever there is an opportunity a light horse should always be tried either in saddle or in harness, both in and out of traffic. When pairs of harness horses are offered for sale it is common knowledge that, whilst one of them may be a very good animal, the other is frequently bad or indifferent. Take particular notice of their ages, sex, colour, markings, and general conformation throughout. Action, manners and mouth are to be specially noted. Uniformity of action greatly enhances the value in a pair of horses, whilst a good mouth and good manners are equally essential. If one horse has a tender mouth and the other is hard in the mouth it is impossible to have harmony of action. It is upon such harmony that the beauty of a pair of horses depends. It is impossible to pay too much attention, in both saddle and harness horses, to mouth, manners, temperament and action, all of which features are far more important to a buyer than absolute regard for soundness, but unfortunately these are too often overlooked. The number of vicious horses intro- 
duced into the British Army through the agency of inexperienced buyers during the recent war was considerable, but nevertheless, very regrettable, as animals otherwise excellent had to be destroyed as they were useless for either military or any other purpose.

Vicious horses are sometimes, before sale, heavily doped, and when the effects of the dope have passed off the vice is revealed in all its severity. Animals treated in this manner are difficult to discover, but sometimes reveal it by their stupidity of manner. Latent vice, i.e. vice which remains dormant for a time and then recurs is one of the most objectionable features that a horse can possess, though it is by no means infrequent. It is comparable to latent or occult disease, and either may prove equally disastrous. If buying from a private source it is a wise expedient for the buyer to obtain a general warranty of soundness and freedom from vice, in order to enforce liability should the exigences of circumstances require it.

Light horses may possess many defects, but soundness of eyesight and wind are particularly necessary. Roaring, broken wind, cataract, opacity of the cornea and total blindness, interfere with or destroy the commercial value and usefulness of the animal

There are several common diseases affecting the fore and hind limbs, the chief of these being splint in the forelimbs, also ring-bone, and in the hind limbs, bone-spavin, whilst drop sole and navicular disease are frequently met with in the fore limbs.

If a horse is five years old, free from lameness, and the splint in a good position, the animal may be regarded as practically sound. On the other hand, a horse under or about four years of age, having splint, can hardly be regarded as sound, there being greater liability to develop lameness.

For description of the other troubles alluded to the reader is referred to the chapter dealing with these. 


\section{CHAPTER IX}

THE AGE OF THE HORSE AS INDICATED BY THE TEETH, ETC.

IT is very necessary that every one interested in horses, either for pleasurable or for business purposes should possess a knowledge of the method adopted by experts for ascertaining the age of any particular animal. It is not, as a rule, a difficult matter to know, say, a colt from an old horse, by mere casual inspection, but it is quite a different matter to distinguish a horse five or six years old from one of ten or twelve without referring to the teeth. The latter affords the only reliable method of recognising these differences, but this can only be done by noting the appreciable changes which take place on the cutting surfaces of the incisor teeth.

Apart from the teeth, horses do display certain indications when they become old, and by an old horse we mean an animal ranging from sixteen to thirty years, or even a few years beyond the latter age. A great deal does, however, depend upon the treatment or rather the care bestowed upon the animal in relation to the last-named. Quite a number of horses are, through their indiscriminate employment, prematurely worn out, consequently it is not a difficult matter to note the physical changes thus brought about. On the other hand, the writer has seen quite a number of horses, approximately thirty years of age, which show little obvious signs of wear, simply because the owners have bestowed infinite care upon their charges. It must be accepted that horses working in towns wear out more quickly than those working on 
the land, whilst lameness is much more frequent in the former animals.

The physical signs of old age are chiefly denoted by hollowness in the back and hollows above the eyes, puffy swelling about the joints (the so-called wind-galls), thickening of the tendons, enlargement about the pasterns, along with a wasting of the muscles covering the quarters and buttocks, the mark in the latter situation often being very pronounced. It is sometimes spoken of as the " poverty mark," though it may be present in horses which are by no means old. It is customary to speak of a horse as being "aged " after it is eight years old.

In connection with the dentition of the horse the words "rising " and " off " are commonly employed, and imply that the animal is within six months of its conventional birthday, or the converse, when the word " off " is used, meaning that it has passed its birthday by three to six months. Thus, for instance, a horse at three years plus three to six months is three years "off"; when about three years nine months it is usual to speak of the animal as "rising" four. Nominally, thoroughbred horses have their birthday dating from January Ist, whereas harness and heavy draught horses date from May Ist. As previously stated, the teeth referred to for ageing a horse are the incisors, the molars being of secondary importance for this purpose. All horses have two kinds of teeth, viz. temporary or sucking teeth and those which subsequently replace these-the permanent teeth. The temporary teeth consist of I 2 incisors, viz. 6 above and 6 below, and I2 molars, 3 in each jaw; so that the temporary teeth number 24 , whereas the permanent ones are either 36 or 40 . In the mare they are 36 and in the male 40 . In exceptional instances mares have rudimentary tusks, therefore the female may have 40 teeth. The temporary teeth are different from the permanent ones, being smaller, whiter, and without a well-marked vertical groove on their faces. It is expedient for the amateur to make 
himself thoroughly acquainted with the difference between temporary and permanent incisors. There need be no difficulty about this if visits can be paid to the horse slaughterers, as specimens of the incisor teeth in the lower jaw can usually be obtained from the carcases at different times; in fact, most horse slaughterers will, if asked, reserve specimens for anyone wanting these. Mouths showing the teeth at various ages can thus be obtained for comparison. The molar teeth are, of course, not required. An incisor tooth conprises the following parts, the nominal differentiation of which is essential in order to understand the changes which take place in the teeth: That part of the tooth which projects above the gum is called the crown, below which is the neck of the tooth, this being encircled by the gum. The fang fixes the tooth in the socket and is covered by a cement substance. The face of the crown is covered by enamel. The cutting edge of the tooth is known as the table, and it is by the changes through wear which take place on the table that we are enabled to form a fairly accurate estimate of any particular animal's age, exceeded only by absolute proof of date of birth. To begin with, an incisor tooth is elongated, or rather, elliptical on its cutting edge. The table is encircled by enamel, which forms the outer boundary of the tooth. This is the "outer enamel ring." As the table forms there is another enamel ring, and this is spoken of as the "inner enamel ring," which encircles a central " mark" or depression, known as the "infundibulum "a dark mark arising through particles of dirt insinuating themselves into the small depression previously referred to.

By horse dealers this mark is called the "bean." As the wear of the tooth proceeds the table alters in shape, and so does the inner enamel ring, until the latter and the " mark" are finally obliterated, as happens in old age. An incisor tooth is mainly composed of a substance known as dentine, and it is this which forms the bulk of the table. 
The area between the front of the tooth and the inner enamel ring is referred to as the anterior edge of the table, whilst the corresponding area behind is the posterior portion of it. These two areas are rather important, mainly because they are so intimately associated with wear in relation to age. It is customary to make use of the lower incisors only as indicators of age, excepting when the incisors of the lower and upper jaws are in close apposition, and then it is only the corner teeth which are of any value as a means of judging the age.

In a young animal, or at any rate, up to the age of eight years, the gums are circular and the teeth practically vertical. With advance in years, the incisors gradually lose this position until they finally become, say in a horse thirty to thirty-five years of age, almost horizontal and greatly elongated. Long teeth may at all times be accepted as positive evidence that the animal is an old one, and the older it becomes the more the gums recede and the more horizontally inclined the teeth become.

Soon after birth a pair of incisor teeth appear in the upper and lower jaws, and as these are in the centre of the mouth, they are spoken of as the "centrals." The next pair are known as the "laterals" and these are followed by the "corners," so that by the time the foal is twelve months old it has a complete set of temporary incisors. These teeth continue to serve the foal until it has turned two years old, after which time they are replaced by the permanent incisors. The shedding of the temporary teeth is carried out with a fair degree of regularity and it is accompanied by redness of the gums and subsequent absorption of the fangs of the teeth about to be replaced. In exceptional instances the crown of the permanent tooth becomes entangled in the fang of the temporary one and in this manner some irregularity is occasionally observable.

The incisor teeth are replaced exactly in the same order 


\section{THE HORSE}

as the temporary ones made their appearance, viz. the centrals, the laterals and the corners.

Shortly after two years-say, two years " off," the central pair of incisors are replaced, therefore, the presence of a pair of permanent central incisors indicates that the animal is between two and three years old. They are half-way up about two years and a half, and their anterior edges are in wear by the time the colt is three years old.

At three years " off" the laterals show signs of being replaced, and about this time, or within three months, i.e. from three years and three months to three years and six months, these teeth are in the mouth and grow in exactly the same manner as the centrals, hence fully developed laterals indicate that the animal has reached its fourth birthday, or thereabout. In other words, that it is a " four-year-old."

The corner teeth are replaced soon after four years, at four " off," and when fully developed indicate a "fiveyear-old " mouth. At four years and a half they are just about half-way up, but the anterior edges of the teeth do not come into wear until the animal is five years old.

At five years the mouth has a very neat appearance, the gums being very circular, whilst the centrals and the laterals have their tables well in wear, and stand out in marked contrast to the recently developed corner teeth. A critical inspection of the tables will show these differences in detail. There should be no difficulty in recognising a five-year-old mouth at a glance. It is an important matter for the amateur to be able to do this, because the writer has frequently seen horses sold as five-year-olds when really only four.

The presence of the lateral incisors is the best positive evidence one can have (apart from proof of age by date of birth) that the colt has passed its fourth birthday. No further changes take place in the incisors excepting those upon their wearing surfaces or tables, barring those 
resulting through old age, viz. their increase in length, and contraction of the gums. The amateur is likely to experience the greatest difficulty in ascertaining whether a horse is six, seven, eight, nine or ten years old. A great number of buyers, especially for town work, prefer to purchase a horse at six years old, and vendors usually adjust their description according to the requirements of the purchaser.

Quite a large proportion of horses are sold as sevenyear-olds, whereas they are often twelve or fourteen years old, and quite commonly ten, and it is at the latter ages horses begin, to a certain extent, not to increase in value, but rather to decrease. The changes which take place in the tables of the teeth have to be mainly relied upon, but valuable evidence is afforded by looking at the upper and lower corner incisors when the mouth is closed. At six year " off " the upper corner incisor projects slightly over the front edge of the lower corner incisor, and this becomes more marked at seven years " off." However, as previously stated, most reliance must be placed upon the tables. If a horse is six years old the anterior edge of the table of the lower corner incisors are well in wear, but fully formed tables of the last-named certainly indicate that the animal is in its seventh year. The "mark" at seven years old is " elliptical" in the corner incisors, and lies close to the hinder edge of the table. Moreover, at seven years the tables of the central teeth are more triangular, and still more so at eight. At the last-named age the inner enamel ring is also triangular in the centrals and laterals and has lost the elongated form which it had at seven years. This inner enamel ring finally becomes obliterated, in fact, is almost lost from ten years onwards, and the same applies to the " mark." The incisor teeth at these ages are much longer than they were at six, seven and eight, and the only alterations which take place are as previously stated.

Many years ago, Galvayne introduced a method of 

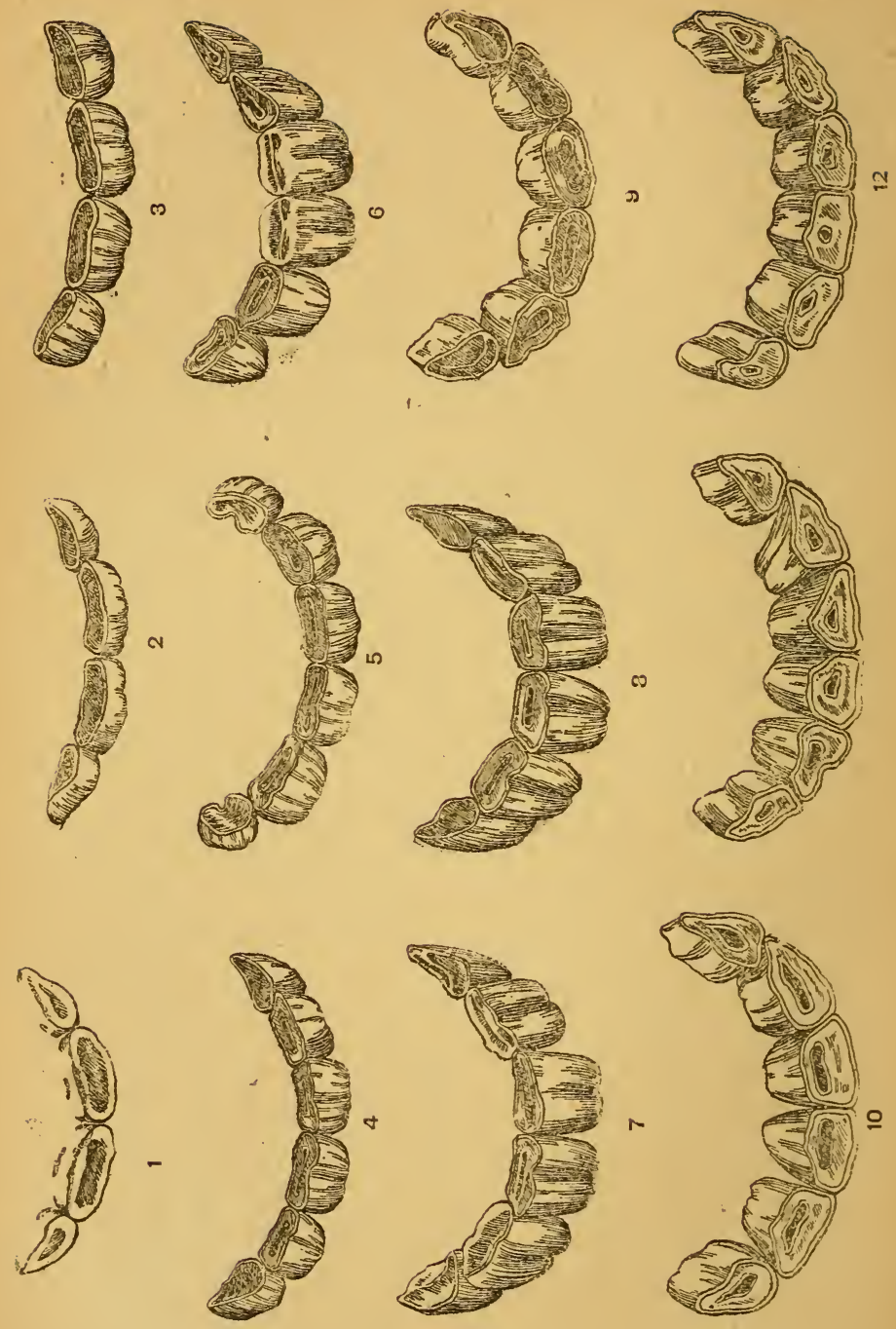

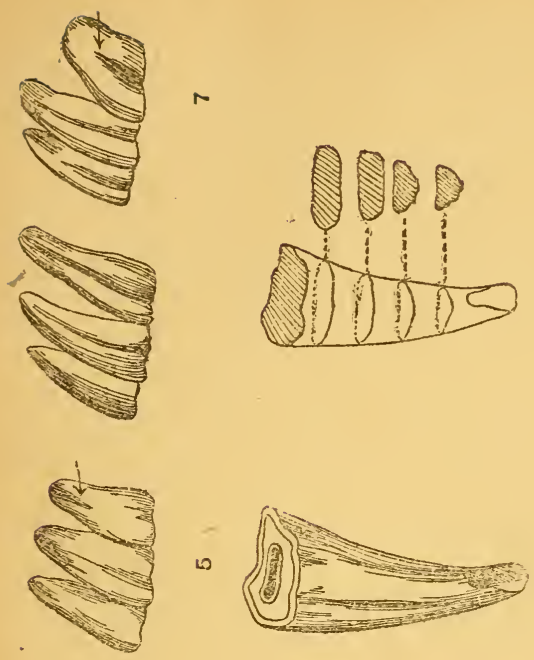

L
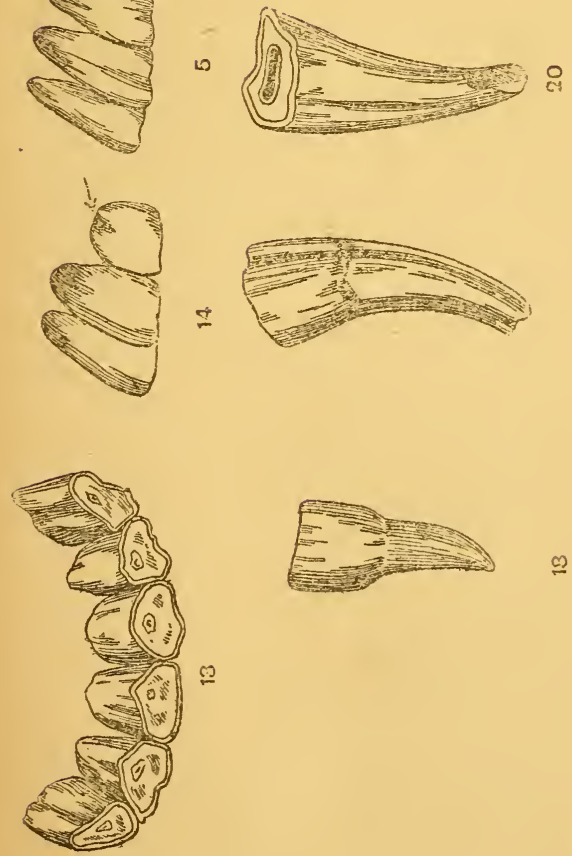

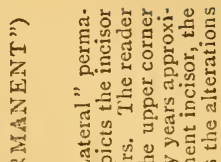

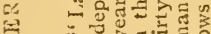
F $\quad \therefore 0$ - $\quad \therefore 0000$

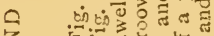

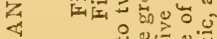
$\therefore$ 离

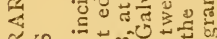

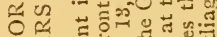
\& द व 在 I $>$ हु [-

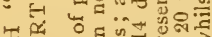

플

0 경 त

F

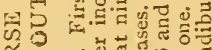

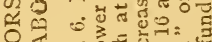

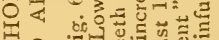

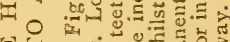

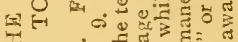

सQ मि

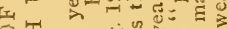

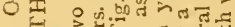

I士

다

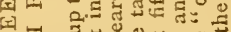

다 司

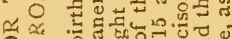

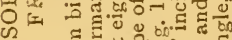

U इ ठ

r

되 गु

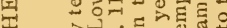

स

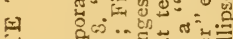

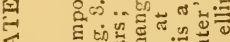

¿ स纟 ฏ

in कि

थ $\quad$ में क्षे

Ю

$\equiv \quad$ की

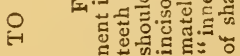


approximating age in horses by a reference to a groove making its appearance in the upper corner incisors at the base of the tooth, that is, at its junction with the gum. It makes its appearance at ten years and is about half-way down the tooth at fifteen and extends the whole length of the tooth at twenty-one. By the time the animal is twenty-five years of age this groove becomes effaced next to the gum but extends from the middle of the tooth down to the cutting edge, whilst at thirty years it is situated very close to the cutting edge.

With regard to the molar teeth, the first, second, and third molars in each jaw are only temporary, whilst the fourth, fifth, and sixth are permanent. The first-named three teeth occupy the front position in the jaws, but none of these are replaced before the fourth molar has made its appearance.

The reader will receive some assistance in the foregoing description of the teeth by reference to the accompanying illustrations, but he should in every instance supplement this by a practical application of the knowledge thus acquired, as nothing in connection with animal dentition could possibly be truer than the old adage, "An ounce of practice is worth a pound of theory" - in other words, "Knowledge increaseth practice and practice increaseth knowledge." 


\section{CHAPTER $\mathrm{X}$}

\section{VICE}

IT is impossible to frame any accurate definition as to what does or does not constitute vice in the horse. It is a question of degree and can only be appropriately regarded in this light. Minor vices may not in any way interfere with the animal's health or with its usefulness, whereas in other cases a vicious habit may render the animal perfectly useless. Some forms of vice are disclosed in the stable, others out of it, either whilst in harness or when being ridden. Some horses are so vicious as to render them unapproachable, much less employable for any useful purpose. In this last Great War, quite a number of horses of this description were purchased but had to be destroyed in consequence of their dangerous proclivities. Doubtless a good deal of the vice is acquired as the result of bad treatment, which horses are not slow in remembering. Minor stable vices comprise pawing in the stable and scraping the bedding to one side, eating the bedding, kicking at the stall-post, tearing bandages and clothing, biting whilst being groomed, etc. Wind-sucking, weaving and crib-biting are usually regarded as vices when discovered of sufficient importance for the rejection of the animal on the ground of unsoundness. A wind-sucker certainly is unsound, whilst a weaver never remains still when in the stable. Continual movement of the head from side to side wears out muscular energy in front of the body, therefore this represents unsoundness. Horses which are kickers in harness and very often given to bolting as well are perfectly useless, owing to the fact 
that they may give way to this vice on the slightest provocation, and endanger the lives of those in the vehicle. Latent vice may develop at any time as many unfortunate purchases have proved. Some hunters will kick at hounds when near to them, and this is certainly a vice. Kicking at other horses in the stable and at stable attendants, also biting, represent forms of vice of the worst kind. Some horses are troublesome to shoe and have to be placed under restraint before this can be done. Forge vice of this nature sometimes leads to complications. There are many other objectionable habits in horses, but we have given an outline of some of the common ones. 


\section{CHAPTER XI}

\section{LAMENESS IN THE HORSE}

Amongst all the troubles to which the horse is liable perhaps none are more frequent than lameness, and the percentage of horses which are rendered either temporarily or permanently useless on this account is greater than that from all other causes.

The horse, by virtue of the work it has to perform, may be regarded as predisposed to injuries in connection with its locomotor apparatus, such as sprains of tendons and ligaments, injuries to joints, bruises to the feet and various other causes of disability which render it, for the time being, unworkable.

Lameness may be either acute or chronic, or rather, we ought to say, the affection giving rise to the lameness is of this nature ; the lameness being the result or expression of pain arising out of the affliction. As previously stated, it may be temporary or permanent. In the latter case quite a large percentage of horses are disposed of for work on the land, etc., where they very often continue to work for years.

Lameness is much more frequently met with amongst horses working in towns than in animals employed in agricultural labour. Young horses are much more liable to become lame if they are worked before their limbs have had time to fully develop, hence the reason why it is customary to reject a young horse, say at three or four years of age, for some obvious defect such as splint, spavin, etc., whereas a horse fully matured, though 
affected in the manner indicated would, under similar circumstances, be passed as sound.

Lameness is more frequent in the fore than in the hind limbs, probably because the degree of concussion is greater, more weight being borne by the fore than the hind limbs. One fore or both fore, or one fore and one hind may be implicated in the lameness. Quite commonly the seat of the lameness is in the foot, in fact the majority of lame cases arise in the region last named. Although experience is one of the best schoolmasters in the diagnosis of lameness, it is an everyday occurrence amongst those who are expert at this particular kind of work to be unable to determine the nature of the trouble, or to locate the cause operative in the production of the lameness. That some horses are lamed during the time that they are being shod is indisputable, but the farrier is often blamed for that for which he is not responsible. No skilled craftsman has been more dictated to than the farrier as to how he should or should not shoe horses, and the writer has known some of the most expert shoeingsmiths instructed as to how particular animals should be shod by those who knew nothing whatever about the matter.

The amateur commonly finds it difficult to recognise the limb upon which the horse is lame unless there is obvious indication of the seat of the trouble. Greater difficulty, however, exists when the animal is lame in both the fore and hind limbs simultaneously. Some horses are lame when they walk, others only when they are trotted. Again, lameness is often most obvious directly the animal comes out of the stable, but frequently decreases when the horse is put to work. On the other hand lameness may increase with exercise. If a horse or mule is lame, say in the near fore limb, it follows that it will, when putting the foot to the ground, endeavour to take off the pressure as much as possible, consequently additional weight being thrown upon the off fore limb, the 
head and fore quarter is dropped on the sound side during movement. In other words the animal "drops " on the sound side.

On the other hand lameness in the hind limb is indicated by elevation of the quarter on that side of the limb affected. In order to deceive, an unscrupulous vendor, having a horse to dispose of which is lame in one fore limb, will make it lame on the opposite limb in order to counterbalance the original lameness. A horse lame in both fore limbs without any obvious injury to account for this lameness is less likely to be detected than when the lameness is confined to one side.

Lameness is much more pronounced on hard than on soft ground. It may be continuous or intermittent, slight or severe. Intermittent lameness is that which comes on at irregular intervals, persists for a variable period, and then disappears.

There is a diseased condition known as thrombosis, in which the circulation of the blood in a blood-vessel, or some branch of it, becomes suddenly arrested with the result that an acute paroxysm of lameness occurs, so painful that it may cause violent sweating and other signs of acute suffering. This may last only a few minutes and then pass off. In every case of lameness the first thing to do, even when the cause is obvious, is to remove the shoe and search the foot, because, as stated elsewhere, the majority of horses go lame through some form of foot trouble. It is impossible to emphasise this too strongly, otherwise all sorts of mistakes are liable to occur. The foot must be thoroughly searched in every case, the nail holes pared out and the sole pressed with the farrier's pincers all around the nail holes. Unless this is properly done even the farrier may overlook the cause of the lameness.

A multiplicity of troubles in connection with the limbs are responsible for lameness in the horse, so that having examined the foot with negative results the remainder of the limb or limbs should be critically examined and 
manipulated in order to assist in arriving at an opinion as to the cause of the lameness. The writer can only indicate some of the principal abnormalities which are capable of causing lameness, and these are as follows: sprained tendons, especially the flexor pedis tendon; the extensor pedis tendon; sprain of the suspensory ligament; paralysis of the radial nerve; sprain of the fetlock joint; split pastern, or fracture of the first phalanx; fracture of the second or third phalanx; navicular-arthritis; fracture of the navicular bone; a bruise to the coronet; sand-crack; thrush (if severe); canker of the foot; over-reach; bruised heel ; cracked heel; fistula of the foot; puncture of the foot; pickedup nail ; laminitis, either acute or sub-acute ; periostitis ; ring-bone; splint; and various other injuries to the bones, joints, nerves and tendons, all of which are frequently met with in lameness of the fore limb, and likewise in the hind limb, but, in addition, we find the following troubles are fairly frequent in the last named. Bonespavin, curb, thoro-pin, sprain of the hock joint, sprain of the flexor-metatarsi and dislocation of the patella or slipped stifle.

In addition to the foregoing a not uncommon cause of lameness in the foal and of sudden development is the so-called rheumatic-arthritis, or joint-ill-a septic infection of one or more of the joints. As already stated, the degree of lameness varies in its intensity, its duration and its termination. Dislocations and fractures are usually marked by the sudden development of the lameness, likewise by its severity. A fracture is not necessarily accompanied by displacement of the fractured ends of the bone, consequently a part may be broken without being discoverable by external manipulation. Direct violence is the usual cause of injuries of this nature, but they are sometimes produced by sudden muscular contraction such as sometimes results through pulling a horse up suddenly and violently. Sprained muscles and tendons are 
very frequent causes of lameness in the horse, and these injuries are commonly accompanied by increased heat, pain on manipulation, swelling; but any or all of the foregoing may be absent. For a description of the diseases referred to the reader must turn to the chapters dealing with these affections. If lameness is severe it is usually accompanied by a certain amount of constitutional disturbance such as loss of appetite, uneasiness, and so forth. In every case of lameness the first principle of treatment comprises rest in the stable for a few days, or, if necessary, it may be for weeks. When lameness is likely to be prolonged as in many cases of spavin and ring-bone it is a very good plan to keep the animal in a loose box. Many horse owners under these circumstances turn the animal out at pasture for a few months. The adoption of this plan is, in the author's opinion, indiscreet, as the exercise hinders repair of whatever structures are damaged. In concluding the remarks on lameness we must not forget to add that the horse owners will find it the most economical to call in a veterinary surgeon, as expert knowledge is most certainly necessary because sometimes " apparently" trifling injuries are followed by the most untoward results. 


\section{CHAPTER XII}

SHOES AND SHOEING-PREPARATION OF THE FOOT

THE shoeing of horses is an important branch of industrial labour, though, unfortunately for the horse, and also the farrier, the business of the latter has been on the decline since motor traction made its appearance, consequently we find that many hitherto prosperous shoeing forges have fewer hands working in them, whilst a certain percentage have had to close down altogether. Amongst all classes of craftsmen, perhaps none have received from the public more instruction as to how horses should and should not be shod than the farrier. Both stable and farm boys have been known to issue their instructions as to how a horse ought or ought not to be shod, and the patience of the shoeing-smith must often be sorely tried by their ignorance and stupidity. The author holds no brief for the farrier, as there are quite a number of these who could never hope to become experts in their work; still, after a life-long apprenticeship, plus the average degree of intelligence, it is surely reasonable to assume that a man must have learnt the general principles of his business, and be in a much better position to fulfil the requirements of his craft than a wholly inexperienced person. There are horse-shoers and horse-shoers, and the public are generally able to make their own choice, even if the forge is not always the most convenient one. Shoes may be fitted either hot or cold, but there is no comparison. A hot fitting is by far the best. In the one case you fit your shoe to the foot, whereas in the other it may be necessary to make the foot fit the shoe. All horses require so be 
shod with great regularity, irregularity in shoeing being very bad for their feet, but what is still worse, bad for ligaments, tendons, and joints, owing to the unequal distribution of pressure which arises from shoes more worn at one part than another. Moreover it is just as easy to fix a particular date for a horse to be shod, and for the proprietor to see that the animal is shod on the date specified. No time can be fixed as to how long a horse will carry its shoes, or rather when it should be shod, as horses differ in a remarkable manner. For instance, some horses will wear a set of shoes out in ten days, whereas others will carry them very well for three weeks or a month or even longer. The average time is three weeks. Again, inequality on the wearing surface is another matter to be considered. A horse may wear its shoes as thin as a sixpence at the toe or at the heel, whilst the rest of the shoe shows very little signs of wear. In most forges machine-made shoes are now extensively employed, and these can be obtained from the manufacturers in a large variety of sizes. The old-time prejudice against machine-made shoes is an affair of the past. New shoes made from old are certainly more durable and may last a week or two longer than new ones. In some forges, especially where business is rather slow, the farrier often makes up the old material into new shoes, but whether it is more economical to do so is very questionable. The preparation of the foot for the shoe is always an important matter and, unless this is properly done, trouble will sooner or later follow. The sole and the frog should be left alone, unless there is any loose horn (exfoliation). If so, this should be removed. On no account must the sole or the frog be pared except in the case just stated. The wall grows at the average rate of an inch in three months, and this growth is mainly at the toe, so that if a shoe were left on too long, the growth of the horn would carry the shoe with it, the result being that the animal would be inclined to stumble during progression. The 
wall must be lowered with the knife and the rasp and a level bearing surface obtained. In fitting the shoe the latter should be applied at a dull red heat and the surface lightly charred in order to produce the requisite bearing. It must be borne in mind that the wall and the junction of the wall and the sole are the weight-bearing structures of the foot, and the shoe should press upon these structures only. Opening up the heels, as it is called, i.e. paring away the " bars " is a most objectionable practice and should never be done. The heels of the shoe should never be too long, otherwise they will press on the heels and lead to bruising of these. All horses, for preference, should be shod perfectly flat, but it is a general practice to put calkings on the heels. If this is done, a corresponding piece should be put on the toe, in order not to disturb the balance of the various structures in the limb. It is quite true that horses get a better grip of the ground, especially on granite sets in towns, but both calkings and toe pieces destroy the proper functions of the frog and favour contraction of the heel, so that whenever they can be done without it is so much the better. The weights of shoes vary. For instance, race-horse shoes weigh about 4 oz. ; those for hunters and hacks, I lb. ; carriage horses, $I \frac{1}{2} \mathrm{lb}$. ; heavy draught horses, 3 to $4 \mathrm{lb}$. Shoes may be plain or fullered. For hunters and race-horses fullered shoes are nearly always used. The number of nail holes is usually 3 on the inner side and 4 on the outer, but in shoes used in the army, extra holes were provided, in case of necessity. In shoeing hunters and polo ponies, neat and close fitting is essential, more especially in the latter, and this remark also applies to the fitting of shoes for the race-horse. There is one mistake a farrier often makes, and this is rasping the wall of the hoof, whereas all that is requisite to do is to rasp it along the line of exit of the nails. By rasping the wall, the foot's protective varnish, viz. the periople is removed, the loss of which tends to brittleness of the wall. Sometimes horses are 
shod with pads, of which there are various kinds and makes. They are all, more or less, bad for the feet although they diminish concussion and some of the evil effects arising therefrom. Leather soles are frequently used when a horse has a thin sole, a drop sole, corn, or some other abnormal condition of the foot or feet. During frosty weather when the roads are icebound and slippery, frost cogs or frost nails are necessary. These should be removed when the animal is in the stable. Frost nails are quite temporary, much more so than frost cogs. There are various patterns of these cogs, some having a flat surface, others a pointed one. Again, some of them screw in, others are without screws. Perhaps the screw $\operatorname{cog}$ is the best of all, as it is more secure in the shoe than cogs without screws. When a horse "casts a shoe" it is either due to the nails breaking, the clinches giving way, the nail heads wearing off, or the horn below the clinches giving way. It is often a sign of inefficient work. If so, the remedy rests with the owner. Sometimes nailsare used which are too large, other times too small, and examination of the ground surface of the shoe after it has been fitted soon discloses this. Unless the nails are driven well home, of the right size and tightly clinched, the shoe will never keep its place properly. Horses with flat sole, with corn or with sand-crack, must have the pressure taken off the part affected, otherwise trouble will arise. Sometimes horses will travel very lame through corn, herce the expediency for the removal of the shoe in every case of lameness. A corn merely represents a bruise, and if it is a recent one, is denoted by a bright red or pink discoloration of the horn on the sole and usually at the inner quarter. If infection by pus organisms occurs along with the bruise, the corn becomes a suppurating one, and sometimes this suppuration undermines the whole of the foot, leading to separation of the horny and sensitive sole-a most serious condition and one necessitating immediate professional advice. 


\section{CHAPTER XIII}

\section{THE FOOT IN HEALTH AND DISEASE}

IRRESPECTIVE of age, sex, or breed, sound feet are indispensable, and it is an absolute truism " no foot no horse."

Horses' feet, more especially horses working on the hard roads in cities and towns, are subject to a great deal of wear and tear, consequently if an animal has any structural defects, such weakness will soon show itself either in one form or another. If breeders of horses would only pay more attention to the feet during colthood many of the infirmities which so commonly make their appearance later on in life would be altogether unknown.

Concussion and bad shoeing are responsible for the majority of foot troubles, but by no means the cause of all. A certain proportion of horses have bad feet, or a predisposition to such, as an inheritance, thus showing how essential it is to breed from sires and dams in which soundness of feet constitutes a well-marked feature.

It is quite an easy matter to have working horses regularly shod, and this is a matter either for the master to supervise, or else to depute a person, on whom absolute reliance can be placed, to do so.

No hard and fast rule can be laid down as to when a horse should be shod, because some horses will wear out a set of fore shoes in a week or ten days, whereas others will carry their shoes from three to five weeks. If a horse does not wear its shoes out in three weeks they should be removed, the feet trimmed, and the shoes refitted. 
Growth mainly takes place at the toe, and if the toes are too long the animal is apt to stumble through this cause. The foot growing at the toe carries the shoe with it, and the result is that the distribution of pressure on the wall becomes unbalanced. Foals and colts when out at pasture should have their feet periodically inspected, and the farrier should be instructed to do whatever is necessary. Unequal distribution of pressure is not only bad for the feet but for other structures in connection with the limbs, such as the ligaments and tendons, etc.

It is quite an easy matter to grade the feet into three categories, viz. good, bad, and indifferent. A good foot should be of a bluish colour, free from cracks or fissures in the wall, and the latter ought to slope at an angle of from forty-five to fifty degrees, being concave on the sole, well open at the heels, and having a well-developed footpad, along with prominent bars. The wall at the heels should be of medium height, and there must be no signs of brittleness of the wall or any indication of separation between the wall and the sole, such constituting a brief description of what a good foot should be Apart from its structural features, it must be proportionate to the size of the animal, and during its movement it must be carried in a straight line with the body, and not in an inward or outward direction. This, however, is a matter more intimately concerned with action rather than that appertaining to the foot.

Feet belonging to the second category, viz. bad, comprise all those in which the wall shows some structural defect, such as sand-crack, false quarter, contracted heels, low heels, flat or drop sole, pumiced foot, in which the foot becomes more or less flattened, as commonly happens after one or more attacks of founder. All brittle feet must be classified as distinctly bad, likewise feet in which there is any tendency towards separation of the sole and the wall. The last-named is a most serious defect, and it is one that is commonly concealed either by filling 
up the space or by the shoeing. Hence the necessity for removing the fore shoes before purchase. In addition to the foregoing there are other foot troubles associated with bad feet, and the unwary purchaser may easily be led astray through the existence of these defects.

The indifferent foot is one which combines some of the essentials of a good foot with those of a bad one. Thus, for instance, the wall of the sole may be excellent in its construction, but the footpad may be contracted or actually the seat of disease. In exceptional instances the feet are odd in point of size, but not necessarily structurally defective. If the wall or the sole are too thin it renders the foot much more liable to injury, although a foot of this description could hardly be classified as bad.

In order that the amateur may appreciate, or rather, we should say, be capable of more clearly comprehending the various features of the feet in health and disease, it is expedient to give a résumé of the anatomical construction of the foot, and follow this up with a brief description of the various pathological conditions associated with the structures now under consideration.

\section{STRUCTURE OF THE FOOT}

The foot consists of the wall, and this is divisible into the toe, the quarters, and the heels, and it is formed of a number of horny tubes united together by a cementing substance. These horn fibres correspond to hair. The wall has an upper and a lower border; the former is encircled by a prominent band-the coronary bandand it is from this band that the horn fibres are secreted ; consequently any injury to the coronet or coronary band may lead to some permanent defect in the wall of the hoof. The horn fibres are really secreted by papillæ on the surface of the coronary band. For the purpose of study, the fact is regarded as comprising sensitive and 


\section{THE FOOT IN HEALTH AND DISEASE I05}

insensitive structures, the former being all parts enclosed within the horny box, and the latter consisting of the wall and the sole only, and being comparable to the finger-nail. The wall is thickest at the toe, thinner at the quarters, and thinnest of all at the heels. The outer surface of the wall should be perfectly smooth, and it is covered by a protective material known as the periople, which, in reality, represents a natural varnish, and this is secreted from the "perioplic ring" at the upper border of the hoof and beneath the coronary band. In the unshod foot it forms a bluish bloom on the wall. In the shod foot it is not often observed, as the farrier frequently, but unwittingly, removes it with his rasp, a thing which should never be done. The inner surface of the wall consists of a number of leaf-like structures, arranged perpendicularly with the upper and lower borders. These leaf-like structures are known as the horny or insensitive laminæ, and their use is to accommodate corresponding structures covering the pedal-bones, and known as the sensitive laminæ. The two opposing structures are so dove-tailed into one another as to constitute a very firm bond of union between the two; in fact, the weight of the horse is mainly distributed through this channel.

The horny sole joins the lower border of the wall at the so-called white line, which is readily discernible when the foot is pared. The lower border of the wall and its junction with the sole at the white line constitute the chief weightbearing structures of the foot, therefore the shoe should press upon these parts only. The ground surface of the sole is, normally, concave, but as stated earlier on may, through disease, become flattened, constituting the socalled "dropped sole." Its inner surface is convex. The sole is formed from papillæ on the lower surface of the pedal-bone exactly in the same manner as the horn of the wall is secreted. The footpad, or the "frog," consists of a wedge-shaped piece of elastic tissue, with the point of the wedge directed towards the toe. It is spoken 


\section{THE HORSE}

of as the "insensitive frog," in contradistinction to the "sensitive frog," upon which the former is moulded, and secreted by the papillæ on the lower surface of the latter. The horny frog has a central depression or middle cleft, and on either side a lateral cleft, plainly visible on the lower surface. The inner surface of the frog is, as previously stated, moulded upon the sensitive frog, and there is a backward projection or plate of horn called the frog-stay. Normally, the frog is a welldeveloped elastic pad and a very effective anti-slipping agent, therefore it shows how very important it is for the farrier to leave it intact as much as possible, and to shoe the animal in such a manner that the functions of the frog may not in any way be interfered with. Contraction of the heels immediately follows the removal of frog pressure, which readily takes place when the heels are raised, hence the advisability whenever practicable of shoeing a horse perfectly flat.

Situated on either side of the frog are the "bars," which represent reflexions of the wall at the heels. The bars give additional strength to the frog, and to some extent are weight-bearing structures. Like the frog, they should not be interfered with, although we have seen-fortunately, not often-the farrier slicing them away, and so paving the way for the future ruin of the foot. The horn of the wall, likewise that of the sole and the frog, is continually being renewed, therefore there is a gradual shedding of the most superficial layer. This is particularly well seen in the unshod foot on the sole, in which ex-foliated portions of the horn sometimes accumulate, which should be removed with a knife.

All the soft structures are enclosed within the hoof, and the foot has a very rich blood supply. In order to facilitate a free circulation of blood the veins of the foot, unlike those of the body, are without valves, in addition to which the vessels form a complex network. This distribution of the blood-vessels is largely in connection 
with the sensitive laminæ on the pedal-bone, but the bone itself is densely packed with minute openings for the passage of small blood-vessels into its interior, augmented by larger vessels of supply.

The coronet, as previously stated, consists of a dense band of tissue encircling the top of the hoof, supplied with blood by the coronary artery.

The sensitive structures of the foot comprise the sensitive laminæ, the sensitive sole, and the sensitive frog. We have already :-eferred to the sensitive laminæ, so that it only remains to deal with the sensitive sole and the sensitive frog. The first-named forms a velvety tissue spread over the lower surface of the pedal-bone, and from which the horny sole is formed. The sensitive frog is composed of fibro-elastic tissue, which confers upon it a degree of expansion when the foot is on the ground. There is no expansion of the wall at the toe, and very little at the quarters, but at the heels it is present in a limited degree.

Two tendons pass down the back of the foot, viz. the flexor pedes perforans and perforatus, the former being attached to the lower surface of the pedal-bone, and the latter to a small bone known as the navicular or shuttlebone, which is in juxtaposition to the pedal-bone. In addition to this we have ligaments and nerves distributed to the sensitive structures enclosed within the foot.

The bones of the foot are entirely enclosed by the hoof, and occupy a very sheltered position, so that one would expect injuries in connection with these to be excessively rare, but such is not the case. In fact, the writer has seen apparently trifling accidents result in fracture of either the pedal-bone or the navicular-bone as revealed by an after-death examination of the parts concerned. The pedal-bone, also known as the coffin-bone, the navicularbone, and the second phalanx, or the os coronce, are the bones embedded within the hoof, and two of these present many special interesting features, to which, in a 
work of this description it is not necessary or advisable to allude.

\section{Diseases OF THE FeET}

Having acquired an elementary knowledge of the anatomical construction of the feet we shall now consider some of the principal diseases affecting these structures. There are some foot troubles which cause, or rather lead to the production of the most severe pain and its attendant lameness, and the degree of this is usually proportionate to the acuteness of the affection; but there are certain exceptions to this rule. It is customary to speak of the lameness as being either acute or chronic, in accordance with the duration and severity of the trouble. Fully fifty per cent of lameness in horses is due to trouble in the feet. Some diseases implicate the wall, others the wall and the sole of the insensitive foot, whilst the frog and the sensitive structures within the hoof are commonly affected.

In some instances permanent structural changes are the result of either acute or chronic malady, and when. this is the case the value of the animal as a commercial asset is usually materially reduced, and, of course, if the intending purchaser possesses a reasonable degree of perspicuity he will pay the price accordingly.

One of the commonest diseases, both in its acute and chronic manifestations, but particularly the latter, irrespective of age, sex, and breed, is that which is popularly known as

\section{LAMINITIS OR FOUNDER}

and most horsemen are more or less acquainted with this complaint. It is a trouble which is much more disastrous so far as permanent damage is concerned when it exists in its acute form. It is surprising what a number of horses working in towns develop founder as a sub-acute affection, and the only indication, in the majority of 


\section{THE FOOT IN HEALTH AND DISEASE IO9}

instances, is that which is afforded by an inspection of the sole, which loses its concave character and becomes flat, or in horseman's vernacular " dropped "-dropped sole. The lameness is not as a rule particularly well marked, but it is always present in a variable degree, and most pronounced when the animal is first put to work. This abnormal condition is apparently due to the continued concussion on the hard roads and possibly favoured by the degree of action possessed by the animal, i.e. the higher the action and the harder the roads the greater the liability towards the development of this disease. Some horses seem to be, however, much more capable of their conservancy of energy when placing their feet upon the ground; at least, this is the writer's experience. In other words, some horses will batter their feet to pieces, whereas others bring them lightly to the ground. Hard driving is a predisposing cause. Laminitis consists of a variable degree of inflammation or congestion of the sensitive laminæ and blood-vessels within the hoof, and it is a most painful affection, as previously stated, when the attack is an acute one. If the reader has digested the paragraph relating to the elementary construction of the foot, he will understand what a serious matter it must be for a horse to be troubled with the disease now under consideration. Founder, also sometimes spoken of as fever in the feet, presumably on account of the increased heat, so palpable when the hand is placed upon the latter, when acute, makes its appearance quite suddenly, and those acquainted with the affection are at a loss to know why the animal should have become so suddenly unable to move. In every instance the premonitory symptoms are rapidly succeeded by those of an unmistakable character to the expert. The owner may have been driving the animal perhaps harder than usual, when, after returning to the stable he finds his charge refuses its food, stands in one position, and when an effort is made to move it or turn it round in the stall, the 
pain in the feet is so acute that the horse is either unable to do this or does so with difficulty. When the attempt is made to back the animal it will be at once seen that the feet are the seat of the trouble. Either the fore, hind, or all four feet may be implicated, and there is no rule as to those which will be affected with the malady. In the majority of instances both fore feet are the seat of the trouble, consequently, in order to diminish the pain by relieving the pressure, the fore feet are thrown forwards, and the hind ones drawn more under the body. This allows the animal to place the greatest weight on the heels, and alleviate the painful toe pressure. When all four feet are ixplicated, they are bunched together under the body.

In addition to these more purely local signs, we have others of a constitutional nature, indicated by sweating, increased temperature of the body (usually I0 $5^{\circ}$ or I06 $^{\circ}$ Fahr.), congestion of the eyelids, rapid and full pulse and distressed breathing, and as the disease progresses the patient gradually becomes riveted to the ground. In severe attacks the symptoms are excessively urgent, therefore the expediency of having skilful advice is at once obvious. In the absence of this, however, the animal should be placed in a loose box and the shoes immediately removed.

Causes of Laminitis.-As previously stated, one of the chief causes is concussion, but there are others, such as an overdose of physic, feeding on green wheat, likewise as a sequel to parturition, in which case the malady arises from septic material such as decomposing placental membrane, hence the expediency of the early removal of the placenta. Laminitis sometimes is a result of a metastatic inflammation, i.e. a change of inflammatory action from such organs as the lungs to the feet. Animals which are overburdened with flesh, i.e. plethoric, are predisposed, under the foregoing circumstances, to become "foundered," 
General Management and Treatment.-The author recommends that early professional advice should be obtained, as laminitis is one of those affections that can be only treated upon conservative principles when the trouble arises from some simple cause. When following parturition, unskilled advice would probably mean the loss of the mare, whereas with professional treatment a valuable animal may, perhaps, be saved. Under ordinary circumstances treatment is divisible into $(a)$ the local, (b) the general. The former comprises the removal of the shoe and the application of either hot or cold bran poultices to the feet. It seems to make little difference whether hot or cold water is employed, but it is absolutely necessary that the fomentation should be of a continuous character ; in other words, the feet must be kept constantly wet.

Up to the present nothing in the way of treatment has been introduced to supplant, in a satisfactory manner, the irrigation method. In every case it is essential to commence the treatment with a dose of physic, either in the form of Epsom salts added night and morning to the drinking water, or in the form of an aloes or cathartic ball. Without a shadow of doubt, a dose of purgative medicine is the sheet-anchor in the treatment of this disease, but considerable circumspection is necessary, hence the advisability of early professional advice. The temperature ustrally falls through the use of saline laxative medicine, and this is materially assisted by the discriminate use of green food. No hay should be given, but scalded oats and bran, along with boiled linseed, constitutes the most rational system of dieting a horse when suffering from an acute attack of laminitis. Treatment is of a less urgent character when the trouble is subacute or chronic. Laminitis sometimes terminates very unfavourably, necessitating the destruction of the animal. This is due to the effusion-the result of the inflammatory action-between the sensitive and the insensitive laminæ, 
loosening the bond of union between the two, and favouring the descent of the pedal-bone. This in some instances becomes so far displaced as to male its exit at the toe through the horny sole. In every case, after an attack of this complaint, it is advisable to graze the patient on marshy land, in order that the feet may benefit from the moisture present. A great deal more might be said concerning this malady, but it is only intended to serve as an outline for the guidance of the amateur.

\section{NAvicular Disease}

This is a disease which affects those structures in juxtaposition to a small bone-the navicular boneimplicating the cartilage covering the bone, the bone itself, the synovial membrane or sheath, and the tendon, all of which structures become, sooner or later, associated in the diseased processes. It affects one or both fore feet, and seems to be confined to horses of light draught, more especially harness horses and those employed for light van work. It is a common disease and apparently incurable-always progressive, never retrogressive, as far as known. Horses affected with this trouble are permanently lame, and an animal suffering from this complaint is known by horsemen as a " grog," owing to its groggy method of progression. The lameness is most marked immediately the animal comes out of the stable, particularly if a short rest has been immediately preceded by active work. There is nothing in the way of positive signs indicative of navicular disease, but when both feet are implicated the step is usually very short and cat-like, with pointing of the toes. The heels may or may not be contracted, but the shoes usually show more wear at the toes than elsewhere. Pointing of the foot in the stable is very often present, and sometimes the animal will be continually scraping the ground when in the stall. In advanced navicular disease the shoulders 
become somewhat wasted, this being apparently due to diminished functional power of the muscles, owing to disease in the foot. Quite a number of horses with navicular disease are offered for sale and find purchasers, as it is an easy matter for the inexperienced to overlook a trouble so obscure, for obscure it certainly is, and it renders the animal of very little commercial value.

For the relief of the lameness, and in order to work a horse thus affected, say, for a year or two longer, the operation of " neurectomy," or unnerving, is practised in some instances. It is not, however, a very commendable operation, and is, when performed, occasionally a means towards fraud. Sometimes the operation is a success, and sometimes it is not. When successful the lameness is no longer observable, though of course the disease pursues its slowly progressive course, and must finally end either in the destruction of the animal or in its becoming useless for work.

\section{SAND-CRACK}

This is a disease affecting the wall, and begins immediately subjacent to the coronet by making its appearance in the form of a crack or split in the wall of the hoof. If in the fore foot or fore feet it occurs as a rule at the inner quarter, but to this there are exceptions, whereas in the hind foot it occurs generally at the toe. Sand-crack may begin on the inner or outer surface of the wall of the hoof, and its onset may be gradual or sudden. Every class of horse is equally liable to its development, but predisposition is unquestionable in hoofs which are dry or brittle, and those in which the integrity of the secreting structures of the coronary band have been damaged. Some hoofs are much thinner than others and this, along with continued work on hard, dry roads often leads to the production of sand-crack. A condition technically known as "false quarter," i.e. a furrow in the wall of 
the hoof at the quarter naturally, when such exists, favours the production of sand-crack. The crack in the wall may be either partial or complete, whilst its degree of extension may vary. When completely through the wall it sometimes causes lameness, as the sensitive laminæ are liable during movement to be nipped in the fissure. Under these circumstances it is cruelty to work a horse, but not otherwise. Firing below the crack, bolting the crack, and the application of tarred string are the commonest methods of dealing with sand-crack, though the results are variable. Blistering the coronet is also commonly employed.

Sand-crack is not as a rule very satisfactory to treat. Its presence when discovered is considered as a sufficient reason for the rejection of the animal when examined with regard to soundness. It is quite an easy matter to overlook the existence of sand-crack if the feet are covered with mud, and still more to do so if the crack or cracks have been filled in.

\section{FALSE QUARTER}

We have already alluded to false quarter as consisting of an indentation in the wall of the hoof at the quarter. It represents unsoundness owing to the fact that it predisposes to the condition alluded to in the preceding paragraph.

\section{CANKer OF THE FoOT}

This disease as a rule makes its appearance in the frog, and is sometimes mistaken for a simpler trouble known as thrush of the foot, but it is a far more serious condition than the latter. The author has been very unsuccessful in the treatment of canker, although many elaborate and patient measures have been employed in order to effect a cure. All experienced veterinary surgeons are only too well aware of its extremely malignant nature. The adoption of the most drastic methods have not, in the writer's hands, ever been satisfactory, therefore the most 


\section{THE FOOT IN HEALTH AND DISEASE II5}

that can be recommended is to keep the feet clean and as dry as possible, along with properly applied pressure over the whole surface of the frog. This can be done by means of a sliding iron plate and a packing of tow, along with the application of some antiseptic powder. An animal may continue to work for years with its foot or feet patched up in this manner, which is, in the writer's opinion, infinitely better than keeping the horse idle, contracting a large veterinary bill, with every prospect of failure at the end. Canker may affect one or more of the feet, and it is easily discernible by paring the frog, which begins to bleed when cut, and a soft, spongy, greasy-like, foul-smelling material is observable. Lameness is commonly present, being due to implication of deeper structures.

The writer looks upon canker as a progressive and practically incurable disease.

\section{THRUSH}

This is an extremely common trouble, and in the majority of instances it is due to negligence on the part of the attendant.' No good horse master would allow this state of affairs to exist, although a badly drained stable may easily lead to its production. It arises through the irritation in the cleft of the frog caused by decomposing organic matter, allowing this to accumulate in the feet. The "foot picker" is the best preventative of thrush, and no stable should be without this useful appliance, but what is still more important is that of using it regularly. The cleft of the frog, as previously stated, is the seat of septic infection indicated by a suppurative inflammation and an objectionable odour. The fore or hind feet may be affected, but particularly the hind, these being more liable to become fouled. In nine cases out of ten the existence of thrush in the feet may be accepted as evidence of want of proper attention to the feet, and it 
is to a large extent preventable. As a rule it is not a difficult matter to cure it, and the farrier usually puts in a stopping of tar and tow, which may or may not be effective, according to the stage at which the disease has arrived. A solution of chloride of zinc or sulphate of zinc, ten grains of either to each ounce of water, will usually effect a cure if applied twice a day for a few days consecutively, but it is useless to try to treat this affection if the source of irritation is still allowed to exist. As a dry dressing equal parts of powdered boracic acid, calcined magnesia, and powdered starch makes an excellent application. Thrush varies in its severity. Sometimes it is extremely slight, whereas in other instances the frog may be partly underrun, and lameness even result. The cleft of the frog should always be packed, when treating this disease, with tow.

\section{SIDE-BONE}

The pedal-bone has, attached to its wings, two flexible plates of cartilage which project backwards and upwards at the heels. These are known as the lateral cartilages. It is quite common to speak of side-bone as an ossification of these structures. There is a considerable amount of interest attachable to the lateral cartilages and their relationship to limbs. The author believes that side-bone is quite a common cause of lameness, and the majority of veterinary surgeons are in agreement with this. Specimens obtained and examined after death by the writer afford positive proof as to this being the cause of lameness. Doubtless a certain percentage of side-bones never cause the slightest inconvenience, as the writer has known horses to have large side-bones, yet remain free from lameness; in fact, the majority of cart horses working in towns have side-bone. There is a natural tendency for the lateral cartilages to become calcified-_" ossified "-this being a degenerate change 
in them, and it is rather remarkable that the trouble should be mainly confined to animals required for heavy draught purposes. The percentage of light horses with side-bone is comparatively small, and when this state of affairs does exist it is considered to be much more detrimental than in the case of a heavy draught horse, owing to its greater liability to produce lameness. The writer has, however, examined light horses with well-marked side-bone, yet these showed no indication of lameness. As a precautionary measure it is always expedient, apart from legal responsibility, to look upon side-bone as sufficient cause for the rejection of a horse in relation to soundness. Old horses of the cart horse type have almost always signs of this disease.

There is a preliminary stage to calcification, viz. induration, and the cartilages are often found in this condition. It is customary amongst veterinary surgeons to pass horses-heavy draught horses-with side bone as practically sound, provided that the heels are strong and free from contraction. Unquestionably there is a predisposition to contraction of the heels in well-marked instances of side-bone, probably due to decreased functional power in this particular region. Side-bone is regarded by horse breeders as hereditary, and horsebreeding societies are not supposed to make use of sires having their lateral cartilages thus transformed. The question is whether this is a correct view to take. It is impossible to answer the question with any degree of certainty, though it is equally certain that it is better to choose a sire without side-bone than one with it, and this is equally applicable to the dam. Perhaps the reader will say that very few foals of the cart horse type would be born if this rule were followed, a statement which is undeniable. Probably one of the chief factors in the production of this trouble is concussion, and it affects the fore feet almost exclusively. Sometimes only one cartilage is implicated, at other times the inner and the 
outer of both fore feet are concerned. Normally, the cartilages yield when pressed with the thumb, and any loss in their flexibility can immediately be felt by this pressure at the extreme back part of the upper ball of the hoof, that is, just close to the heel.

The lateral cartilages increase the area of the wings for ligamentous attachment, and it is possible that sidebone sometimes starts-probably very often-in the structures in contiguity with the lateral cartilages.

Once side-bone is established it is permanent, and little good can be done towards the amelioration of the lameness. Hoof section is really of little use, though satisfactory results have been recorded in some instances. The author's experience in this direction has been very unsatisfactory, therefore he does not feel justified in recommending the operation.

There are quite a number of other diseases affecting the feet, all of which are important to the veterinary surgeon as causes of unsoundness, lameness, or inefficiency, either temporary or permanent. Amongst these mention must be made of bruises to the coronet; also frost-bite of this structure. The coronet or coronary band, as stated, when speaking of the structure of the foot, encircles the upper border of the hoof and is a very non-yielding structure, consequently it leads to the production of pain and lameness when it is bruised, or implicated in disease through any other cause. The degree of lameness seems disproportionate to the injury, though it is accounted for by the absence of any degree of swelling. All affections of the coronet require very skilful treatment, therefore professional assistance should be obtained as soon after the injury is noticed as possible. As a palliative measure, in the meantime, the owner should put the foot into a pail of hot antiseptic solution for half an hour night and morning, which is the most conservative measure we feel justified in recommending. 


\section{CutTing oR BRUSHING}

This consists of an injury on the inner side of the fetlock, usually the hind one, and the injury is done by the shoe of the opposite foot striking the skin and sometimes inflicting a nasty wound. It is a form of injury which can sometimes be remedied through the use of a three-quarter shoe and keeping the wall of the hoof well rasped down the inner side. All sorts of devices are employed, and every farrier has his own ideas as to how a horse should be shod as a preventative against the infliction of this injury. Some horses are incurable owing to peculiarity of conformation and action. This trouble is sometimes spoken of as "striking " or " interfering." It may cause a horse to go quite lame, and when the animal has a habit of doing it, it leads to thickening of the skin and permanent scarring at this particular part. Some horses are compelled to wear a leather shield or piece of flannel around the fetlock. The writer cannot recommend the purchase of a horse addicted to this habit. Sometimes by thickening the inside branch of the shoe-making it thicker than the outside and driving all the nails on the outside and at the toe, one can remedy this trouble. At any rate, it is worth while to try this and any other devices which may be suggested, in order to mitigate the evil.

\section{FORGING}

This consists of striking the inner edge of one of the fore shoes with the toe of the hind one. The sound produced is very annoying, and some horses have a constant habit of doing it. Animals very short in the body and a trifle long in the limbs are very liable to forge, and so are horses which are green or not settled in action, say after a period of rest. Try rounding off the inner edge of the fore shoe and keep the toe of the corresponding hind one short. 


\section{Bruised HeEL}

The heels and the fore feet are sometimes struck with the toes of the hind ones, either on the knee or the off side, and if the injury is severe enough the pain inflicted may cause a horse to fall and do still further injury to himself or to others. Bruised heel produces lameness in many instances, and there may be a flap of skin lacerated by the injury. A wound in this situation heals slowly. The animal must be kept off work, the wound cleaned, and then dressed with some healing ointment and a bandage until cured.

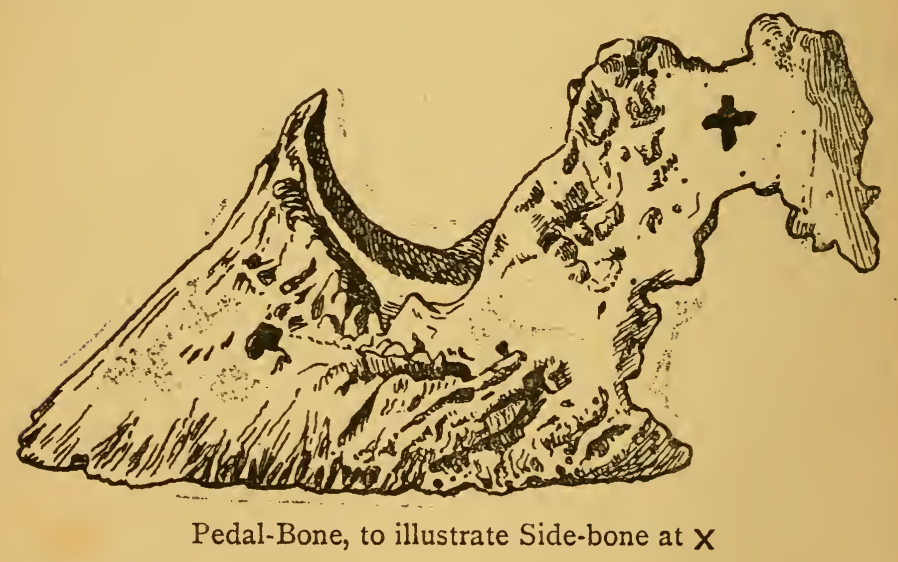

CORN

A corn consists of a bruise on the sole, usually on the inner quarter. It is denoted by a red discoloration of the horn. It often causes lameness. Remove the shoe and the pressure on the corn. 


\section{CHAPTER XIV}

FACTS OF GENERAL INTEREST

\section{The Pulse}

THE most convenient place to ascertain the condition of a horse's pulse is on the artery which winds round the lower jaw, on either the near or off side. It is customary to use the second and third fingers of the right hand, selecting the near side of the head. The fingers are applied lightly, just sufficient to gently press upon the wall of the artery. The number of pulsations in an adult horse ranges from 36 to 45 beats per minute, each beat being clear and distinct. In certain diseases the pulse conveys a sensation of being hard and a wanting in its normal fullness. Sometimes it is very rapid, 80 or Ioo per minute and correspondingly small. These changes and the sensation imparted to the fingers are the result of inflammatory action in some organ or tissue. In certain diseases the pulse becomes very slow. It is liable to great variation under abnormal conditions, and nothing but long tuition will enable anyone to appreciate the many significant states of it.

\section{The Temperature}

For taking the temperature of a horse a clinical thermometer is employed. These small instruments can be obtained at all chemists for a few shillings, and anyone having anything to do with sick animals should not be without one of these, as it is an invaluable aid for marking the onset, progress, and decline of disease. A clinical thermometer consists of a bulb and stem. The bulb 
contains the mercury and the stem is marked with the figures 95, I00, IIO. These are degrees on the Fahrenheit scale. All the long strokes represent degrees and the short ones between, two-tenths of a degree, usually expressed by the decimal point in front of the denominator. Between the bulb and the stem there is a constriction which prevents a small detached rod of mercury from uniting with the mercury contained in the bulb. This rod is called the index, and it serves to register the temperature, as it remains standing in the position it was when the thermometer was in use. A horse is said to have a slight degree of fever if its temperature is $103^{\circ}$ or I0 ${ }^{\circ}$; a moderate degree of fever when the thermometer registers $105^{\circ}$ or $106^{\circ}$; whilst the fever is high at $107^{\circ}$. Temperatures higher than the last-named are by no means frequent, in fact rather the reverse. It is customary to take the temperature at the same time night and morning in the rectum or lower end of the bowel, making a note of it for future reference. Take the stem in the fingers of the right hand, raise the tail with the left and then gently insert the " bulb" into the rectum.

\section{The Breathing}

During the act of inspiration pure air is taken into the lungs and in expiration carbon dioxide is given out. Normally the respirations number about I4 per minute, but during exertion they are greatly increased. Quick breathing, or " blowing hard " as it is called, is very often significant of lung trouble, either acute or chronic.

\section{Physicking Horses}

It is customary to speak of the administration of a ball or bolus, composed of Barbados aloes and ginger, as physicking a horse for the purpose of removing waste products from its system. Physic balls vary in their weight from 4 drms. up to 8 drms., and their action is 
usually, though not always, in accordance with their weight. Some horses are much more susceptible to the action of physic than others ; moreover, a great deal will depend whether the animal has, prior to the administration of the ball, been prepared by giving it a bran mash. The latter makes all the difference, and no horse should have physic unless it has been thus prepared, otherwise the proper action of the medicament is not obtained. For light horses a $5 \mathrm{drm}$. ball is all that is necessary and 6 drms. for heavy draught horses. In Scotland $8 \mathrm{drm}$. balls are commonly given for heavy horses. For a cob a $5 \mathrm{drm}$. ball is correct and for a pony 3 or 4 drms., after being duly prepared. The effects of the physic usually pass off within 24 hours. If purgation is excessive put the animal on dry bran, but keep it without hay for the time being. It is not advisable to work a horse whilst the physic is acting. Exercise increases the activity of the ball, so does warm water, and so do bran and linseed mashes. If there is any drug in the British Pharmacopœia which is universally employed in veterinary work that drug is Barbados aloes, and in nine cases out of ten it is given in the form of a ball. There are plenty of other medicines capable of establishing free purgation in the horse, but somehow or another they have never found the popularity of the physic ball. Indisputably it is a valuable remedy for a multiplicity of ills from which our equine friends suffer. It should never, however, be abused, which, unfortunately, it very often is.

\section{AdMinistering MEdicine to HoRSES}

Medicine can be given to the horse either in solid or liquid form. Drenching horses with nauseating drugs has been far too much practised, and we hope to see less of it in future. Whenever possible give a horse its medicine either in its food or with its drinking water. We do not argue that drenching may not be necessary, but it should 
usually be done under professional guidance. Many horses have died from pneumonia brought on through the careless administration of fluid medicine. The simplest method of doing this comprises the application of the twitch to the nostrils and supporting, the head sufficiently high to enable the medicine to gradually trickle down through the back of the throat. The great secret is to give the medicine slowly; otherwise the animal either suffers or else three parts of the draught are wasted on the stable floor. It is surprising how very few stable attendants know how to administer a draught properly to a horse, and still fewer know how to give a ball. There is an art in both and a degree of manipulative dexterity necessary which is not possessed by every one. Salts and other soluble substances can be dissolved in a quart of water and given the animal to drink. Horses will seldom refuse medicine given this way. In soluble powders it may be mixed with the food provided that they have no unpleasant odour. Some horses will eat anything in this line, but others will refuse it. In cases of pneumonia it is simply madness to try to drench a horse. Veterinary surgeons now largely employ the hypodermic method of medication, sometimes with and sometimes without results.

\section{BLISTERING AND FiRING}

Both these methods of dealing with injuries in connection with the limbs, bones and joints are largely practised by the veterinary profession and by many of the empirical humbugs found wandering about the country. Judiciously used both blistering and firing have their virtues. It is their abuse which has placed them so often in disrepute. It is impossible to lay down any rule as to when either shall or shall not be employed. The blister pot has been more used upon the horse than anything known. There are very few stables without a box of blistering ointment, 
varying in colour from red to green and from green to brown, according to the irritant employed for the purpose. Before a part is blistered the hair should be clipped off, the skin washed with warm water and soap, dried, and the blistering ointment then rubbed well in. Both blistering and firing produce a variable degree of inflammatory action in the skin and subjacent tissues depending upon the degree of application. Firing, or the application of the actual cautery, is more severe in its effects than that of a blister, but sometimes the action of both is combined; thus, for instance, the area involved is fired with the firing iron and the blister then lightly smeared over the bound surface. Deep firing, though surgical, seems to be cruel unless the animal has been put under a general anæsthetic in order to produce complete narcosis. Both firing and blistering are resorted to in cases of spavin, splint, sprung tendon, ring-bone, side-bone, curve and a host of other troubles.

A part can be fired either in points or in lines. For splint and spavin point firing is generally resorted to, but the degree of severity or otherwise varies. After a horse has been blistered or fired it should be tied up short for twenty-four hours, or if turned out to graze, it is advisable to fix a cradle on, so as to prevent the animal biting the part and blistering its nose. When a limb is blistered or fired in any particular part, the hollow of the fetlock should be freely smeared with lard or vaseline. It is not a good plan to blister the flexous surface of the joint or immediately beneath the throat, as the skin is apt to crack and become very sore. To soothe a blistered surface, apply the carron oil, recommended elsewhere in this book. It consists of equal parts of lime water and linseed oil, shaken together.

\section{Fomentation}

Fomentation comprises the application of hot or cold water to a given area and it may be for the reduction of 
swelling, to arrest hæmorrhage, or to encourage an abcess in its formation. Both the application of hot and cold water affords an invaluable means of dealing with a variety of troubles which are accessible to their application. If water is applied too hot it will blister the skin, and if cold water is applied for too long it will shut off the circulation, or at any rate it is very liable to do so at the part to which it is applied. Never go to extremes in the application of either of these simple remedies, as they can become just as harmful as they may prove useful.

\section{Feeding Sick Horses}

The special feeding of horses which are affected by various diseases is a different branch of the horse attendant's work, but it is one that every horse owner should make himself personally acquainted with. It is surprising how one person will often fail to coax a sick horse to eat, whereas another will succeed. The great matter is to test the appetite of the patient with various food materials such as steamed carrots, steamed oats, barley, clover or other green food when obtainable; natural grass; scalded hay and treacle ; scalded oats ; bran and boiled linseed ; linseed cake ; condensed milk and warm water ; oatmeal gruel. When possible, select a bit of very sweet hay from a truss. Try hand feeding in bad cases of sickness. Do not leave any food in front of the patient. Unconsumed food should be removed forthwith. The great secret is to try the patient at frequent intervals throughout the day.

\section{Castration of Colts}

Colts are usually operated on when they are one year old and in the spring of the year, but if the weather is very cold it is customary to defer the operation until such time as more propitious weather supervenes. The operation can, however, be performed at any season of the 
year ; in fact, it commonly is in the case of adult animals which have been kept for stud though subsequently desired by their owners to be utilised for work. It is a comparatively simple operation and can be performed either in a standing or recumbent attitude. If the former, the colts must be housed the night before and, for preference, kept without any food until they are operated on the following morning. When operated on in the recumbent posture, a straw bed should be put down or else a piece of soft ground provided for " throwing " the colt. As a rule, the operation only occupies a few minutes and the fee ranges from $7 \mathrm{~s}$. $6 \mathrm{~d}$. to a guinea or 2 guineas, according to circumstances. In the case of rigs, the fee for the operation varies from 5 to Io guineas. Castration is a safe operation and ninety-five per cent of colts never show any ill effects from it, but the remaining five per cent may and sometimes do.

If a colt is ruptured, a special operation is needed, but this should be discovered before the animal is operated upon, and then dealt with according to surgical principles. Sometimes infection occurs and the part begins to swell extensively and suppurate. Under these circumstances it is necessary to keep the wound open so as to give free exit to the discharge. Normally a certain amount of swelling is usual, and to dispel this many operators believe in turning their colts out to graze immediately after they have been operated upon. Another unforeseen accident is prolonged hæmorrhage, or bleeding from the cord, due to the artery not having been properly sealed, or it may be that the hæmorrhage is brought on through the animal itself after the operation. There is no need for any alarm, as the loss of three or four quarts of blood from a horse is of very little importance. Anything beyond this demands professional skill and can always be dealt with. Sometimes cold irrigation will stop it, but the owner should never interfere with the wound, as he may quite easily, though unwittingly, infect it 
Lastly, there are two other diseases sometimes associated with castration, viz. tetanus or lock-jaw and botrymycosis, the latter disease being one which affects the cord and is due to a species of ray fungus, similar to a corresponding disease occasionally observed affecting the tongue in cattle. This disease leaves one or more suppurating points and may persist for many years. It is accompanied by great thickening of the cord but can be cured by operation. The author has performed a number of operations of this kind and always very successfully.

Healing Ointment

Ry Pure Carbolic Acid . . 40 drops Vaseline . . . 4 ounces

\section{WOUND LOTION}

R7 Pure Carbolic Acid . . I drachm Glycerine . . . . I ounce Water . . . . I pint

Apply with tow two or three times a day.

Lotion For SORE BAcks, Sore Shoulders, AND SADDLE GALL

Ry Powdered Oxide of Zinc . I ounce Methylated Spirit of Wine . 4 ounces Oil of Eucalyptus . . $\quad \frac{1}{2}$ ounce Water . . . . I pint

TONIC POWDERS

R7 Powdered Sulphate of Iron . I $\frac{1}{2}$ ounces Powdered Gentian • • $4 \frac{1}{2}$ ounces

Mix and make I2 powders. One night and morning in food. 


\section{Saline Fever Powders}

Ry Epsom Salts . . . 3 ounces Bicarbonate of Potash . . I I $\frac{1}{2}$ ounces Nitrate . . . . $I \frac{1}{2}$ ounces

Mix and divide into 6 powders. Give one night and morning mixed with a quart of the animal's drinking water.

Dressing For Wounds in Summer to KEEP FLIES OFF

R7 Oil of Turpentine . . . 2 ounces Creosote . . . . I ounce Olive Oil . . . . 6 ounces

Mix by shaking well together. Apply to wound once a day. 


\section{CHAPTER XV}

ANATOMICAL OUTLINES OF THE CONSTRUCTION OF THE HORSE

IT is always an advantage for the amateur to make himself acquainted with the elements of the anatomical construction of a horse, in order that he may be in a better position to appreciate some of the simpler facts when speaking of diseases, injuries, etc. The old maxim that a little knowledge is a dangerous thing holds good so far, but it is equally true that the possession of such may be decidedly advantageous rather than otherwise.

It is customary to divide the various parts of the animal body into different systems, such as: the muscular; the nervous ; the vascular ; the gestive ; the respiratory, etc. The whole of these systems, along with others not mentioned, are either placed within or upon a framework of bone, which we recognize as a skeleton, the structure of which is of a highly interesting nature, and the more it is studied, the more complex it appears.

In an elementary work of this description it is impossible to do anything more than mention the most rudimentary facts relating to the matter now under consideration.

\section{The Skeleton}

The framework is made up of a number of bones of various kinds, articulated together by ligamentous attachments, through which a variable degree of movement is allowed.

All the bones forming the skeleton are primarily laid 
down in the form of cartilage, in which condition they appear prior to the birth of the foal. Their transformation into bone is spoken of as ossification, a process which commences at certain centres in each bone and gradually extends until the whole structure becomes converted into bone. The bones of the limbs differ from those in the rest of the framework; most of the former have a medullary canal filled with red marrow, whilst the ends of the bone have in their interior cancellated bony tissue filled with yellow marrow. These are spoken of as long bones in contradistinction to short, flat, and irregular bones participating in the construction of the rest of the skeleton.

The head is composed of a number of bones which, soon after birth, become more or less ossified, and the only movement, or rather, we ought to say, freedom of movement, is that executed between the upper and lower jaw.

The neck is composed of seven segments. These are the cervicle vertebræ, and the bone next to the head is called the atlas, and the one following it the axis. The articulation between the atlas and the head gives the horse its nodding movement, whereas that between the atlas and the axis confers a rotatorial one. The rest of the vertebræ articulate amongst themselves. Each vertebræ is hollow, forming a segment of a canal, so that when all the vertebræ, extending from the atlas to the bones of the tail, are united together, they form a canal - the nural canal - which lodges the spinal cord, and from which the spinal nerves originate, to be subsequently distributed to various organs and tissues throughout the body.

The spinal cord commences at the base of the brain in a structure known as the medulla oblongata, and from the latter numerous nerves arise. The spinal cord is an extremely delicate structure composed of white and grey matter, and it is invested by three membranes corresponding to those covering the brain. The nural canal, in which 
it is lodged, forms a very protective shelter to it ; nevertheless, in spite of this fact, the spinal cord is occasionally implicated in disease.

Reverting to the structure of the skeleton, the bones of the neck are followed by eighteen dorsal vertebræ, each of which has a well-developed spine on its upper surface, to which ligamentous and muscular structures are attached. The spines are longest at the withers, the summit of which they form. Following the vertebræ last named are those of the loins, called the lumbar vertebræ, of which there are six or seven. Succeeding these are the five sacral vertebræ, which assist in forming the bond of union between the latter, the pelvis, and the hind limbs. Following the sacral vertebræ are the bones of the tail (coccygeal vertebræ).

The whole of the vertebræ possess limited movement, and the spinal column is a fairly flexible rod, but this degree of flexibility is much greater in some horses than in others owing to the special nature of the work required of them. The ribs number eighteen pairs, eight of which are regarded as true ribs and the remaining ten as false. The first-named are joined on to corresponding segments on the sternum or breast-bone. The last-named forms the floor of the chest.

Each rib possesses a certain amount of elasticity, consequently these structures are able to resist, without injury, a good deal of external violence, though of course fracture of the ribs in the horse is not in the least uncommon. The ribs form the lateral boundaries of the chest wall and part of the roof of the cavity, being assisted in the latter by the bodies of the dorsal vertebræ.

The fore limbs are not attached to the skeleton as in the case of the hind limbs, being merely slung on to the body through the medium of muscular tissue, the skin and sub-cutaneous tissue.

The hind limbs are attached to the spinal column by the pelvic girdle, therefore there is a greater degree of mobility in the fore limbs of a horse than in the hind ones, no 
matter whether the movement is backward, forward, outwards or inwards.

Each fore limb is composed of the following bones: the scapula, or shoulder-blade ; the humerus, or the arm ; the radius and the ulna, or the forearm ; the bones of the knee or the wrist; the large cannon bone; and the two splint bones behind this. Technically, the bones last named are the large and small metacarpals. These are succeeded by the sessamoids-two small bones at the lower end and the back of the large cannon bone.

We now come to the long pastern bone, the short pastern, and the coffin or pedal-bone. Sometimes these three bones are spoken of as the first, second, and third phalanges. All these bones articulate with one another so that we have the shoulder joint; the elbow joint; the knee joint; the fetlock joint; the pastern joint; and the coffin or pedal joint; the two last-named being enclosed within the hoof.

All the bones in the fore limb are fairly strong, and two at least of them occupy a very sheltered position which materially diminishes their risk of injury. These are the shoulder-blade and the arm, though of course neither are exempt from fracture.

Each hind limb consists of the femur, or first thigh-bone; the tibia fibula, or second thigh-bone. The fibula is a very slender rod of bone.

The second thigh is succeeded by the hock joint, composed of the os calcis (heel), the astragalus, and several other small bones. From the hock to the foot the remainder of the bones bear exactly the same names and occupy corresponding positions to those bones in the fore limb. At the back of each pedal-bone there is a small shuttle-shaped bone-the navicular.

The joints in the hind limb are as follows: the hip ; the stifle; the hock; and those of the phalanges. At the stifle there is the patella, or bone which forms the knee-cap. 
Following the stifle joint is the hock, and this is like the knee composed of a number of small joints formed between the individual bones of the hock. It is of interest to note in passing that the point of the hock corresponds to the heel in man, whilst the knee is comparable to the wrist, and the stifle to the knee.

In the horse the metacarpal bones are reduced to three (in man five), and are represented by the back of the hand. The hind limbs, as previously stated, are united to the skeleton by means of the pelvic girdle or innominate bone, each half of which is composed of three portions, namely, the ilium, the ischium, and the pubis. These are united together by ossification and form a solid bond of union between the hind limbs and the trunk, the articulation being formed by the bones of the sacrum.

In looking at the skeleton of the horse (see illustration), the reader will notice the remarkable position which some of the bones occupy, the angles they form, together with the extremely rigid nature of the whole structure. All the bones forming the skeleton present various roughnesses, depressions, prominences, and other marks indicating the attachments of muscles, ligaments, tendons; the passage of nerves and blood-vessels, and the coverings of the bones themselves.

The joints are of interest, as showing the various movements that they are capable of executing, and also the surfaces of the opposing ends of the bones are of additional interest.

Taking the fore limb and commencing at the shoulder joint we find that the lower end of the shoulder-blade, or scapula, shows a cup-shaped depression or concavity, whereas the upper end of the humerus, or arm, presents a large convex surface, the whole joint being closed by what is known as a capsular ligament. This represents the so-called enerthrodial, or ball-and-socket joint, and it is obviously one which allows a considerable amount of freedom of movement. The same remark is applicable 


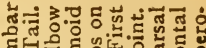

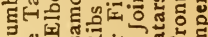

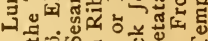

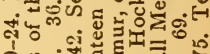

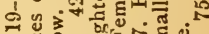

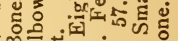

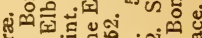

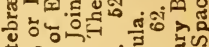
(n) (n) (n) (n) (n) (1) 
to the hip joint, which is also a ball-and-socket joint, but it differs from the shoulder joint in one remarkable respect, namely, that there is a short round ligament(the so-called round ligament)-which passes between the articular head of the first thigh bone and the cavity into which it fits on the pelvis. This exercises a restraining movement by preventing abduction of the limb. This ligament is practically absent in cattle, hence the reason these animals are able to kick in an outward direction as well as backwards and forwards.

The shoulder joint of the horse, as previously stated, allows a great freedom of movement, and this is superadded to by the manner in which the scapula or shoulderblade is slung on to the side of the chest wall. All joints, in addition to being enclosed by a capsular ligament, have the ends of the bone covered by cartilage, whilst the capsular ligament is lined by synobial membrane, the special functions of which are to secrete synobia, or what is popularly known as joint-oil-an albuminous fluid allied to the white of egg.

From what we have already said the reader will have learned how a joint is formed. Following upon the shoulder joint is the elbow joint, and this is quite different from the first named. To begin with there is practically no lateral movement, this being what is known as a hinge joint, and is formed by the union of three bones, namely, the lower end of the humerus, the upper end of the radius, and the articular surface of the ulna. Extension is the principal movement of this joint.

Succeeding the elbow joint we come to the so-called knee, which is composed of a number of small bones, each having several minute articular surfaces or facets for articulation amongst themselves, and conferring upon them a slight gliding movement. In reality the knee joint is a complex one. Thus, for instance, there is that formed between the lower end of the radius and the upper row of the carpal bones, constituting the so-called 
radio-carpal articulation; then that between the individual of the carpals - the inter-carpal articulation; and lastly, the one between the lower row of the carpal bones and the upper ends of the large and small metacarpal-carpo-metacarpal articulation. The whole of this complicated system of joints is completed by fibrous tissue, capsular ligaments, and the sheaths of tendons, plus the skin and sub-cutaneous tissue. It is rather important for the reader to know this because he will be in a better position to understand the degree of injury to the structures of the knee in the so-called broken knee, or knees, which ranges from a mere superficial abrasion to actual fracture of the bones of the knee.

The knee is capable of a great degree of flexion, and attains its maximum flexibility in the hackney.

The fetlock joint is the next one, and is formed by the lower end of the large canon bone by the sessamoids and the upper end of the first phalanx, or long pastern bone. It is a hinged joint and allows complete flexion and a limited amount of lateral movement. Like the knee joint the fetlock should always be capable of being freely flexed during manipulation, though unfortunately both these joints are often stiff through usage, and in some instances variable degrees of anchylosis or stiffening exist. This naturally diminishes the value and utility of a horse irrespective of age and breed.

The remainder of the joints in the fore limb are of the same hinge-like nature as that of the fetlock, modified of course in accordance with the special functions they have to perform.

Passing to the hind limb we may say that the stifle joint possesses an extreme degree of mobility and is a complex joint, there being in reality several joints here. First of all there is one between the lower end of the femur or first thigh and the upper end of the tibia, or second thigh (femoro-tibial articulation), and secondly between the patella and front of the lower end of the 
femur (femoro-patellar articulation). To limit the degree of concussion in this region discs of cartilage are interposed between the opposing articular surfaces, the whole being enclosed and supported by capsular and straight ligaments.

The stifle joint is frequently the seat of various injuries, the principal one being slipped stifle (dislocation patella), and this is commonly met with in foals and colts, but also in adult animals, both horses and mules, more especially those in poor condition.

The hock joint-corresponding to the ankle in manis like that of the knee, composed of a number of joints formed between the lower end of the tibia and the large and small bones of the hock, as well as the upper ends of the large and small metatarsals; but the principal articulation is that between the lower end of the tibia and the astragalus, or screw-bone of the hock. This is called the true hock joint, and it allows a great degree of flexion, and the greater this degree, the better the hock action. The rest of the joints correspond to those in the fore limb.

\section{The Muscular System}

The muscular system of the horse is a well developed one, and comprises the whole mass of muscle or flesh attached to the skeleton upon which it is moulded. Muscular tissue is divisible into two varieties, namely, the striped or voluntary muscle, and the plain or involuntary; whilst a third variety forms the whole substance of the heart, and is known as cardiac muscle, in which the fibres are disposed in a special manner.

The whole of the muscles on the skeleton are of the striped variety, whilst plain muscle is found in the walls of the stomach, intestines, etc. All the muscles of the skeleton have what is known as an origin and an insertion, and those of the limbs, particularly below the knee and the hock, have long tendinous attachments, both to the 
front and back of the limb forming the flexor and extensor tendons. It is of some importance to note that there is an absence of flesh or muscle below the knee or hock, hence it follows why wounds and other injuries are usually so slow in healing.

The muscles of the neck, back, loins, and quarters are long and well developed, whilst those in the limbs have their tendinous prolongations gliding through lubricating sheaths at the joints, either at the front or the back of the limbs. Each muscle has its own particular functions to fulfil, and it may either act in consort with other muscles or in opposition to such in fulfilling its functions.

All the muscles are richly supplied with pure blood by the arteries and by veins for carrying away the impure blood. Their power of movement is regulated by their nerve supply.

The more highly developed the muscular system, the more specialised the functions in this particular area.

\section{INTERNAL STRUCTURE OF A HoRSE}

The nervous system comprises the brain and spinal cord, and the nerves issuing to and from these structures. The brain is lodged within the cranial cavity, and it occupies a very sheltered position, but in spite of the protection thus afforded it, it is liable to injury, to disease, and to participate in functional derangement. It is composed of a right and left hemisphere, the whole constituting the cerebrum, whilst there is a smaller portion of the brain known as the cerebellum, beneath which lies the medulla oblongata and the pons varolii, both of which look like expanded portions of the spinal cord and with which they are in direct continuity. From the base of the brain twelve pairs of nerves arise, such as the nerves of smell, sight, taste, and so forth

The brain has three protective coverings, the outermost of which is thick and fibrous. The blood supply to the brain is of a very complex nature. 
The substance of the brain consists of white and grey matter, the grey matter being disposed externally, whereas the reverse is applicable to the spinal cord, in which the grey matter is placed internally. Like the brain, the cord has three coverings.

Highly specialised nerve cells enter largely into the formation of the structure of the brain and the spinal cord. Twenty-two pairs of nerves arise from the cord, conveying afferent and efferent impulses to and from it.

\section{The Respiratory System}

In a horse the respiratory system (or respiratory organs) is well developed, and comprises the nasal cavity, the air sinuses, the larynx, the trachea, and the lungs, plus the bronchial tubes. The nostrils are fairly wide and divisible into two portions, one being known as the false nostril, and one as the true. The nasal passage is divisible into right and left portions, the partition between the two being composed of a plate of cartilage known as the septum nasi, and this, like the remainder of the passage as well as the air sinuses, is covered by mucous membrane, which in health is of a bright pink colour.

The air sinuses are compartments formed within the skull, and contain a reserve supply of air. They are in communication with one another and with the nasal passage, and in addition confer a degree of lightness on the head.

The horse, being an animal required for swift progression, renders it necessary that the foregoing features should be present. The sinuses are divided into the superior maxillary, the inferior maxillary, the frontal, and the sphenoidal, the last named being the smallest of the four. The sinuses are not uncommonly implicated in various diseases.

The larynx forms the entrance to the trachea or great air tube, and it is particularly well developed in the horse. It is composed of cartilage, muscles, and inter- 


\section{THE CONSTRUCTION OF THE HORSE I4I}

vening connective tissue. It is commonly the seat of disease, particularly in " roaring." The trachea is composed of a number of cartilaginous rings united together to form a single tube, which, as it enters the chest, bifurcates into the right and left bronchial tubes, each of which passes to the lungs, again divides and subdivides until, finally, its ramifications, plus blood-vessels, fibrous tissue, etc., form the lungs.

The trachea in the horse is close to the surface of the skin throughout a considerable portion of its course, consequently access to its interior, in other words, tracheotomy, is an operation comparatively easy to perform.

The lungs are large and occupy the bulk of the cavity of the chest ; the heart and the great vessels are suspended between the two. Each lung is covered by a delicate glistening membrane known as the pleural membrane, and this is also reflected over the inner side of the ribs to form the costal pleura in contradistinction to that covering the lungs, the pulmonary pleura. This serous membrane is also reflected over the heart, forming the pericardium in which the heart is enclosed.

The lungs have a very rich blood supply, and the three principal vessels are the pulmonary artery, the pulmonary vein, and the bronchial artery. Unlike other vessels in the body the pulmonary artery carries impure blood, and the pulmonary vein arterial blood, but the nutrient aitery of the lung is the bronchial. These features, however, are of merely passing interest to the reader of this book.

During the act of inspiration pure air is admitted into the lungs by the trachea, and it passes into the pulmonary alveoli which are encircled by the capillaries, containing impure blood, for oxidation during the act of inspiration. The expiratory effort comprises the discharge of carbon dioxide from the lungs after purification of the blood in these structures. 
The lungs are suspended in the chest through the medium of blood-vessels and connective tissue. Like other structures they are commonly liable to disease.

The cavity of the chest is separated from that of the belly by a single muscle known as the midriff, or the diaphragm, through which there are several openings for the passage of blood-vessels, the gullet, etc.

The diaphragm is the chief muscle of inspiration.

As previously stated the heart is enclosed in a sac-the pericardium. It is a hollow muscular organ with a right and a left compartment below, namely, the ventricles, and a right and a left compartment above, the auricles, the divisions between being formed of muscle in each case, but the right ventricle is separated from the right auricle by a valve, a remark which applies also to the left auricle and ventricle. These valves are of extremely delicate construction and their integrity is absolutely indispensable for the maintenance of perfect health. Unfortunately, however, they are often the seat of disease, more especially in that disastrous trouble chronic rheumatism.

Impairment of the valves leads to their inefficiency, and the result is that the circulation of the blood becomes interfered with. As stated elsewhere in this chapter the heart is composed of a special kind of muscle which confers upon it its powers of contraction and expansion for the distribution of blood throughout the body and its subsequent return to the heart after having been purified in the lungs.

The animal body has two circulations, namely, the pulmonary, or lesser, which is confined to the right side of the body, and a left, or systemic one, for the general supply of the whole body. In order to facilitate this distribution of blood throughout the body the left side of the heart is a great deal thicker than the right, hence its power of contractility is much greater than that of the right. 


\section{The Digestive System}

The digestive system, plus the accessory organs, comprises the tongue, the teeth, the salivary glands, the pharynx, the œsophagus, or gullet, the stomach, the small and the large intestines, the liver, and the pancreas. For a description of the teeth the reader is referred to the chapter dealing with these structures, namely, "The Age of the Horse."

The tongue is a muscular structure covered by mucous membrane and numerous papillæ. Its functions are to assist in maintaining food in the mouth, to ensure its thorough ensalivation, and to hand it to the back part of the mouth, that is into the pharynx, from which it subsequently passes along the œsophagus directly into the stomach. The tongue of the horse is relatively large, and is maintained in its position on the floor of the mouth through the medium of the hyoid bone and connective tissue.

The salivary glands are placed beneath the tongue, and also immediately behind the jaw. Their function is to secrete a fluid - the saliva-which, as it intermingles with the food, converts, through the medium of a ferment, the insoluble starch into sugar. Digestion really begins in the mouth.

The œsophagus, or gullet, passes down the neck immediately behind or at the side of the trachea, and after entering in the diaphragm is continued into the stomach to form the cardiac end of the latter. Only one half of the stomach of the horse is functional as far as digestion is concerned, owing to the fact that the lining of the gullet is continued as part of the lining of the stomach, forming the cuticular portion of the last named.

The stomach of the horse is comparatively small, only having a capacity of three or four gallons. It possesses many features of anatomical interest to which it is not necessary to allude. Its position in the abdominal cavity 
may bear some relation to the fact that vomission but rarely occurs in the horse.

The spleen is attached to the stomach externally by a ligament.

Digestion, to a large extent, takes place in the stomach, but to a greater extent in the small intestines.

The total extent of the intestines in a horse is about I20 ft., 70 of which is comprised in the small intestine. These extend from the outlet of the stomach to the cæcum. The large intestine is divisible into the double colon, the single colon, and the cæcum, the latter being a blind portion of the intestine. The double colon has a capacity of about twenty or thirty gallons, and its length is about twenty feet, therefore in order that the abdominal cavity may accommodate this huge structure the double colon is flexed or bent over upon itself.

The intestines, like the stomach, are composed of three coats, namely, an outer, or serous ; a middle, or muscular ; and an inner, or mucous. The digestive and mucous glands are situated in the latter.

All the digestive organs have a rich blood supply, nerve supply, and in addition absorbent or lymphatic glands.

The liver is large and situated on the right side of the body on a level with the last three or four ribs. Like the rest of the abdominal viscera it has a capsular investment or serous covering, together with ligamentous attachments which maintain it in position in the cavity. It is composed of liver cells, connective tissue, bloodvessels, and bile ducts. The bile ducts open into the duodenum, which is comprised in the first two feet of the small intestine. The liver acts as a store-house for starch and for the manufacture of bile, the functions of the latter being indispensable in assisting and completing the various digestive processes.

The pancreas, popularly known as the sweetbread, is a secreting gland for the manufacture of the pancreatic 
fluid-a fluid intimately associated with digestion. The duct of this gland opens into the beginning of the small intestine and conveys the fluid secreted into the latter.

This completes the description of the digestive organs.

\section{The Urinary and Generative Organs}

The urinary apparatus comprises the right and left kidneys plus their capsular coverings, the ureters or tubes conveying the urine from the kidneys to the bladder, the latter being a reservoir for the temporary storage of the urine, from which organ the urethra conveys the fluid outside the body. In the mare the urethra is short and straight, but much longer in the male. The kidneys are situated beneath the loins, and their functions are to separate the waste products of the blood and excrete it as urine. The whole of the urinary apparatus occupies a very sheltered position in the anatomy, but in spite of this portions of it are sometimes implicated in injuries to the loins, pelvis, etc., whilst those organs are also, and not uncommonly, affected by diseases.

The generative organs in the female comprise the mammary gland, the external generative organ, the fallopian tubes, and ovaries. The male organs consist of the testicles and the spermatic cord, along with the external generative organ. Like a portion of the urinary apparatus, part of the generative organs are contained in the pelvic cavity, i.e. the area within the pelvis. Diseases and injuries commonly affect both these systems, and always demand professional skill in dealing with them. 


\section{CHAPTER XVI}

\section{Specific Infective Diseases}

THE horse is liable to suffer from quite a number of specific diseases, that is, diseases due to micro-organisms or germs. These organisms are of an extremely minute size and require high powers of the microscope for their demonstration. Some of these organisms are capable of perpetuation outside the body by means of spores, and may continue their lives for a prolonged period. Nearly the whole of the specific diseases affecting the horse have been, during the last half-century, scientifically investigated and found to be due to the presence of micro-organisms or bacteria. The older observers had not the facility or requisite appliances for the proper investigation of the maladies now under consideration. The microscope has been the medium for the solution of some of the most complex problems in connection with pathological and bacteriological results. Many hitherto undiscovered causes of disease have been satisfactorily revealed. Moreover, microscopical research has resulted in the production of serums and vaccines, agents which are used both for the prevention and cure of disease, and their value in some cases is indisputable. These diseases are communicable from one horse to another by direct or indirect means; likewise some of them are transferable to man, and in him may take a short and fatal course, as, for example, glanders and anthrax. The specific infective diseases are nearly all notifiable, that is, if their existence is suspected on any premises the matter must be reported to the local authority of the district, which in some cases, 
in rural districts, is the police-inspector. In a small work of this kind all the writer can do is to indicate a few of the principal features of some of the diseases, and if the reader wishes for other information upon the subject he must consult some larger manual relating to this matter.

\section{CATARrh}

This is one of the commonest diseases affecting the horse, and it is prevalent during all seasons of the year, but more so during the spring and the autumn. Although catarrh is a comparatively mild complaint its existence should never be overlooked amongst a stud of horses, because an animal that is affected should, for the time being, be kept from work. During the recent Great War this affection was very prevalent amongst the horses, and it was responsible for the inefficiency of a large percentage of animals, both at home and abroad. Moreover, there is a predisposition for catarrhal symptoms to develop into a much more serious trouble, viz. pneumonia; hence the advisability in all cases of catarrh, amongst a small stud of horses, to take the temperature of each affected animal daily. The clinical thermometer is an invaluable instrument for this purpose. In all ordinary cases of catarrh the temperature seldom exceeds $104^{\circ}$, in fact, it is usually below $103^{\circ}$ Fahr., the normal temperature of a horse being $100^{\circ}$, or at any rate not more than Ior $^{\circ}$. Any rise of temperature beyond IO $^{\circ}$ should be looked upon with suspicion and the temperature taken, not once, but twice a day, morning and evening. It is wonderful how rapidly catarrh will extend throughout a stud of horses, and how very persistent it is whenever it appears in any particular district. There is a disease known as strangles, and this is usually accompanied by a catarrhal discharge from the nostrils, consequently the owner may think that the animal has got an ordinary attack of catarrh, whereas in reality it is the 


\section{THE HORSE}

trouble formerly named. Certain other diseases are also accompanied by catarrh, though very often the discharge is of a chronic nature-chronic catarrh. When a horse has catarrh it is seldom that it produces much constitutional disturbance, but sometimes the affected animal goes off its food for a day or two. The leading symptom in this trouble is a catarrhal discharge from one or both nostrils, along with increased redness of the mucous membrane lining the nose and eyes. The discharge is at first thin and watery, but later on becomes purulent and adheres around the margins of the nostrils, therefore it is quite an easy matter to detect the existence of this trouble, unless the nostrils have been previously sponged, but immediately prior to inspection. The heightened colour of the nasal mucous membrane should arouse suspicion as to the probability of this disease developing. The channels through which this disease are spread are not very clearly understood, but the chances are in favour of its perpetuation through the medium of the nasal discharge, as directly and indirectly, and another possible source of infection is the atmosphere in which an infected animal resides. The channel of infection is the respiratory tract. The sources of infection, in addition to the living animal, are the hands and clothing of attendants, mangers, stall posts, private and public drinking troughs, forage, litter, clothing, saddlery, etc. Doubtless some horses contract the disease in railway trucks, in which previously infected animals have travelled. The public water trough may act as a source of contagion, as it is not unlikely that street troughs are frequently infected. Horses which are picketed together may easily spread the disease from one to another by direct contact of the nasal discharge, or through the medium of lines and ropes. The general idea concerning catarrh, more especially amongst the uneducated, is that it is produced by cold or sudden changes of temperature, but this is in all probability quite an erroneous view. The 
only treatment necessary is to throw the animal off work and allow a small dose of Epsom salts in the drinking water, night and morning. If applicable, clothe the body and bandage the limbs. Unless the weather is too cold, all cases of catarrh should be kept in the open, as experience proves, when horses have this trouble, they get better much more rapidly in the open air, and are seldom troubled with a cough, which is certainly not the case when kept in an overheated stable, more especially if the latter is none too sanitary. Two or three weelss' rest is usually sufficient time for recovery to take place, but exceptions to this rule are not at all uncommon. Benefit does, unquestionably, follow fumigation of the nasal passage with medicated steam. A little turpentine added to boiling water and poured over sawdust contained in a close-fitting bag, suspended to the head, will be found beneficial. These inhalations can be repeated night and morning.

\section{STRANGLES}

There is a disease affecting the horse which is characterised by swelling below and between the jaws, usually accompanied by a nasal discharge. This swelling may be sufficiently extensive to press upon the upper part of the windpipe and impede respiration. The disease is, therefore, spoken of as strangles. It affects horses of all ages and of any breed, but it is one of those troubles which are more prone to attack the young than the fully matured animal. Some cases of strangles are of an exceedingly mild nature, others quite the reverse, more especially when the disease appears in connection with vital organs, such as the brain, the heart-sac, and structures in contiguity to the intestines. Under these circumstances the disease is spoken of as "irregular" or "bastard" strangles, the latter a vulgarism which is well understood. Like catarrh, strangles was extremely prevalent amongst the horses in the British Army, and had it not been for 
isolation, or segregation, there is no doubt that this malady would have given much more trouble than it did. The organisms, or germ, of strangles have been cultivated outside the body of the animal, and the cultures thus obtained, when injected into the body of an animal, have reproduced the disease. Horses coming from dealers' stables, markets, and fairs, particularly young animals, seem to be very prone to the development of this trouble. Strangles is characterised by a preliminary malaise, to which the expression " breeding strangles" is applied. It is the horseman's vernacular for expressing the " dor mant" or "incubative" period of this disease. Following this preliminary indisposition a swelling can be felt or seen and felt beneath and at the side of the jaw. It is somewhat tender and painful, though these features are not uncommonly absent. The swelling increases from day to day, until the intermaxillary space is considerable. This is the formative stage of the abscess, and as the skin becomes tenser every day, it finally softens at one point and then breaks. To save time the veterinary surgeon usually lances the abscess and keeps the wound open for several days in order to encourage free suppuration. Sometimes the abscess forms at the back of the jaw, just below the ear. When this is the case the animal suffers a great deal more, and the course of the disease is more prolonged. Several abscesses sometimes form ; in fact, the writer has seen them extending down the neck, following the course of the windpipe. Fever may or may not be present. Sometimes the breathing is seriously disturbed ; in fact, so much so as to necessitate the windpipe being cut open and a tube inserted (tracheotomy). Recovery usually occurs within a month, provided that all goes well. Very little treatment is necessary beyond that of clipping the hair off the seat of the swelling and rubbing in a little blistering ointment, but it will be found that the best advice we can give is to call in a $q u a l i f i e d$ veterinary surgeon and leave the case entirely 
in his hands. The food in both strangles and catarrh should consist of scalded oats, bran and linseed, scalded hay and green food, when such can be obtained.

\section{INFLUENZA}

A large percentage of cases which it has been customary to speak of as influenza are nothing but catarrh or strangles. It would, however, be injudicious to speak of typical cases of influenza as belonging to either of the foregoing diseases. Influenza is one of those troubles which are often present in horses coming from dealers, and, like catarrh and strangles, it follows the lines of traffic. It is customary to speak of the malady as being a specific infective disease, accompanied by a considerable degree of prostration, loss of appetite, catarrh, and a harsh and persistent cough, rendering swallowing difficult. The internal temperature ranges up to $107^{\circ}$ Fahr., and it is quite common to find horses with a temperature of $105^{\circ}$ and $106^{\circ}$. At first the nasal mucous membrane is heightened in colour and its surface dry, but this is soon followed by moisture, and later on by a purulent discharge from the nose. Influenza assumes various forms, such as the respiratory, the hepatic, the intestinal, and the cerebral, all of which symptoms merely represent the predominating clinical features of the disease. The pneumonic form accounts for the greatest number of deaths, whilst the ordinary respiratory one is indistinguishable from catarrh. The supervention of pneumonia is indicated by a rise of the bodily temperature, increased respirations ; in short, the animal begins to "blow hard," and the nostrils are dilated, becoming more and more so as the disease in the lungs advances. The pulse is greatly increased in number, sixty to seventy per minute, whilst if pleurisy is an accompaniment the animal has a short suppressed cough and very often grunts when it moves. All horses when they have got 
lung trouble persistently stand in one position, and that position is where they can take most advantage of the fresh air, which is usually near to the door or window. This fact should never be lost sight of in the treatment of lung complaints; in fact, fresh air is one half the battle in dealing with lung trouble. Experience proves that horses should be kept out in the open air as much as possible, provided that the animal can be kept dry. The open air treatment of pneumonia cannot be too strongly insisted upon ; in fact, all respiratory complaints should be dealt with after the fashion indicated. "There is a trite saying, " Give him air and he'll straight be well." In disease, more particularly that in connection with the lungs, pure air represents food, and it will do more good than all the medicine in the world. In nine cases out of ten pleurisy accompanies pneumonia, which is not to be wondered at, considering that this serous membrane invests the lung structures, being reflected over the lungs as well as lining the cavity of the chest. In the bilious form the predominant symptom is yellowness of the skin and visible mucous membranes. For instance, the lining of the eyelids is yellow, the nasal passage has a yellowish tint, the cheeks are yellow on their inner side, the mouth is dry and the tongue yellow, the white portion of the eyes is yellow, whilst the pulse is full and slow, the temperature elevated two or three degrees, and the animal is torpid, with little or no desire for food. Sometimes this trouble is spoken of as bilious fever, and is due to the bile pigments entering the circulation. These bilious symptoms sometimes persist for several weeks before they show any signs of abatement. The urine is of a deep yellow colour. In the intestinal form of influenza the animal is restless, indicating that there is a certain amount of abdominal pain or colicky disturbance. The stomach and the intestines are very often implicated in the bilious form previously alluded to. When the brain and spinal cord are participating in the disease now 
under consideration the variety of nervous symptoms become either partly or completely established. Influenza as it appears in the civilian stables is a muchdreaded disease, as the horse master knows that it is extremely liable to extend throughout the stud, rendering them for the time being more or less ineffective. Another modification of influenza is found in a Canadian horse disease known as " pink-eye," or " epizootic " cellulitisa disease characterised by an œdematous or swollen condition of the mucous membrane lining the eyelid, resulting in the eyes being partially or completely closed. Periodical invasions of this disease make their appearance in Great Britain, and it is a very undesirable complaint to have amongst horses, because for some reason unknown there is liability to sudden death of the patient, and the percentage of deaths is higher in this trouble than in ordinary influenza. Irrespective of the nature of the prevailing symptoms, all influenza cases require careful nursing, the disease being one that is disposed to run a definite course. It is an equine distemper, and cannot be cut short through the use of medicines or serums. The latter have been a good deal used in the treatment of this trouble, but the results cannot be said to be very satisfactory ; in fact, nothing can be said to favour their use. Influenza is a disease which must be treated in accordance with those symptoms which are the most striking feature of the trouble. The amateur should never dabble in the treatment of a complaint of this nature. He will find it much more to his interest to employ professional assistance, as every case must be dealt with on its merits. The animal should be placed under the best conditions possible, and, whenever applicable, suitable clothing should be put on the body and flannel bandages on the limbs. Immediately a horse is suspected of having this disease it should either be segregated or else isolated. By segregation we mean separation from the rest of the stud, whereas isolation 
shuts off all contact, directly or indirectly, from other animals. Scalded food, such as oats, bran, and linseed, scalded hay, to which a little treacle has been added, carrots and green food are the usual requisites when nursing a sick animal. A free supply of pure water is essential, and to each pailful of this an ounce of Epsom salts and half an ounce of powdered nitre can be added daily. Good nursing is fully half the battle, and the other half comprises pure air, plus the discriminate use of medicinal agents. As weakness is so very marked in this trouble a liberal supply of milk and some stimulant is always beneficial. The disease usually lasts for several weeks, but all will depend upon the nature of the attack.

\section{GLANDERS}

This is an extremely serious malady, as it places so much restraint upon all animals in contact with one that is suffering from the disease. It is due to the bacillus malleus, which is an extremely minute organism circulating in the blood and invading the lungs, respiratory tract, and absorbent vessels and glands in which the skin participates. When it attacks the absorbent vessels and skin the malady is known as farcy, or cutaneous glanders. The disease is communicable to man and assumes both acute and chronic forms, but it is commonly observed in its chronic state. Glanders offers a tremendous field for investigation, and it has always been a disease which has received a great deal of attention at the hands of those who are interested in the study of diseases of the horse. Its existence has been known for several centuries, and was studied by some of the oldest observers. It is gradually on the decline; motor traction and legislation have done a tremendous lot towards stamping out the disease, but so long as the horse exists, so will glanders and its allied manifestations be in existence. During this last thirty or forty years it has undergone some 
modification in its severity, as there are fewer cases in the present day of the malignant nature which prevailed many years ago. It is generally accepted that the disease commences in the lungs, and may exist for years in an animal without the owner having the slightest suspicion that he has this disease upon his premises. Time after time this has happened, but since the introduction of mallein as a test for the existence of glanders, it is possible to diagnose the disease when it exists in its most elementary state. Had it not been for mallein during the Great War there is no doubt glanders would have been very prevalent amongst the horses, with all its evil consequences. Mallein is a very reliable agent provided that its use is respected. Plenty of horses are working in the larger cities with this disease upon them, for the simple reason that there may be no clinical indications of the disease. All horse owners are not willing to have the mallein test applied, fearing that unforeseen trouble may arise. It is a notifiable disease, and if its existence is suspected no time should be lost in reporting the matter to the local authority, as the danger to mankind is considerable, and numerous deaths have been caused through glanders in the horse. Compulsory slaughter is enforced by the Board of Agriculture and compensation paid accordingly. It is hardly likely that any horse owner would recognise this disease, as there might be an entire absence of any visible signs of its existence. In typical cases there is ulceration of the mucous membrane lining the nose and of a discharge from one or both nostrils, but very often from one side only. In addition to this, there is often a hard but painless swelling on the inner side of the lower jaw, which, unlike that of strangles, has very little tendency to increase in size. In the mule the discharge from the nose is brownish grey, often intermingled with blood, and often accompanied by a peculiar snuffling sound in the upper part of the nasal cavity. In the disease called farcy, small bud-like swellings arise 
along the course of the absorbent vessels, and in course of time these buds burst and discharge an unhealthylooking pus. A great deal will, however, depend on whether the disease is acute or chronic. Diagnosis is based upon reaction to the mallein test, but it is not necessary to enter into any further consideration of this disease.

\section{ANTHRAX}

Anthrax as it appears in the horse is by no means a common disease in the British Isles, but in India and various other countries it is a fairly common malady. One of the worst features about it is that it is extremely fatal and also communicable to man, through even the most trifling abrasions of the skin, provided that blood from an anthrax carcass accidentally gains admission to a wound, which as previously stated may be ever so slight. It is a disease of considerable antiquity, but it is not much more than half a century since that organisms producing it were demonstrated to exist in the blood. Cattle, pigs, and certain other animals may contract the disease ; in fact, in cattle it is not at all an uncommon trouble, in which animals it is spoken of as splenic apoplexy. Sheep are likewise affected, whilst pigs occasionally contract the disease through feeding upon the offal of an anthrax carcass. As in the case of glanders, immediate notification of its existence or suspected existence is required by the Board of Agriculture, and upon the opinion of that body diagnosis will rest. In the horse the course of the disease is usually very rapid, and the animal may die within two or three hours from the onslaught of the attack. In some cases the lungs are the main seat of the trouble; in others the intestines. The pain is very acute, the temperature high, IO $7^{\circ}$ or thereabout, pulse rapid and small, the breathing quick, along with other signs of a malady which indicates death from the outset. Anthrax is due to minute rod-shaped 
organisms-the bacillus anthracis circulating in the blood. The spores of this disease are very resistant to many chemical agents, consequently this malady has often been perpetuated through the medium of an anthrax carcass or the grave where such has been buried many years before. In man this affection is known as wool sorter's disease, a malignant pustule contracted through handling infected wool, alpaca, mohair, and hides, either dried or fresh, whilst in exceptional instances, anthrax has been transmitted through the apparently harmless kid glove, plus some abrasion on the finger or hand. Flies, especially the blow-fly, have been known to carry infection to man, with fatal results. Legislation compels the owner of an anthrax carcass to have it cremated, which is done by the local authorities' instructions, immediately under police supervision.

\section{Tetanus (Lockjaw)}

Tetanus is a disease due to micro-organisms, but these do not enter the circulation as in the case of the anthrax germs. They remain at the seat of the wound, where they manufacture toxins of a very deadly nature. It is a fairly common disease among horses in particular localities; in fact, the most trifling injuries are often followed by the development of tetanus, the organisms of which are found in garden soil, drift sand, etc., hence the reason why it is always expedient, even with trivial wounds, no matter whether man or animals, to clean these thoroughly and paint them with iodine liniment-one of the most valuable antiseptics known, and one which should always be kept handy in every stable and household throughout the world. In the horse, tetanus very often follows wounds about the feet, such as " picked-up nail," puncture of the foot through a misdirected nail at the forge, abrasions of the skin and following upon castration, the latter in particular. The size of the wound bears no 
relationship to the development of the trouble, which may be acute or sub-acute. In nearly every instance acute cases of tetanus are fatal, but about 35 per cent of sub-acute attacks are followed by recovery, which is generally very slow. It is a most unsatisfactory disease to deal with, and unless the owner is prepared to bestow a large amount of professional attendance, it will be better to destroy the animal at the outset. There is a serum both for the prevention and treatment of tetanus, but like certain other sera, as a cure for the disease, has not, in the author's hands, proved of any value, whilst there are no reliable records to support a contrary opinion. The great principle in dealing with this disease is to keep the animal perfectly quiet in a darkened loose box and give it sloppy food and water to drink. Its existence is denoted by a general rigid condition of the muscles of the neck, back, loins, and tail, and by inability to open the jaws (trismus), but an animal may have tetanus without the jaws being locked, though in the majority of cases this state of affairs does exist ; in fact, it may be the only sign which the owner has noticed. An early indication is afforded by making a feint to touch the horse beneath the jaw, when the animal's head is thrown suddenly up; when the third eyelid or membrane nictitans is shot across the eye. This is a very significant sign and should always be employed as a test if this trouble is suspected. The tail is elevated and held out in a quivering manner; muscular spasms come on under the slightest excitement; temperature slightly elevated and the breathing distressed. Tetanus is a disease with considerable variation in the symptoms, but sufficient has been said to give the reader an elementary notion as to what this malady is like.

\section{JOINT-ILL OR ARTHRITIS IN FOALS}

Unfortunately this is rather a common affection in foals and usually makes its appearance within a few days 
after birth. In certain features it is allied to rheumatic arthritis, but it has been proved to be a septic infection along the tract of the umbilical cord, and the infection starts at the umbilicus or navel, hence the advisability of taking the necessary precautionary measures to prevent the onset of this septic process. Cleanliness is an indispensable factor when tying the cord with string, etc., at the time of birth. By far the best treatment which can be suggested, so far as the prevention of this trouble is concerned, is to paint the end of the cord and round about the navel with iodine liniment. It is only necessary to do this once or twice and joint-ill will seldom be heard of. There is a serum for the treatment of this affection when developed, but this is a matter to be dealt with by the professional adviser. Joint-ill comes on very suddenly and is indicated by lameness and swelling at or around a joint, such as for instance the shoulder, hock, or knee. These swellings are hot and painful, and the foal refuses to suck. Those who are acquainted with this disease think that the little creature must have been injured, but such is not the case. It is a very fatal disease, and the foal may be dead within a few hours; in fact, it usually is. As already stated, there is no need for this disease to exist at all, provided that the simple measures which the author has indicated are adopted. Quite a number of foals have been lost in some studs through this complaint, but the reduction of this loss to a minimum always lies within the owner's grasp.

\section{Rheumatism}

Horses, like man and other animals, are liable to suffer from rheumatism, and also to have it both as an acute and chronic affection, although it is not a particularly common complaint in the horse in either form. Nevertheless, it is worth while to mention the fact that it may and does sometimes occur. Either the muscles or the 
joints may be attacked. Sometimes typical cases of muscular rheumatism do occur, and when this is so it is quite an easy matter to recognise this trouble, there being a general stiffness observed, and the patient moves with difficulty. It is quite possible that many of the troubles affecting the bones and joints of horses, more especially ring-bone, are of a rheumatic nature. If the joints are attacked there is swelling, increased heat, and pain. There is a peculiar liability for these swellings to shift from one joint to another and to exist for a variable time. The causes of rheumatism never seem to have been definitely settled, but it is usually believed that exposure to cold and wet are the forerunners of this disease, or at any rate, they apparently act as exciting causes in its development. It is quite possible that it is an organismal disease, and that whatever abnormal condition of the blood takes place, it is brought about through chemical changes as a result of such organisms existing in the body. In this complaint a warm and comfortable stable is most important, and the body must be kept clothed, the limbs bandaged, and the affected parts freely massaged once or twice a day with some stimulating embrocation, such as ordinary white oil. Saline laxative medicine should be given internally. Epsom salts in the drinking water along with half an ounce of bicarbonate of potash twice a day will fufil all requirements. Iodide of potash is one of the principal drugs employed in the treatment of chronic rheumatism.

\section{PURPURA}

This is a blood disease, or at any rate one in which there is an alteration in the composition of this fluid. It is a complaint which usually follows diseases of an exhausting nature, such as influenza, strangles, catarrh, and pneumonia, particularly where insanitary surroundings exist. It was a very common disease among army horses coming from aboard ship, more particularly when 
the holds were overcrowded, the trip prolonged, and other debilitating factors in operation. Some of the worst cases of purpura that it was possible to conceive came under the writer's notice, and the animals had to be destroyed in consequence. It is not, however, an uncommon disease in some civilian studs of horses, owing, doubtless, to the insanitary state of the stables. Its disappearance in such cases has coincided with improved sanitary arrangements. Horses of any age, sex, or breed are liable to purpura, and it is always a trouble which renders the patient useless for work for several weeks and sometimes for months. It is a troublesome disease to treat and commonly fatal. It is denoted by the development of swelling, more especially about dependent parts of the body, such as along the floor of the belly, the sheath, the breast, around the nostrils, along the course of the neck, and also about the limbs. These swellings are neither hot nor very painful, but there is a strong tendency for sloughing of the skin at the part indicated, and this along with the oozing of watery blood still futher aggravates the affection and tends to the greater exhaustion of an already exhausted body. The patient becomes in a very weak condition and refuses food. The mucous membranes, such as those of the nose and eyes, commonly show blood spots indicative of a degraded condition of the blood. In milder cases recovery is hopeful, but irrespective of this fact it is always advisable to have professional advice, on the ground that whilst there is life there is hope; moreover, there is always satisfaction in doing one's utmost to save the life of an animal.

\section{INFECTIOUS STOMATITIS}

This complaint was extremely common amongst the Army horses in France, and it is very questionable whether it was not much commoner than supposed 
amongst the horses at the home depots. It is closely allied to foot and mouth disease in cattle, and like that trouble extremely communicable from one horse to another, and to mules and asses. It spread amongst the horses with extraordinary rapidity, and very few escaped having it. The principal lesions were in the mouth, viz. on the lips, cheeks, tongue, and sometimes around the mouth and around the coronet. Some horses had the disease severely, others only slightly. An early indication of the disease is the appearance of foam about the lips, or else the dribbling of saliva from the mouth. When the mouth is examined blisters are observed, and after these break they leave a raw patch of variable size. One blister may fuse with another, and in this manner the whole of the tongue may be stripped of its superficial layer, giving it a bright scarlet appearance. The soreness of the mouth is unquestionably severe, and the animal feeds with difficulty, excepting in the milder cases, where it apparently produces very little inconvenience. Most of the affected animals recovered within three weeks. If the coronet was implicated slight signs of separation of the wall of the heel was sometimes observed, but the author is not aware of any extensive sloughing having occurred in the region last named. The situation of the trouble, viz. inside the mouth, necessarily favours the spread of this complaint. It is quite possible that it was introduced into Great Britain when the Colonial horses began to arrive.

\section{TUBERCULOSIS}

As this disease occasionally occurs in a horse the author considers that it is worthy of mention, even in a small work of this description. In cattle it is an extremely common complaint; in fact, one of the commonest diseases from which these animals suffer. Tuberculosis has only one cause, and that is the bacillus tuberculosis or tubercle bacilli, as they are sometimes called. These 
organisms circulate in the blood and various other tissues of the body, but in the horse the principal lesions are found in the spleen (melt), and in the lungs. A horse having this disease gradually becomes emaciated, until it is either destroyed or else succumbs. The symptoms are usually obscure. Sometimes excessive urination accompanies this trouble; at other times it does not. Tuberculin is the only reliable method of testing for the existence of this disease.

\section{Actinomycosis}

This disease is due to the ray fungus, or actinomyces and it sometimes attacks the tongue of the horse an foal, whilst there is a corresponding disease not uncommonly affecting the spermatic cord, following castration. The disease first named is fairly common in cattle, being known as woody tongue. Sometimes it affects the skin and the udder of the mare, but it is by no means a common disease in the horse, apart from the exception referred to. (See also Castration.) 


\section{CHAPTER XVII}

\section{AFFECTIONS OF THE RESPIRATORY AND CIRCULATORY}

SYSTEMS

THE horse suffers from quite a number of respiratory troubles; in fact, it seems to be somewhat predisposed to complaints of this kind, some of which are of a " chronic" nature, others " acute." Any portion of the respiratory system (see Anatomical Outlines of the Horse) is liable to be affected, but the commonest trouble of all is that implicating the upper portion of the great air tube, the larynx, and popularly known as " roaring."

This last-named affection occurs to all classes of horses and mules, and it is customary to regard its existence in any horse as a sufficient reason for rejecting the animal on the ground of unsoundness. It is not always due to a laryngeal affection, but in quite 90 per cent of instances it is due to degenerative changes in certain muscles of the larynx.

The trouble is usually progressive and permanent, but sometimes this abnormal sound is only temporary as sometimes occurs in strangles and lead poisoning, likewise through the consumption of the Indian vetch. Some horses, instead of making a roaring sound whilst at work, make a whistling noise-the animal being known as a "whistler."

Both these sounds vary in their intensity according to the duration of the disease and with the degree of exertion the animal is compelled to undergo.

It is an unfortunate matter for the horse that the disease is so common. Some of the finest thoroughbreds 
that have ever run on the course have had to retire from the field owing to the development of this abnormal condition. Many horsemen look on it as hereditary, and consequently will not breed from any stock having this trouble in their family history.

It is quite likely that roaring comes as an inheritance to some horses, whilst to others it is acquired. Some horses develop it quite early on in life. Sometimes it remains as a legacy of strangles. All classes of horses are subject to it, but it is most prevalent amongst hunters, hacks, hackneys, and thoroughbreds. The heavy draught horse and the vanner are quite commonly afflicted, which materially detracts from their value as marketable commodities. Judged from a utilitarian standpoint the matter is quite different, more especially in the case of horses required for slow work. A great deal will depend upon circumstances. Some horses make quite a loud noise under the most trivial exertion, whereas others only make a slight noise even under the most severe exertion, but there is always liability for those that are only slightly affected to become worse.

The majority of roarers "grunt " when a feint is made to strike them with a whip or stick; in fact, grunting is generally a sign of roaring, although it can and does exist apart from the trouble now under consideration. Its existence is quite sufficient for a thorough trial of the animal regarding its soundness of wind or otherwise.

There is an abnormal condition of the wind closely allied to roaring known as "high blowing," which is apparently due to some diminution in the calibre of the nasal passage. Quite a number of horsemen pay very little attention to this, and the author has examined many horses afflicted in the manner named. However, a " high blower" should really be regarded as unsound, as there are so many probabilities relating to it.

"Thick wind" is another horsey term, practically synonymous with either " high blowing " or mild " roar- 
ing." As a rule, roaring comes on gradually, though it can be developed quite suddenly, as sometimes happens in "intermittent roaring." This remark is of some significance, because a horse might be passed as "sound," and yet immediately afterwards make a noise. This has happened on more than one occasion, and the professional examiner sued for damages, but without any results. For many years advanced roarers have been kept at work through the use of a tube in the windpipe-tracheotomy-but it is very necessary to remove the tube daily or even twice a day to clean it. There is another operation now practised by the veterinary profession for the removal of the roaring sound, and consists of stripping the ventricle of the larynx. In some horses it is successful, in others not so. The disease is, of course, still in existence in any case, even if the sound disappears. This operation may, in certain instances, prove valuable, in others it may be the means of fraud, or it may be useless. It is impossible for the author to recommend its adoption in view of its doubtful utility. Many people confuse roaring with another abnormal condition of the wind spoken of as

\section{BROKEN WIND}

The last-named has no connection with the larynx, but is closely associated with changes of a chronic character in the lungs-emphysema-although scientific investigation has, up to the present, failed to yield any satisfactory explanation of this trouble.

A chronic cough is the most significant indication of broken wind, but a fraudulent vendor has been known to disguise this by the use of lard, shot, etc., given internally immediately prior to sale. The breathing is also abnormal, the expiratory portion of the respirations being double- " double lift."

"Broken wind" is often associated with lesions of the 
digestive organs, more particularly the stomach. It is a complaint which affects all classes of horses, irrespective of age, sex, or condition, and once established is an incurable affection, as nothing can restore the structural changes which have taken place in the lungs, wall of the stomach, and possibly the nerves supplying these regions. The commercial value of a broken-winded horse, provided that this defect is discovered, becomes comparatively small; nevertheless, many a broken-winded horse continues to perform its work for years. Hundreds of horses are sold, both privately and in open market, which are broken-winded, and yet the buyer and sometimes the seller is unaware of its existence. It is a slowly progressive disease, and its development is sometimes due to feeding a horse upon dry and dusty forage, and watering it immediately, then driving it or putting to work. Plenty of horses have become broken-winded through these causes. The moral is for horse owners to avoid this pernicious practice.

\section{SORE THROAT}

Sore throat is not at all an uncommon complaint, and the majority of horsemen are quite familiar with it, more especially in connection with influenza, strangles, and catarrh, of which it forms, in some cases at any rate, one of the principal symptoms. It consists of a variable degree of inflammation around the larynx and pharynx or other part of the throat. It is quite an easy matter to note whether the throat is sore if the animal experiences difficulty in swallowing, and coughs very frequently, more especially whilst it is being fed. Sometimes this trouble is " acute," sometimes it is " chronic," according to the cause of the ailment. As a rule it is an "acute" affection. If so, it will usually decline in a week or ten days' time, provided that the animal is properly looked after. The cough is hard and dry at first, but later on it becomes of a moist character, therefore this change may 
be looked upon as a favourable one, more especially when it is accompanied by nasal catarrh. Sometimes, however, the trouble will persist for weeks when associated with influenza. The stableman's remedy for sore throat consists of stimulating the throat through the application of mustard paste, blistering ointment, or white oil, but it is not advisable to do too much in this line, as the skin becomes very sore ; in fact, blistered, and this external soreness is very liable to become worse than the original trouble. There can be no objection to a single application of mustard, but it should be washed off in an hour or two and the part throughly dried. An ounce of chlorate of potash should be added to the drinking water night and morning. Scalded linseed, bran, and oats is the best fodder under these circumstances. Do not give any hay or dry food. We must not forget to state that the majority of cases of sore throat occur in connection with strangles, and must be treated according to the lines laid down under that trouble.

\section{PNEUMONIA}

Inflammation of the lungs and structures in close relationship to the same has always been a fairly common malady in the horse, and one which accounts for quite a large percentage of deaths, more especially where a number of horses are congregated together, under conditions which are not favourable to their general welfare. During the Great War pneumonia was the principal scourge amongst Army horses, and the percentage of deaths from this cause was extremely high. The disease under consideration has always been referred to as "septic pneumonia," probably on account of the extremely fatal nature of the malady, coupled with its rapid dissemination amongst the animals. There can hardly be a shadow of doubt as to the extremely virulent nature of the malady, combined with its infective nature. If a 


\section{RESPIRATORY \& CIRCULATORY SYSTEMS I69}

horse in the latent stages of disease were put on board ship amongst healthy horses, that animal would constitute a centre of infection, with every probability of many other horses becoming infected, and these in their turn would become capable of infecting others. Although rigid veterinary inspection took place on embarkation and disembarkation it was practically impossible to avoid an accident of this kind when dealing with thousands of horses. Moreover, administrative inefficiency and the indiscriminate application of knowledge-knowledge of a very limited character-was responsible for the misdirected energy applied and the consequent high percentage of deaths amongst horses from this disease, both at home and abroad.

Sometimes this contagious lung fever of horses occurs in civilian studs, particularly if the ventilation and general sanitary arrangements are defective. Unquestionably the disease is due to the presence of micro-organisms in the lungs and blood, and its appearance amongst horses is always the result of infection from a pre-existing case. Previous to the European war it was customary to regard this form of pneumonia as constituting part of the epidemics of influenza; in fact, the majority of horse owners, in Great Britain at any rate, usually looked upon it as the lung form of that disease. It is very doubtful whether this form of pneumonia should be looked upon or regarded in this light. The method of transmission is, in the writer's opinion, through the ingestion of infected food, and to a less extent by direct inhalation of air infected by the organisms of this disease. The period of incubation is from three to eight days, but usually about the first-named period. In the majority of instances the pathological changes in the lungs and their coverings are of a very acute character and nearly always accompanied by effusion or dropsy of the chest of a very severe nature. Commonly several gallons of fluid are found in the chest after death, and the whole cavity is filled with feebly 
organised bands of lymph ; in fact, the latter is a very striking characteristic of this disease. Extension of the inflammatory action to the heart sac and structures in contiguity to it are commonly observed after death. It is very insidious in its development, and one may find, before being aware of it, that the animal is well advanced in the disease unless special observation is kept. If this complaint is suspected immediate isolation is one of the best safeguards against extension of the malady. An early indication of pneumonia developing is afforded by using the clinical thermometer. The temperature rises several degrees and the breathing is disturbed. The last-named is one of the best guides for the amateur, more especially when he is aware that the animal is out of sorts. It suddenly becomes very dull and listless and probably food is left in the manger. The mucous membranes of the eyes and nose are intensely red as a rule. The symptoms rapidly increase until the breathing becomes very laboured, when death is certain to occur. As previously stated, this lung fever of the horse is an extremely fatal malady, but the mortality is considerably reduced by the intra-venous injection of formalin which the writer and some other Veterinary officers employed. This treatment is of unquestionable value when it is applied. As stated elsewhere in this small manual, pure air is of the utmost importance, consequently all pneumonia cases do better in the open than when they are stabled, provided that the animals are kept dry and properly clothed.

There is another form of congestion of the lungs, technically known as acute pneumonia or acute pulmonary apoplexy, the latter part of the title being derived from the fact of its suddenness of onset. It sometimes occurs in unconditioned hunters or in horses which are put to extremely severe exertion without being previously made fit for this extra exertion. In the vernacular of the horseman it looks as though the animal had " bellows to mend "- a very expressive term. Its development is so 
sudden that the rider is amazed to see his horse in this condition. "Prevention is better than cure" even when the latter is possible, but pulmonary apoplexy is a very fatal disease, and the symptoms extremely urgent.

\section{PLEURISY}

This consists of an inflammatory state of the pleural membranes, i.e. the coverings of the lungs and the lining of the chest walls. As stated in the preceding paragraphs it usually forms part of pneumonia. Sometimes it is the result of a wound in the chest wall. It is a painful disease, and commonly fatal, except in the case of mild attacks. It is often accompanied by effusion, and if this is severe the probability is that the animal will die. The removal of fluid from the chest of a horse is not, as a rule, a successful operation, and it is desirable to avoid this whenever possible.

\section{The HeART}

The heart is enclosed in a sac-the pericardium-and this organ, likewise its investing membrane, is liable to suffer from various diseases, some of an organic nature, others purely functional. The cavities of the heart are lined by a very delicate membrane known as the endocardium, and this membrane assists in forming the valves of the heart. The functions of the heart are those of distributing blood throughout the body for purification at the lungs and thence back to the heart. Large bloodvessels spring from the base of this organ, which help to suspend it from the roof of the chest, with the apex inclined towards the left side. Heart affections occur much more frequently in the horse than may be suspected, doubtless owing to the severe strain which is necessarily put upon this organ under certain conditions. A sound heart represents a measure of the animal's vigour, and it is indispensable for the due maintenance of proper health. 
Ailments in many parts of the body owe their existence to some defect in the functional capacity of the heart. Normally the heart beats from 35 to 45 times per minute, but this number usually is either greatly increased or slightly decreased in various diseases. By placing the ear to the left side of the chest wall, immediately behind the elbow, the normal beat of the heart, or abnormal as the case may be, can be distinctly heard. The number of pulsations felt by pressure upon an artery in a given time, say a minute, corresponds to the beats of the heart. All affections of the circulatory apparatus are of a more or less obscure nature, so far as the layman's knowledge of disease is concerned, consequently it is not advisable to enter into a consideration of any other troubles directly or indirectly connected with this vital structure. 


\section{CHAPTER XVIII}

SOME COMPLAINTS OF THE DIGESTIVE ORGANS

THE whole of the digestive apparatus in the horse is well developed and, as the forage of this animal is liable to continual variation, we often find that it suffers from various digestive disorders and also from disease in connection with the same. As a matter of fact, so far as complaints are concerned, troubles arising from disordered digestive functions are of an extremely common nature. A great many digestive disorders are purely the outcome of bad horsemastership, and when any particular stud of horses is troubled with colic, one may accept it as a sign that there is something radically wrong either with the forage, the drinking water, or the manner in which these are supplied to the animals. Quite a number of horse owners seem to think that they can give a horse what they call a good feed of oats and hay, water it and either drive it or ride it immediately afterwards. This is simply madness and the straight road to the ruination of the animal. A large proportion of digestive troubles, as previously stated, are due to bad management, therefore preventable, but on the other hand, there are many which are not preventable. Internal parasites or worms account for a considerable percentage of deaths, both in colts and adult animals. As a rule, the sources of parasitic infestation cannot be traced, so far as the horse is concerned. Quite a number of internal lesions, which always terminate fatally, such as twisted gut, rupture of the stomach, rupture of the bowel, rupture of a blood-vessel, etc., would appear to be due to over-exertion of a previously weakened 
part, the result of disease. Predisposition to digestive trouble may be brought on through one or more antecedent attacks. Both old and young horses are liable to irregularities in connection with the molar or grinding teeth. In every case when a horse is not thriving properly, the mouth gag should be brought into requisition, the tongue grasped with the left hand, and the teeth critically examined by illuminating the mouth with an electric torch. Old horses sometimes have what is known as a "shear-mouth" caused by the molar teeth wearing away after the manner in which the blades of a pair of shears overlap. Shear-mouth varies. The deformity may be slight or it may be excessive. In the former case, rasping the teeth will assist matters a little, but in the latter the case is quite hopeless. Sometimes a molar tooth is decayed and in other instances the fang is the seat of disease. In colts, during the shedding of the temporary molars and their replacement by permanent teeth, it occasionally happens that the teeth become entangled, i.e. the fang of the old tooth becomes fixed on the crown of the new one. As a rule this is not a difficult trouble to deal with. It is absolutely essential that the grinding teeth be in good order. When a diseased molar tooth is removed the cavity fills up shortly afterwards, but sometimes the opposing tooth, or rather, what was the opposing tooth, becomes too long and presses on the opposite jaw. The overgrowth can be removed with the tooth-shears, but this is a dental operation for a veterinary surgeon to perform. The gullet is occasionally the seat of obstruction, either owing to disease of its wall or through some foreign body lodging in it. The stomach may be over-distended with gas as in flatulent colic, in which complaint the intestines are extensively implicated. Worms of various kinds, more especially sclerostomes, are not uncommonly found in its mucous lining. When horses are affected with these parasites they are always in a more or less debilitated condition, 
and a number of deaths amongst Army horses were caused through this. The lining of the gullet is prolonged to form a portion of the lining of the stomach -its cuticular lining-and it not uncommonly happens that the larval form of the horse bee or bot-fly (gastrophilus equi, as it is called), is found attached to this lining. It is of interest to note that this fly lays its eggs on the skin of the horse about hay time-July. The eggs or nits will be found adhering to the hair, especially about the inner side of the forearm, on the shoulders, etc. They are very often mistaken for the nits of lice but they are larger. Somehow or another the horse licks these parts, probably on account of the irritation induced. The eggs develop into the maggot stage and the tongue of the horse must transfer them to the stomach, where they develop into the so-called " bots," and there they remain attached to the cuticular lining throughout the winter, until the following spring. About this time the grass, plus nature, causes them to pass out of the body and remain concealed in the ground, until metamorphosis is completed and the adult fly the result.

Starlings and various other birds must account for the destruction of a large percentage whilst in the larval form on the ground. The stomach of the horse provides a very safe but temporary home. Whilst in the stomach they are barrel-shaped and usually fixed closely together, in fact, in colonies. In exceptional instances their presence may do harm, but not as a rule. The position they occupy in the stomach is against this. The chances of survival are extremely small, nevertheless the gastrophilus equi is quite a common fly, but not as common as the ox-warble fly. The best remedy that we are acquainted with is turpentine and linseed oil, $2 \mathrm{oz}$. of the former to a pint of the latter, repeated at intervals of about a week or ten days. The commonest digestive trouble is that known as 


\section{Colic}

This affection is also spoken of as "gripes," "fret," "belly-ache," the " bats," and various other appellations. It is one of those affections which usually make their appearance without any previous warning, and many horses are attacked with colic whilst they are at work. Sometimes the attack is slight and passes off within half an hour, whereas at other times it is very severe and the pain so acute that the poor animal begins to sweat all over the body, is continually rising and lying, rolling and wandering round about the box through the agonising pain which it is enduring. Frequently a horse attacked with colic will continue in pain for several days and then finally recover, particularly if proper treatment has been administered. Things, however, do not always go as favourably as this, the case not being one of simple colic but due to some disease, such as a twisted gut or inflammation of the bowels, rupture of the stomach, internal hæmorrhage, or some other organic lesion. As pointed out, the symptoms of colic vary in their severity, their course, their duration, and their termination. In most inflammatory conditions the pain is more sustained, more severe, and the animal presents general indications of impending dissolution. The causes of colic are as variable as its termination, but we may say that excessive food, sudden changes of food, drinking too much cold water when over-heated, prolonged feeding on dry food, worms, super-purgation, too much green food, a concretion or concretions in the stomach or intestines, strangulated rupture, etc., are all liable to produce it, but symptoms allied to those of colic arise through gastro-enteritis produced by mechanical, chemical and specific causes.

Intussusception or invagination of the bowel ; strangulation of it; changes in the wall of the bowel ; in fact, anything which leads to obstruction of it is capable of producing violent pain in the belly, which in 99 per cent 
of instances proves fatal, when arising from the lastnamed causes. There is a very common round worm of the horse known as ascaris megalocephala, which infests the horse, and if there are only a few of these they do no harm, but if very numerous they are capable of, and occasionally do, set up acute inflammation of the bowels. The favourite habitat of these worms is at the commencement of the small intestine. The author has found most severe inflammation from this cause, the intestine being completely blocked to the extent of several feet.

Having enumerated the causes it only remains for the writer to state that whilst simple cases of colic may be dealt with by the owner it will usually be found far more satisfactory to have professional advice, as every case of colic presents an individuality, and treatment must be based upon this feature. An effort to try to ascertain the cause is extremely necessary and should always be taken into consideration, but failing this, the owner can give a pint of linseed oil, to which $2 \mathrm{oz}$. of turpentine and $2 \mathrm{oz}$. of sweet spirits of nitre have been added. This is a very safe and often very efficacious draught, and it can be given pending the arrival of professional skill. Very often colic is accompanied by a flatulent condition. If so, the draught referred to is most suitable. In cases where, there is no veterinary advice obtainable, the draught can be repeated at intervals of three hours, until three or four doses have been given. It is customary for many horse owners to walk their horses about when they have belly-ache, but there is no need for this if the animal can be put in a loose box. It is always advisable to take all food away for the time being and for the next two or three days to feed the animal-unless contrarily indicated - on bran and scalded oats, with a gradual return to hay. Never overlook the possibility of the forage being the cause of the trouble. 


\section{DiARRHCEA AND SCOUR IN FoALS}

Horses sometimes suffer from super-purgation, the result of an overdose of physic; a change from dry food to grass; through the irritation produced by worms, and other causes. Colts are frequently troubled with a severe form of diarrhœa and they gradually become emaciated, finally dying, unless appropriate treatment has been adopted early on in the affection. The cause of this trouble is usually parasitic, being due to what is known as the four-spined strongyles, whose habitat is in the large intestines, into the wall of which they enter, or migrate from here into other situations. The strongyles referred to seem to be more abundant on some grazing land than in others, but the method of infection has not been properly worked out. If a colt is affected in this manner it should be housed, most liberally fed and put on a course of iron tonic powders. Worm medicines are useless, but arsenical preparations are invaluable. If this trouble is suspected, send for the veterinary surgeon. Foals frequently suffer from scour or acute diarrhœea and they sometimes die from this trouble. Begin treatment with a couple of ounces of castor oil to remove the source of irritation. A drachm of chlorodyne can, with advantage, be added to the oil. As in the last case, have professional advice.

\section{LYMPHANGITIS (WEED)}

This affection seems to be closely associated with digestive disturbance and congestion of the absorbent vessels and glands. It is a very common trouble, particularly amongst heavy draught horses, especially those of sluggish temperament. Light horses are not exempt from the complaint, but the proportion of sufferers in animals under I5 hands is comparatively slight. One attack of weed, also known in Scotland as a "shoot of cold," predisposes the animal to subsequent attacks, 
which, if recurrent, lead to permanent enlargement of the limb, with accompanying stiffness. It is spoken of by some stablemen and by farmers in certain localities as "Monday morning" disease, owing to the fact that it often occurs after Sunday's rest. If horses are exercised on Sundays for ten minutes or a quarter of an hour, this complaint will not make its appearance, or, at any rate, it will seldom be observed. The absorbent glands on the inner and upper side of the thigh become tender, swell, and the swelling rapidly extends down the limb, so that the animal may be unable to bend the leg. It usually commences in the near hind, but may appear beneath the arm, although it is not frequently met with in the latter situation, as there is sufficient movement in the stable to retard its development. But the matter is quite different in the case of the hind limbs. Sometimes considerable constitutional disturbance is associated with lymphangitis and several degrees of fever are present, with or without symptoms of colic. As previously stated, "prevention is better than cure," but if this malady does develop, the owner should obtain veterinary advice. A 5 or 6 drm. physic ball will usually do considerable good. It is generally several days before the swelling and stiffness disappear. This disease must not be confused with a much more serious malady, known as Epizootic lymphangitis, which is a notifiable disease, and of much more serious consequences. In the latter affection sores and ulcers form on the skin of various parts of the body. It is a contagious malady, and immediate isolation is necessary in the disease last named. 


\section{CHAPTER XIX}

\section{SOME AFFECTIONS OF URINARY ORGANS}

ANy portion of the urinary apparatus is liable to become the seat of various complaints, and the horse is by no means exempt from the numerous troubles which involve the urinary tract. The kidneys are fairly large and situated beneath the loin, consequently these structures are sometimes involved when the muscles on the inner side of the loins are sprained. Congestion of the kidneys is sometimes associated with other abnormal conditions, and when a trouble of this kind is apparent the symptoms which it produces are those of suppressed urination, pain over the region of the kidneys, and colic. Stone in the kidneys is by no means an unknown affection, and its presence in these structures causes the animal serious inconvenience. It takes the form of either gravel or as a calculus placed within the pelvis of the kidney, in which situation it obstructs the flow of urine from the kidneys to the bladder. The bladder is sometimes inflamed and sometimes it is in an irritable state through the existence of gravel or a calculus, or it may be several calculi. As a rule, bladder trouble produces painful and difficult urination, but these symptoms are common to other affections in connection with the urinary organs. Stricture of the urethra also leads to difficult urination, the urine being passed at very frequent intervals, but in small quantities. In every case of urinary trouble it is advisable to have professional aid, as abnormal conditions of these organs can only be successfully dealt with when skilful advice is employed. The urine is liable to contain 
various abnormal constituents, such as blood, pus, gravel, tube-casts, etc. In a disorder known as

\section{AZOTURIA}

the urine becomes coffee-coloured. This affection, whilst not common, is occasionally met with, especially in horses and geldings. It comes on without any warning and in nearly every instance whilst the animal is at work, but usually after the latter has been kept in the stable for two or three days, without any reduction in the amount of oats, etc., supplied as forage. The kidneys and the muscles seem to be primarily implicated in this disorder, and the most significant sign is the changed colour of the urine. Apart from this, the muscles, more especially of the loins and quarters, become as rigid as boards and remain in this condition until there is an abatement in the severity of the attack. Sometimes the affection is of quite a mild character, whereas in other instances it is severe and soon terminates fatally. One of the worst effects of azoturia is the wasting of the muscles which follows recovery, if this is fortunate enough to occur. The most hopeless cases are those in which the animals are unable to rise. Doubtless, to place the animal in slings as early as possible is distinctly advantageous and can be recommended. Treatment is, however, a matter which must be left to a veterinary surgeon-to a qualified man (M.R.C.V.S.) and not to any of the hopeless and useless emperics scattered throughout our own and other countries.

\section{DiABETES OR EXCESSIVE URINATION}

Excessive urination is not at all uncommon amongst studs of horses, in which it is chiefly due to feeding the animals upon damaged or musty forage. The urine is very light-coloured and an extraordinary amount of fluid is passed from the urinary apparatus. It appears to be due to some disturbance of the digestive organs, which 
the kidneys endeavour to deal with and rid the system of the noxious material which has entered it along with the forage. Mow-burned hay and musty oats commonly produce the symptom, i.e. excessive urination, now under consideration. As soon as the cause has been removed the trouble should cease. It is only a temporary form of diabetes, although a true form, i.e. one in which sugar is contained in the urine, occasionally occurs in the horse. The treatment comprises the removal of the cause and the use of some medicine, the prescription of which contains iodine and iron. Consult your veterinary surgeon at once. 


\section{CHAPTER XX}

THE NERVOUS SYSTEM AND SOME AFFECTIONS OF THE SAME

THE brain, spinal cord and nerves arising from their structures represent the fundamental portions of the central nervous system. The brain and spinal cord are both welldeveloped structures, consequently liable to be implicated in various ways - sometimes functionally wrong-at others the seat of organic changes. Unfortunately many of the diseases affecting the nerves of the horse are of a very obscure nature. It is quite useless in a small work of this kind to enter into a consideration of these troubles beyond saying that

\section{STRINGHALT}

is a fairly common affection and one that is liable to affect any class of horse, but perhaps vanners and cart horses are the most affected. Stringhalt and shivering are closely allied troubles, and they both, naturally, detract from the value of the animal. Very often the last-named is difficult to detect, and no doubt many shiverers are sold, both privately and in open market, without even the seller being aware of its existence, much less the purchaser.

Stringhalt is less liable to be overlooked. It is denoted by the spasmodic or involuntary jerking up of one of the limbs, sometimes both hind, but commonly one hind limb only, either in the stable or out of it. It is an affection which varies in its degree of severity. Sometimes it is only observed whilst the horse is at work. It is chronic and incurable in the author's experience. The 
causes are not understood. The best test for shivering is to back the horse, or turn it sharply round. If it is a shiverer it may be unable to back, or else the muscles of the limbs tremble. Both these troubles render the animal unsound, and rightly so, because they impair its usefulness to a greater or lesser extent, with a tendency for the symptoms to become worse as the animal becomes older.

\section{EPILEPSY OR VERTIGO}

known under the popular title of megrims also occurs in the horse, without any well understood cause. These seizures come on at a moment's notice, paralysing the sufferer for the time being, and if the animal is at work when seized, very serious consequences may ensue. A horse known to be affected with a trouble of this kind is quite unsafe for any useful purpose and should be destroyed.

The central nervous system is liable to various toxic troubles (see Tetanus) and to the development of abnormal growths, etc., in connection with it. 


\section{CHAPTER XXI}

DISEASES OF BONES, JOINTS, TENDONS AND LIGAMENTS

QUITE irrespective of breed and likewise age, sex, etc., horses are very prone to suffer from various inflammatory conditions, either of an acute, sub-acute, or chronic nature, in connection with the bones of the limbs, ligaments, tendons, joints, etc. Some of these inflammatory conditions are commonly spoken of as hereditary, and nearly all horsemen are acquainted with such troubles as splint, spavin, ring-bone, curb, and so forth. Even the boy in the stable will sometimes point out that "it is a pity this 'ere 'orse 'as splint," spavin, or ring-bone, as the case may be. For the stable hands to discover a splint or a spavin, or to imagine they have discovered it in a horse recently purchased by "Master," appears to be something wonderful, and the confidences exchanged with one another are truly astonishing. This is why the stable lad is often regarded as the " stable oracle," with his knowledge " wondrous and true," yet as false as it is misleading. The horse is a wonderful piece of mechanism, every single part of it being adjusted with a precision unattainable by any artificial means. The bones-their shape and their adjustment ; the joints-their shape and their adjustment; the muscles-their origin and their insertion, their specialised prolongations as tendons, with adaptation to purpose; the intricate system of blood-vessels-arteries, veins, and capillaries; the nervous system-with its central stations and communications to every organ and tissue in the body; the absorbent system and the scavenger work which it performs; the 
digestive, generative, and urinary systems are all part of the beauty of animal mechanism and animal locomotion. Unquestionably the effects of concussion-direct or indirect-the unequal distribution of pressure and hereditary predisposition are all factors concerned with disease and injury in connection with the limbs of the horse, and sometimes other portions of the anatomy. The nature of a horse's work and its age have a direct bearing upon the production of some of the infirmities with which we are about to deal. It may be accepted as a truism that any horse under the age of four years is much more liable to become lame through some trouble than a horse of mature development. In the fore limbs the following diseases are some of the principal ones:

\section{Slipped Shoulder}

The reader will, from the above title, at once imagine that the shoulder has slipped out of its proper place ; in other words, that there has been a dislocation of the shoulder joint. This is not so, however, as the affection is one primarily implicating the muscles of the shoulder, the nerve being known as the "supra scapular," and the trouble alluded to is designated as paralysis of this nerve. The muscles on the outer face of the shoulder lose their proper functional power, and the result is that they begin to waste, and this wasting is particularly obvious on the outer face of the shoulder-blade. This affection is due to injury of the nerve, and some horses make quite a good recovery. Prolonged rest is essential. The muscles should be freely massaged, at least once a day, by vigorously rubbing the shoulder with the hands.

\section{SPLINT}

Almost every horseman is acquainted with this disease. A splint consists of a variable-sized deposit of bone on 
the large cannon-bone, on either the near or off fore limb, or both fore. The splint, i.e. the deposit of bone, is the legacy or result of a circumscribed inflammation of the bone and bone skin-possibly of the ligament as well-or all these structures, usually appearing a short distance below the knee. There is a ligament between the large cannon-bone and the splint-bones, and it often happens that splint forms just where this ligament is, consequently some authorities have regarded splint as an ossification of the interosseous ligament. To a certain extent this theory is true, but sometimes it bears no relation to the actual seat of the trouble. Splint may develop in any breed of horse and at any age, but it commonly makes its appearance in young horses, and in such breeds as hackneys, thoroughbreds, hunters, trotters, cobs, and ponies generally, and very often in van horses. There are many thoroughly practical horsemen who feel amused when you tell them that a horse has got a splint and that it will be necessary to reject the animal on the ground of unsoundness, but it must be borne in mind that there are splints and splints. There is the splint which is harmless and there is the splint which produces irreparable damage and lameness until the unfortunate animal finds its way into the copper, where disease ceases to trouble, and the animal is for ever at rest.

Sometimes there is a large splint, and in other instances numerous very small ones, situated in the channel at the back of the cannon bone, and it is splints of this kind which often lead to an incurable lameness. The reader must understand that the suspensory ligament runs at the back of the cannon bone and the roughened surfaces of the splinty growth or growths are very liable to injure the ligament by abrading its surface. When splints of the nature referred to have been formed, they are sometimes situated immediately. below the knee, and very difficult to detect; in fact, it is impossible for an amateur 
to discover their existence. It must be borne in mind that there is a natural tendency for the interosseous ligament between the splint-bones and the large cannon-bone to undergo transformation in the bone. It is Nature's way and nothing can deflect it. In obscure cases of lameness in the fore limbs it is always advisable to make a critical examination at the back of the leg, from the knee to the fetlock, as the author, and doubtless others, has occasionally found one or more minute splinty deposits below the knee, or in some portion of the back of the cannon bone. Sometimes the splinty deposit is on the front of the bone, sometimes on its outer side, but in the majority of instances it is on the inner side, as everything favours its development in the situation referred to. The size of the splint bears no relationship to the existence of lameness. Under ordinary circumstances lameness, if present, usually occurs during the time the splint is forming, i.e. when the bone and bone skin are inflamed and Nature is endeavouring to repair the damaged part, the splint being, as previously stated, the product of inflammatory action; but the unfortunate part about it is that it does not appear requisite, but it is reasonable to assume that Nature knows her own requirements. Probably 60 or 70 per cent of saddle and harness horses have splint and yet never show the slightest sign of lameness. The position of the splint and the age of the animal are the best guides. Any kind of injury is capable of producing splint. It is a well-known fact that a splint will sometimes disappear, owing to reabsorption of it, and this is the object of blistering and firing.

\section{RING-BONE}

The term ring-bone is applied to a deposit of new bone on the long pastern, or else around the coronet (short pastern). It consists of a variable degree of inflammation of the bone and bone skin (ostitis and periostitis) of the 
long and short pastern bones, and may end in anchylosis of the joints in these regions. It is called ring-bone because the new bony formation has often a ringlike contour, but not always. All classes of horses are liable to it and at any age, but light draught and heavy draught horses are more frequently troubled with ringbone than riders and roadsters. The deposit of new bone, like splint, represents the product of inflammatory action, and it is Nature's method of repairing a damaged part. The new bone, however, commonly leads to the production of lameness of a very obstinate character, and treatment of any kind is, in the author's experience, of little or no practical value whatever. It is quite probable that this arthritis, either in its chronic or acute state, is largely attributable to hereditary influence, as it is so very common amongst heavy draught horses. Manipulation of the pastern joint or from the fetlock to the pastern, during an experience of thirty-five years, especially amongst heavy draught horses, has satisfied the author how extremely common this trouble is. Not uncommonly the joint is obliterated and the growth of new bone sufficiently extensive to impair the integrity and functional powers of all structures in juxtaposition to it. One or both pasterns, either fore or aft, may be the seat of the trouble, which is very common in the fore limbs. A horse may have a large ring-bone and travel perfectly sound, or it may have a small one and be persistently lame. Ring-bone lameness varies considerably, and a horse apparently sound one day may subsequently become very lame on the following one. The effects of rest should always be tried. Work on soft ground is best for them, hence many ring-boned horses which have been going very lame in town will continue to do good work on the land for many years. 


\section{Open JoINT}

The capsular ligament of a joint is sometimes penetrated, and this leads to a condition technically known as open joint. The joint most frequently injured in this manner is the hock. At the time of injury, infection with pus organisms usually occurs, so that a septic arthritis is set up, and this causes the animal acute suffering The hock joint swells and synovia (joint-oil) can be seen issuing from the wound. In addition to the swelling and the discharge of synovia, the animal is unable to bear much weight on the limbs; in fact, the trouble causes so much pain that the horse avoids putting any weight at all upon it, the limb being in a semi-flexed position. Cases of this nature are usually hopeless, but they are more hopeful when at the fetlock joint. Sometimes the knee is the seat of the trouble. Supposing that recovery does occur at either the knee or hock joint, permanent stiffening is a common result of the injury. In any case, professional assistance should be sought and the advice tendered acted upon.

\section{Bursal ENLARgEMENTS OR WIND-Galis}

Joints and tendons have usually lubricating pouches and sheaths to promote the free play of the tendons and joints. These structures are quite commonly the seat of chronic irritation, and the result is the production of a soft fluctuating swelling, free from pain on manipulation, and usually unaccompanied by any degree of heat or tenderness, unless the disease exists as an acute synovitis. (See also Open Joint.) The pneumatic character of the swellings has conferred upon them the title "windgalls," and the majority of horsemen are familiar with them under this name.* If a young horse is subjected to abuse, instead of proper use, it will very soon disclose on manipulation a puffy feeling about the joints, more par- 
ticularly at the fetlocks. The part is unable to stand the strain, and the tendons very often also give way. Bursal swellings are very unsightly, more especially if they are large. They seldom produce lameness, but materially interfere with the selling price of a horse. Capped elbow, capped knee, and sometimes capped hock, are of this nature, but may be complicated by subjacent structures becoming implicated in the abnormal process. "Bogspavin " and "thoro-pin," though not the same, are of an allied nature, but neither of these need have much significance attached to their existence, as they seldom cause the animal any inconvenience, and still less often any lameness. "Thoro-pin" appears as a bulging at the back of the hock on its inner side-and sometimes on its outer as well-just above the point of the hock. Bogspavin, on the other hand, may consist of a slight distention or a very puffy swelling at the front and sides of the hock, more especially on the morning following active work, due to a hyper-secretion of the lubricating fluid of the joint, and the significance attached to it is as previously stated. Wind-galls and other puffy swellings of an allied nature may either be blistered, fired, or what is better still, smeared over with ordinary gas tar. This produces pressure and contraction of the surrounding tissues, whilst its action is allied to both blistering and firing. Operative interference beyond this is seldom advisable.

\section{CURB}

Curb consists of a sprain of one of the ligaments just below the point of the hock, but lying in the same straight line with it. When viewed in profile it appears as a variable-sized swelling, being sometimes nothing more than a slight undulation, but at others as a distinct convexity, free from either heat or pain, and usually the animal shows no indication of lameness. Curb is supposed to be associated with "over-bent" or " sickle- 
shaped " hocks, and the majority of horses with hocks of this conformation usually show a couple of well-marked curbs. Both light and heavy horses are liable to this trouble, and while some veterinary surgeons look upon it as indicative of unsoundness, there are others who pay very little attention to it, unless the animal is lame and the lameness ascribed to the existence of curb. Unquestionably the "over-bent" hock is one which is distinctly predisposed to it, although it may not always develop. The author does not consider it of much significance, but, judged from a legal standpoint in relationship to the soundness of the animal, it represents unsoundness, because it is a departure from the normal standard, and is "liable" at some subsequent periodalthough it probably never will-to impair the usefulness of the animal. It is customary-whether discreet or otherwise-to fire and blister curb, and sometimes to adopt the same treatment with "over-bent" hocks, although no curb is present. We think that the practice is a commendable one for various reasons, but space forbids us to enter into consideration of these.

\section{BONE-SPAVIN}

There are very few horsemen, not excluding the boy in the stable, who would appear to be unacquainted with spavin, but this knowledge is more fictional than real, as any man of scientific training can verify. Bone-spavin is really a chronic arthritis affecting the lower and inner aspect of the hock, whilst the spavin itself consists of a deposit of new bone, the result of inflammatory action, usually localised to a small area, just at the head of the large cannon bone and its junction with the lower row of the bones of the hock. Every variety of horse is liable to spavin, but some more so than others. One or both hocks may be the seat of the trouble, and the statement that "once a spavin always a spavin" is a practical 
truth. In very rare instances the inflammatory bony product, as in splint, may disappear. Bone-spavin is of less significance in a heavy draught horse than in one required for light work. It is reasonable to assume that very few experts would pass a horse with bone-spavin as sound, provided the animal was under five years of age. It must be clearly understood that spavin represents Nature's method of repairing the damaged part, and the inflammatory action produced and leading to the formation of the spavin very often anchyloses or seals together the smaller bones of the hock joint. The writer is not aware that it ever implicates the true hock joint, i.e. the articulation between the lower end of the second thighbone with that of the screw-bone of the hock. (See Structure of Skeleton.) A horse may have one or both hocks spavined and go absolutely sound, or it may have a very small spavin combined with an intractable lameness. Horses which are worn and degenerate-members of the old brigade-with spavin commonly go lame, as the disease sometimes takes on not constructive but destructive changes, in the form of ulceration of the cartilages of the joints, etc. Bone-spavin is considered to be a hereditary trouble; still there are plenty of horses employed for stud purposes, in which unmistakable signs of spavin exist. As to how spavin is caused we have no reliable or authoritative information, but it is probably due to over extension of the hock, to direct injury, such as a blow, etc. The term "Jack-spavin" is practically synonymous with that of "bone-spavin." To detect bone-spavin, stand in front of the horse and view the inner and lower aspect of each of the hocks, noting any difference in size. If spavin exists it should be seen as a variable-sized bone prominence in the situation named. Care must be taken not to confuse this with the prominence normally present on the inner aspect of the hock. If the hocks are compared for the existence of spavin, a slight difference in size will be seen, and this 
can be supplemented by manipulation with the hand, comparing the two hocks by the sense of touch. Both firing and blistering are resorted to for spavin, but they are of doubtful efficacy. If the owner has reason to suspect that a spavin' is forming, he should immediately throw the animal off work and keep it in a stall, as rest is of primary importance. Anything from a few days to several months are sometimes required to assist Nature in repairing the part. Bone-spavin always represents unsoundness, whether detected or undetected, and whether the animal is lame or not lame. A good deal of circumspection is requisite with the expert in deciding as to whether he will or will not advise purchase of the animal.

\section{SpRained Tendons and Ligaments}

Both tendons and ligaments are very liable to be overstretched or strained, and some of the fibres entering into their structure are torn or ruptured as the result of overextension. Ligaments in connection with joints and tendons and tendinous prolongation of the muscles may all be damaged in this manner, and the result is lameness, owing to the pain brought on through the injury. In a recent sprain the part is usually hotter than normally; it is swollen; causes additional pain when manipulated, and very often a certain amount of constitutional disturbance. The tendons at the back of the limbs are very often sprained, particularly in horses which are required for speed. In chronic sprain of a tendon the sprained part remains permanently thickened, and this in its turn sometimes causes the animal to go on its toe. This is frequently observed in one or both hind limbs, but it is by no means uncommon in front. Treatment comprises rest and the application of bandages, along with either hot or cold fomentations, in accordance with the time the sprain has existed. For the first twenty-four hours cold compresses are the best, and after this hot-water 


\section{DISEASES OF BONES}

fomentation and compresses, but not sufficiently hot to scald or blister the skin. When all the acute symptoms have subsided, the application of a blister will sometimes prove beneficial. As a cooling lotion, equal parts of vinegar and water will be found serviceable. A linen bandage neatly adjusted will serve to keep the compresses on, and over this a flannel bandage should be applied. Dress the injured part three or four times a day. 


\section{CHAPTER XXII}

\section{SOME SKIN AFFECTIONS}

THE horse is liable to quite a number of skin affections, some of which are fairly simple in their nature, others more complex. These troubles may be of a parasitic nature or non-parasitic. In the former case the affection is transmissible from one horse to another by direct or by indirect means; in other words, parasitical skin troubles are of an infective nature, and whenever diseases of this kind appear amongst a stud of horses an unlimited amount of inconvenience and annoyance may be caused.

Some skin diseases are acute, others chronic. Horses that are kept under bad conditions, such, for instance, as dirty stables, and with little or no grooming, are predisposed to the development of skin trouble; and if an infective disease, such as mange, exists where such animals are kept, the chances are that it will spread with great rapidity. Sometimes a skin affection represents a general infection of the whole system, as, for instance, in glanders, a disease which primarily invades the lungs and sometimes extends to the absorbent vessels and skin; epizootic lymphangitis and ulcerative cellulitis are of a similar nature. These three diseases are spoken of as specific, being due to micro-organisms.

The causes of skin disease in the horse are various, but the whole of the causative agents are of mechanical, chemical or parasitical origin ; arising in this manner we have saddle and collar galls, burns from acids and strong disinfectants, mange, ringworm, etc. The following brief description of some of the commoner skin diseases affecting the horse are of interest. 


\section{MANGE}

This is a very common skin disease and, since the war, it has been much more prevalent than formerly. There are several varieties of mange, but they are all parasitic, being due to minute acari invading either the superficial or deeper portions of the skin. These different forms of mange are known as psoroptic, sarcoptic, and symbiotic; all of which have been very common amongst army horses and not uncommon in civilian stables. For some years a vigorous campaign has been carried on against mange in order to diminish its prevalence, and local authorities throughout the British Isles have adopted such legislative measures as seemed expedient under the circumstances. In exceptional instances a fourth variety of mange, namely follicular, affects the horse, but it is not of sufficient clinical importance to do anything more than mention its existence. Sarcoptic and psoroptic mange are both scheduled diseases, and if the owner has reason to suspect the existence of mange amongst his horses, the matter must be immediately reported to the nearest local authority.

Sarcoptic mange is more troublesome to treat than the psoroptic, for the simple reason that the sarcoptic acari take up their abode in the skin less superficially than the psoroptic parasites. Sarcoptic mange has a predilection for attacking those portions of the body covered by short and fine hair, which is exactly the converse in psoroptic mange, whilst the symbiotic acari confine their attentions to the limbs, especially below the hocks and knees, where they produce a great deal of irritation, moisture on the skin, in fact, what is popularly known as grease or seborrhœa; but all "greasy" legs are not due to mange acari, some being of a constitutional nature. The latter can only be treated successfully by remedies which improve the general health. Psoroptic mange commonly makes its appearance beneath the mane, between the ears, 
on the back, at the set-on of the tail and on the quarters, in which places the hair is long and the skin very often dirty. All mange parasites are of microscopic size and require the skilled use of the microscope for their detection. They are closely allied to forage acari and very often confused with these organisms. Forage acari would appear to be capable of inducing a certain amount of skin irritation. They exist in the dust of forage, hay, etc. The commonest form of mange is the psoroptic, and it is more communicable from horse to horse than the sarcoptic. The three different forms of mange may coexist in the same animal at the same time, and, in addition, lice may be present, materially aggravating the skin irritation.

The earliest indication of mange is irritation of the skin as shown by the animal rubbing or biting the part, if accessible for the latter purpose. This leads to the loss of hair in patches, and as the disease extends the patches become confluent, so that in course of time, more especially if the trouble is neglected, the body becomes more or less denuded of hair. In advanced cases of mange the pruritis, or irritation, is intense, and, as this leads to exhaustion, loss of flesh follows, and the animal may succumb in consequence.

Mange is, as previously stated, one of those troubles which are favoured by uncleanliness, and its progress is more rapid amongst horses which are over-crowded, badly groomed, and neglected in various other ways. Dirt evidently favours the perpetuation of the parasites. It is important to know that the adult female sarcopt lays her eggs at the end of a tunnel or gallery formed beneath the superficial layers of the skin, and that these eggs hatch out and produce larvæ in from four to six days. Further, that the larva form takes from eight to ten days to develop into the adult, which is then ready to perpetuate the parasites in its turn. The ova are much more tenacious of vitality than the actual parasites, and 
this fact must be borne in mind when dealing with the trouble.

Recurrent attacks of mange are probably due to inefficient treatment of the ova of the parasites. Although microscopic examination is necessary for the verification of the several distinctive forms of mange, the disease presents certain clinical features which do to a certain extent enable one to form a fairly reliable opinion as to the particular variety of mange from which the animal is suffering.

Sarcoptic mange usually makes its appearance in the region of the withers, the face, the neck and the shoulders, in fact whenever mange appears in front of the wethers, excepting beneath the mane and between the ears, one may accept its appearance in the situations referred to as good or fairly good positive evidence that the disease is sarcoptic mange. On the other hand the appearance of mange on other parts of the body favours the opinion that the trouble is of the psoroptic variety. The most practical test for the existence of mange is to scratch the skin on the withers, neck, etc.

Mange is spread by direct or indirect contact; thus, for instance, it may be carried by an infected horse coming directly into contact with another, or through the medium of stall posts and stable fittings, through grooming appliances, the last-named being one of the commonest channels of infection. The hands and clothing of attendants may easily transmit the disease if these are infected. The bedding may perpetuate the disease, consequently it is very necessary that this should, after removal from the stable, be burned. The harness and the shafts of carts may afford a chance of re-infection.

When mange appeals amongst a stud of horses in addition to immediate notification all the affected animals must be isolated, and the in-contacts kept under observation for at least three weeks. Diagnosis is based upon finding the parasites, a search for which is made by taking one or 
more scrapings from the areas which are affected. The material that is thus obtained is placed in a test tube, boiled with caustic potash and then centrifugalised, the sediment being placed on a slide and examined with a lower-powered microscope. This, however, is a matter for the expert.

The irritation which the parasites produce on the skin leads to the formation of vesicles or minute blisters, in other words, to the formation of eczematous sores on the skin aggravated by rubbing, etc.

The Parasitic Mange Order for IgII and I9I 8 is appended as it contains information which will be useful to the reader. In addition to it the rules to be followed for the prevention and cure of mange in horses are also attached, together with the treatment as recommended by the Board of Agriculture and Fisheries.

All mangy horses should be clipped irrespective of the season of the year and then singed, thorough singeing being, in the writer's opinion, of the utmost importance, a remark which is equally applicable when horses are troubled with lice. After clipping and singeing and hogging the mane and tail the animal should be washed with hot water and soda, to which some antiseptic may, with advantage, be added. After the horse is dry it should be dressed with a lime and sulphur dressing prepared according to the prescription attached, as per leaflet of the Board of Agriculture and Fisheries.

Lime and sulphur lotion, as a remedy for mange, is a very old one, and was employed by the writer more than five and twenty years since for this purpose. Very thorough application of the dressing is absolutely indispensable, and it is equally essential that the dressing should be applied warm. It takes about two gallons of fluid for each horse. Lime and sulphur lotion makes the hands very sore, so that gloves should be worn to prevent this. Repetition of the dressing at frequent intervals is very necessary, therefore the writer recommends that 
affected horses should be dressed every fifth day. In the army the dipping bath for mange and as a preventative of this trouble proved valuable beyond words, and had it not been for the lime and sulphur baths distributed throughout the base hospitals both at home and in France, etc., mange would, unquestionably, have become an embarrassing problem.

There are a large number of applications useful in mange, but some of these are, unquestionably, more serviceable as curative agents than others. At the commencement of the Allies' war, those horses suspected as having mange in the British Army were clipped and dressed with a mixture of sulphur, oil of tar and a vegetable oil, colza, rape, etc. They were washed at regular intervals with paraffin soap. This dressing was quite useful in its way, but altogether unsatisfactory, consequently it had to be discontinued at most of the veterinary hospitals. Many other compositions were employed, but the lime and sulphur dip proved to be the real "man of business " both at home and abroad.

\section{Parasitic Mange ORder, IgII}

(I) Obligations under Order and Penalties.-Under the Parasitic Mange Order, IgII, every person in Great Britain having in his possession or under his charge a horse, ass or mule affected with or suspected of parasitic mange is required to give notice of the fact with all practicable speed to the police. Failure to give such notice renders a person liable to a fine of $£ 20$, and, in certain circumstances, to a month's imprisonment.

(2) Prevalence of Disease.-The information obtained by the Board from enquiries made in connection with the many outbreaks of mange reported to local authorities shows that the disease is very prevalent at present, and, though the disease is not of a nature which need alarm horse owners, it is highly desirable that every possible means should be taken to prevent animals becoming 
affected with parasitic diseases, and to cure them promptly if found affected.

(3) Importance of Notification.-One of the objects of requiring notification is to ensure that the affected animal shall be treated so as to be cured as quickly as possible. The Order of IgII as amended by the Order of IgI8 permits of an affected animal being worked subject to certain conditions. An owner may also employ his own veterinary surgeon to advise him regarding treatment.

(4) How Farmers benefit themselves by observance of Order.- It rests mainly with an owner to keep his horses fit and free from such parasitic diseases as mange and lousiness. By so doing he benefits himself, for the small extra trouble involved will pay him, since his animals will improve in condition, will be fit for more work and will require less food than when their bodies are called upon to supply food for thousands of parasites in addition to their own needs. In treating the skin for one kind of parasite, others can be got rid of. It is not a very difficult matter to keep a horse free from parasites.

(5) When in doubt notify Police.-A farmer in his own interests will do well in all cases of doubt to obtain advice by notifying the police. He will then be informed whether the animal has mange or not, what form of mange if any it is suffering from, and how to treat it and prevent it from spreading to his other horses and those with which the affected animal may come in contact.

(6) Horse Owners should be suspicious when symptoms appear.-At present it is as well to regard as suspicious every horse which shows signs of itchiness by rubbing, and particularly when the rubbing has caused areas where the hair is thin and broken.

Now is the time to get to work, as washing or spraying is a simpler matter in warmer seasons. Mange and lou ness can now be got rid of if owners give the matter little attention. See Rules attached for "The Preventi and Cure of Mange in Horses." 
(7) Horses belonging to the Food Production Department are under special rules for the cure and prevention of mange.

Ruies to BE FOLLOWED FOR THE PREVENTION AND CURE of MANGE IN HoRses

(I) To aid in the prevention of mange, all horses should have their manes hogged and the long hair clipped from the feet and coronets.

(2) As far as possible each horse should habitually occupy the same stall, and the harness of one horse should not be used on another horse unless it has been previously wiped over with anti-mange dressing, or otherwise disinfected.

(3) Before another horse is put into a stall which has been occupied by an affected or suspected horse, the woodwork, head-rope or head-stall, and the floor should be washed over or sprayed with anti-mange dressing.

(4) The harness, stable tools, and cart shafts used in connection with an affected or suspected animal should be well dressed with, or soaked in, the dressing, or they should, the case suiting, be placed a in small room and submitted for several hours to strong sulphur fumes. This should be carried out at least once every seven days, until the disease or suspicion has been removed.

(5) When a case of mange is found to exist on premises, all the horses, their harness, etc., for purposes of prevention should be regarded with suspicion, the harness, stable tools, etc., being treated once a week as in (4). The skins of all horses, even though the animals show no outward symptoms of mange, should be sponged over or sprayed once a week, say, Saturday evenings, with anti-mange dressing, and particular attention should be paid to the coronets, the tail, and 


\section{THE HORSE}

the mane. These should be well soaked with the dressing by means of a water brush or spray pump. Particular attention should always be paid to parts which appear to be rubbed. If the dressing be made up with warm water the horses will take more kindly to the spraying. After sponging or spraying of the skin the horse should be left alone for ten munutes, and then the skin should be wisped over to help drying.

(6) If it be found after inquiry that the disease is sarcoptic mange an owner should get his veterinary surgeon to see the animal from time to time, and advise as regards treatment and progress. If it be found that the disease is psoroptic mange, an owner can quite well, after receiving the official instructions, apply the treatment to the animal himself ; but it must be remembered that it is no use treating merely the parts visibly affected; the whole skin should be sponged or sprayed with the prescribed dressing.

(7) The litter from an affected horse should be well moistened before removal. It should afterwards be placed on a manure heap well removed from contact with horses.

(8) All new purchases or borrowed horses should be dressed or sprayed as in (5) at least three times.

(9) For the prevention of external parasitism, which is prevalent in these times, and the infection of which may be picked up in innumerable ways, it would be well for owners of working horses, even when they appear free from parasites, to make a practice of spraying the whole bodies of their animals once a week, say, on Saturdays, with a suitable anti-parasitic dressing. Suitable spraying machines and dressings can be obtained through agricultural implement dealers and chemists, but before placing their orders owners should apply for advice to the Local War Agricultural Committee, who are in a position to recommend the most suitable spraying apparatus and dressings. 
Dressing for Mange IN Horses, suggested By the VETERINARY DEPARTMENT OF THE BOARD OF AGRICULTURE AND FISHERIES

Ingredients.-Lime, powdered sulphur and water in the proportions indicated below.

A convenient quantity for a large establishment to make up at a time would be $9 \mathrm{lb}$. lime and $\mathrm{I} 8 \mathrm{lb}$. sulphur. Method of Preparation.- Shake the lime and make into a thick paste with the sulphur. Place the mixture in a strong cloth, tie the ends and suspend in a boiler containing ten gallons of water so that the water completely covers the contents of the cloth. The cloth must not touch the sides or bottom of the boiler, as otherwise the cloth may be burned and its contents escape. Boil for two hours, then remove the cloth, taking care that none of its contents escape into the water, and throw the solids away. Make up to ten gallons again with additional water and put the liquid into a tight drum or barrel.

\section{APPLICATION}

For preventive.-Dilute the fluid with ten times the amount of water, i.e., one and a half pints of the fluid to every two gallons of water, and apply with a spray to all parts of the horse's body.

For affected horses.-Dilute the fluid with eight times the amount of water, i.e. two pints of the fluid to every two gallons of water, and apply with a spray to all parts of the horse's body.

Quantity used.-Two gallons of the diluted fluid is sufficient to treat one large horse.

\section{LICE}

Horses and mules, also asses, are not uncommonly affected with lice, the horse-louse being a most troublesome pest. The horse-louse (nematopinus equi) has a narrow head and long trunk-like sucking tubes, with three legs 
at the anterior end of the body, the latter being ovoid. Some horses are simultaneously attacked with lice and mange, therefore a considerable amount of care must be exercised when dealing with skin trouble of a horse. If lice are present a critical inspection of the skin will reveal their existence. These pests cause a lot of irritation, rubbing, and even loss of hair, symptoms which are equally significant of sarcoptic and psoroptic mange, and both of these are notifiable diseases. One lousy horse or mule is quite capable of infecting others directly or indirectly, so that it is impossible, for the well-being of horses, to neglect the animal when it is in this condition. Horses which are dirty and badly kept are those which are most liable to be troubled with lice, but every case must be the result of infection, as living matter can never spring into existence from non-living matter. In dealing with a trouble of this kind the first thing to be done is to clip the animal from head to foot, then singe it, and lastly sterilise everything in the stable with which the animal has been brought into contact. Rugs, grooming appliances, stable fittings, harness, the shafts of a cart, must all be treated with boiling water, soda and some strong disinfectant. The horse should also be thoroughly scrubbed with warm water, carbolic soft soap and a solution of some disinfectant, such as creolin. If it is a stud of horses, the trouble must be attacked in a most thorough manner. Horses which are lousy cannot rest, therefore cannot thrive properly. No self-respecting owner and no horsekeeper or groom would allow his horses to get into this condition. A decoction of tobacco-2 oz. strong tobacco to a pint of water, boiled together for an hour, makes a good application for lice. This fluid should be passed through muslin before being applied.

\section{RINGWORM}

This is of common occurrence in a horse and appears to be more prevalent at certain seasons of the year. It 
is one of those skin diseases which have a tendency to spread over the body until a particular stage is reached, when it begins to decline. At the commencement of the Great War, ringworm was very prevalent amongst the horses in the British Army, and the severity of the disease in many cases led to almost complete loss of hair over the body, often extending to the limbs. Although ringworm first of all makes its appearance in patches, usually of a circular character, it very soon assumes a confluent form, owing to the patches fusing with one another. Ringworm may commence at any portion of the body, and in its early stages it is denoted by slight elevation of the hair, accompanied by one or more red points on the skin, with a slight degree of moisture at the part attacked. It seems to makeits appearance quite suddenly and spreads from the centre to the circumference, consequently whilst one part of the patch is alive the other part is more or less dead; hence the necessity for dressing the margin of the ringworm freely with the application employed. If a ringworm patch is examined it will be found that the surface is covered with greyish scales, underneath which the skin is red, proving that the disease is still active. When the surface of the sore is free from scales, perfectly dry and shows no redness when scratched with the finger nail, especially around the margin of the patch, one may accept this as evidence that the patch is no longer active. Although ringworm attacks all classes of horses, both when they are clean and when they are dirty, it is one of those troubles which are favoured by a dirty condition of the skin and by general insanitary environment. It is, however, an affection communicable from horse to horse, mule to mule, and from these animals to man. Further, ringworm is very common amongst calves, and has a predilection in these animals for attacking the face, especially around the eyes and muzzle. It may spread from these animals directly to the horse or indirectly through the medium of feeding-troughs, 
rubbing-posts, the hands and clothing of attendants, by grooming appliances, through water-troughs, by infected litter and by various animals, such as the cat, rats, mice, etc. As previously stated, ringworm will in course of time exhaust itself, more especially if the general health of the animal is improved. It is customary to speak of ringworm as being contagious, but it is more correct to regard it as an infective disease, as it can be conveyed through so many extraneous agencies. For a considerable period of the war, especially during I9I 5 and I9I6, ringworm caused a great deal of trouble and inconvenience amongst the army horses, in fact it was earlier one of the scourges of the war. Far too much attention was paid to it, and horses which were fit for military service were kept idle and without any just reason. There is no doubt that one of the principal methods through which the disease was spread, and its remarkable prevalence in consequence, was by means of the grooming appliances-the body-brush, the stable-rubber and the curry-comb plus the hands of the attendants. Treatment comprises clipping the hair off for two or three inches around the seat of a patch and then dressing the surface of the sore with mild mercurial ointment; with iodine liniment; with red blistering ointment; with lime and sulphur lotion or some other agent of an allied nature. Ringworm is not difficult to cure, but it is essential that the scurf be removed from the surface of the patch and that the circumference of the latter be freely dressed with whatever application is employed. If the trouble is distributed over the body, the lime and sulphur dip, recommended for the treatment of mange, is as good an application as one can possibly need. (See Mange.)

The cleansing of all grooming appliances, stable fittings, harness, cart shafts, saddles, bridles, etc., as well as all other stable appointments, are of course part and parcel of the general outline when dealing with this disease. Thoroughness is the only royal road to success when deal- 
ing with ringworm, mange, lice and other communicable troubles affecting the skin, or for that matter, disease of any kind.

All cases of ringworm are due to the presence of a vegetable fungus or plant which invades the shafts of the hair and the hair follicles. This parasite is known as the tricophyton tonsurans and is reproduccd by means of spores derived from the parent plant.

\section{Collar and Saddle Galls}

Every horseman is well acquainted with sores resulting from the pressure of a badly fitting saddle or a badly fitting collar, or some other sore arising from injury produced by the girth, etc. Horses which are in poor condition and continuously worked in harness which is improperly looked after, are those which are most susceptible to injuries of this kind. As a rule these skin abrasions are the result of direct and continued pressure of one hard substance upon another, and when they do exist the pain inflicted upon the animal is unquestionably very great. One's own personal experience is sufficient evidence of the torture endured under these circumstances. The extent of the injury varies considerably, and so does its course and termination. Neglected bruises on the withers are the chief causes of fistula of the withers, and this remark is equally applicable to the poll when injured and neglected, ending in the so-called poll-evil. As a preventative of saddle and shoulder galls it is absolutely essential to see that the animal is supplied with a properly fitting set of harness or gear, saddle, etc. Directly a horse shows the slightest signs of skin abrasion, it should be immediately thrown off work and the necessary adjustment of the saddle attended to. Horse owners pay far too little attention to the proper fitting of harness, to the care of the same, and often overlook apparently trifling injuries, which later on very often develop into 
those of a much more serious nature. The old motto "A stitch in time saves nine." Doubtless many horses are predisposed to cutaneous injuries of the kind now under consideration, but nevertheless both saddle and collar galls are frequently the outcome of negligence on the part of the owner or his attendants. Any horse suffering in the manner indicated ought not to be worked, or at any rate until the pain induced by the pressure has been removed. A form of injury that has been extremely common amongst army horses picketed out on ground lines is the so-called "rope" or "heel " gall, usually resulting from the head-rope being left too long. Sometimes very severe injuries to the heels resulted in this manner. Through negligence nasty sores were occasionally found on the poll through failure when grooming to shift the strap or halter passing over this region. Both these injuries are the result of pure carelessness and should be dealt with accordingly. To work a horse with either a collar or saddle gall constitutes cruelty and is punishable either by fine or imprisonment. Injuries to the angles of mouth by the bit are occasionally observed, especially in horses which are hard mouthed and strong pullers. It is equally cruel to work a horse in this condition. A bit covered with India-rubber will sometimes abolish a trouble of this nature. At any rate it is always expedient to try whether it is serviceable or otherwise. The point of the elbow and the tissues beneath this are commonly the seat of a bruise, very often the result of the heel of the inner branch of the shoe pressing upon the point of the elbow during lying and rising. This injury constitutes what is known as " capped elbow "-an abnormal condition which may become very unsightly if neglected. A corresponding condition is often observed as "capped hock," usually produced by a bruise or bruises on the point of the hock. Carters and contractors' horses commonly suffer from collar galls, and when a horse has been troubled in this manner there is a special liability 
to its recurrence. Repeated injury leads to thickening of the skin and sometimes to the formation of an abnormal growth or tumour in the area implicated. As already stated, the most trivial injury should always receive attention, thereby saving a great deal of annoyance. When the skin has been nipped or bruised or abraded, a lead lotion constitutes one of the most useful applications that can be employed, but this, of course, is useless if the exciting cause is not removed. Thirty grains of sugar of lead should be added to a pint of water-distilled water for preference. The shoulder should be bathed with this lotion several times a day. A usefuldomestic application consists of half a pint of vinegar and half a pint of water, applied in a similar manner. If the skin is very tender it is a good plan to harden it by the application of methylated spirits of wine, two or three times a day. All parts of the skin beneath the harness sweat freely during work, and if the skin is cooled too rapidly local congestion of it is liable to occur, and in this manner saddle or collar gall may be initiated. As a preventative, allow the collar or saddle to remain on-say for half an hour-after the animal returns from work. Concerning the advisability of leaving a patch of hair, corresponding to the saddle, when the animal is clipped, opinions are divided. The hair thus left must, to a large extent, regulate the rapid loss of heat and, by logical reasoning, it should be a preventative of sore back. There is one very common trouble arising through a neglected injury to the skin beneath the saddle; this is the so-called

\section{Sitfast}

which is nothing but a dead portion of skin attached to a living part, but which nature is apparently unable to cast off. The only treatment for an injury of this kind comprises removal with the surgeon's knife, consequently it is necessary to call in professional aid. In every case it means three or four weeks' rest, but the 
sooner the operation is performed the better, as delay only aggravates suffering and leads to further complications.

\section{Mud Rash ANd Mud Fever}

The skin of the heels and other parts of the body in horses which are neglected as regards grooming sometimes becomes the seat of an erythematous eruption or rash, characterised by a dry condition of the skin, on which numerous minute blisters form, apparently due to some irritating material contained in the mud. The skin seems to lose all its pliancy, and the animal becomes what is called " hide-bound "-a sure indication of unthriftiness. This trouble is also spolken of as "mud fever," owing to the fact that the animal does occasionally suffer from slight constitutional disturbance. The best treatment for mud rash is to give the animal a physic ball and follow this up with a liberal supply of linseed gruel along with the other forage, until the animal shows decided improvement. Plenty of good strapping is essential in order to encourage the circulation in the skin.

\section{Cracked Heels}

This abnormal condition is a very common one, more particularly during the late autumn and winter. The heels are most susceptible to the action of cold and wet, more especially in horses which have been clipped and improperly groomed. Sometimes the skin at the heels becomes so sore and painful as to lead to lameness. Probably one of the most fruitful causes of cracked heel is that of washing the heels and failing to dry them properly afterwards. Many horsemen consider that one of the best preventatives against cracked heels is to allow the hair to grow fairly long in the region of the heels, though of course many horse-masters object to this on the ground of its being unsightly. When horses come in with wet and muddy fetlocks and the hair is long at this 
part, the best plan is to leave the mud to dry on and brush if off on the following morning. Cracked heels have already been referred to under the heading of "Saddle and Collar Galls," where they are described as "rope gall " (which see). The skin at the heels is very rich in sebaceous glands, the functions of which are to secrete an oily fluid for the special lubrication of the heels and to prevent the skin from being too much wetted with water, snow, etc. Cracked heel varies in its severity. Sometimes it consists merely of a superficial inflammation, whilst at others it is in the form of one or more deep fissures, and these are extremely painful. Very often the part suppurates, the result of infection by pus organisms. Whenever the heels are washed, they must be properly dried afterwards, and if necessary, bandaged. In some cases the author is inclined to believe that the trouble arises through a draught from the bottom of the door playing on the heels, more especially after the animal comes in from work. In winter, more especially when the thaw sets in, it is a good plan to grease the hollows of the heels freely with some lubricant, such as vaseline or lard. This is a preventative. Mild cases can be cured by the application of a cream composed of prepared chalk and lime-water. If the heels are badly cracked, smear them with an ointment composed of equal parts of vaseline and mild mercurial ointment. In the treatment of cracked heel one can only deal successfully with it by noting whether the skin is dry or moist. If moist, drying agents are indicated, whereas if dry, an oily dressing usually proves the most beneficial.

\section{Grease (Seborrhea)}

This is a very common disease of the skin and is one that affects the skin between the knee and pastern or hock and the last-named. It is a most objectionable trouble, and the smell arising is of a very disgusting nature; in 
fact so bad, more particularly in neglected cases, that it can easily be smelt as soon as the stable door is opened. Grease is particularly common amongst horses of a heavier class, and when it is once established it leads to permanent thickening of the skin. It is a form of dermatitis, in which the sebaceous glands actively participate. We have already referred to grease under the heading of "Mange," in which we spoke of this trouble as being caused by, in many cases, a species of acari, known as the symbiotic mange parasite-parasites which cause dermatitis in the regions affected with grease. Apart from the parasitical cause of this trouble, the author is inclined to believe that a certain percentage of cases of seborrhoa are of constitutional origin, and can only be successfully treated by a course of internal medication ; whereas if parasitical this disease can usually be cured by local applications only. Old standing cases of grease result in permanent enlargement at the seat of disease, hence the reason why one occasionally sees a cart horse with a huge growth round the fetlock. A common result is the formation of numerous wart-like or grapy growths in the hollow of the fetlock and which in days gone by the farrier used to remove by the application of a hot shovel, as used in the forge. This must have been an extremely painful procedure and seems to be a barbarous method of dealing with a trouble of this kind. All wounds in the heels are of slow healing capacity, chiefly owing to the movement of the part and the small amount of reparative tissue which exists. Grease is much worse during the wet weather, but it exists in some horses perennially, and the damage which it does to the part attacked is usually proportionate to its severity or otherwise. The author considers that it is one of those troubles which demand professional skill for its proper treatment, but when it is due to, or thought to be due to mange mites, the application of lime and sulphur lotion is of unquestionable service. The sulphur in the lotion destroys these parasites, so that when the irritation 
ceases through their existence, the trouble comes to an end. This is indicated by the moisture of the skin drying up and the animal ceases to itch or rub the leg or legs. A common symptom of parasitical grease or mange is that of stamping the feet, especially the hind ones, violently; itching the leg with the opposite foot and the presence of blood and scars above and round about the fetlock. (See Mange.)

\section{NEtTle-Rash (UrTicaria)}

Nettle-rash is quite a common affection and affects all classes of horses, but particularly those which are very fat and fed upon food which is much too stimulating. It is often spoken of under the title of " Surfeit," more especially by some of the older writers of works upon the horse. It is a functional disturbance, apparently intimately associated with some derangement of the digestive organs, possible the kidneys, liver, etc. It is a trouble which makes its appearance very suddenly in the form of numerous weals or elevated patches of skin upon various parts of the body, more especially the neck, back and thigh. The patches commonly disappear as quickly as they come, but they sometimes persist for several days or more. The weals vary in size from a shilling up to a crown or larger, and one may fuse with another to form variouslysized elevations. The skin seldom breaks. Treatment comprises a dose of physic or a little Epsom salts in the drinking water daily. A tablespoonful once a day will be sufficient. All corn should be withheld and green food, if accessible, given. To allay the irritation, vinegar and water can be applied to the skin several times a day. It is a good plan to turn the animal out to graze if the season permits, but for the time being a non-stimulating forage should be given. 


\section{CHAPTER XXIII}

\section{THE EYE AND SOME COMMON AFFECTIONS}

THE horse, like all other animals, is liable to suffer from various diseases and injuries of the eyes, some of which may render it either partially or completely blind. Perfect vision, although not essential for work, is an indispensable feature in relationship to soundness, so that the most venial affection of the eye does, in this animal, materially detract from its commercial value.

A horse may be perfectly blind, yet to a casual observer the eyes may appear quite normal. There are some affections implicating the eyelids only; others the globe of the eye ; the glands in connection with the eyelid and eye, and, in many instances, the whole of the structures in connection with the eyelids and eye become, more or less, implicated.

The eyes occupy a somewhat sheltered position and are protected and shaded by the eyelids and eyelashes; nevertheless, in spite of this, foreign bodies, such as a particle of chaff, etc., frequently become lodged on the transparent surface of the eye, setting up a variable degree of inflammatory action.

The eyelids are lined by mucous membrane, and as this is a highly vascular structure it follows that an injury to the eyelid, or anything which causes irritation is extremely liable to be followed by inflammation.

In addition to the shelter afforded by the eyelids, each eye is lodged in a complete bony cavity, the eyeball itself being pierced at the back by a large nerve-the optic nerve, which is derived from the base of the brain, where the right and left optic nerves cross, and constituting 
the second pair of cranial nerves. The optic nerve forms the innermost lining of the eye-the retina-and through it the impressions are carried to and from the brain.*

The eyeball itself consists of a white portion known as the sclerotic coat, and into this the transparent portion of the eye-the cornea-is fitted, exactly as a watchglass is fitted into the rim of a watch. Immediately behind the cornea lies the iris, which is a structure composed of circular muscular fibres and having a central opening-the pupil. The iris is the pigmented portion of the eye and confers the colour upon it. The pupil dilates and contracts in accordance with the degree of light admitted into the interior of the eye, so that it contracts in strong light, and dilates in the dark. Likewise there is the same response to various chemical agents, such as belladonna and atropine.

Immediately behind the iris is the crystalline lens, through which light is transmitted on to the retina. Between the iris and the cornea there is a small chamber containing a highly refractile fluid-the aqueous humour. This is called the anterior chamber in contradistinction to a much larger, but corresponding, chamber occupying the bulk of the interior of the eye behind the crystalline lens and technically known as the posterior chamber, which contains the vitreous fluid.

When the eye is severely injured it sometimes happens that one or both these chambers is punctured. If so, the eye collapses. If the amateur wishes to obtain an elementary knowledge of the anatomical construction of the horse's eye, he can do so by obtaining a specimen from a dead horse, subsequently placing the organ in ice in order to freeze it, and so facilitate its proper examination, after making a vertical section through it.

The foregoing outlines may serve as a preliminary introduction to such study.

* The horse has a third eyelid known as the membrana nictitans, and this is a triangular piece of cartilage springing from the inner angle of the eye. 


\section{INJURIES TO THE EYELIDS}

Injuries to the upper or lower eyelids are fairly common in a horse, and may involve the skin only, or the cartilages of the eyelids, and sometimes the mucous membrane lining them. In the latter case a variable degree of ophthalmia is an inevitable result, and this, in its turn, not uncommonly leads to opacity of the cornea, which further complicates matters, and may, if neglected, result in either partial or complete blindness.

Many of these injuries are, more or less, the result of carelessness on the part of a stableman through leaving a nail, or some other form of projection, in proximity to the horse's head. A pointed hook, such as one often sees in the farmer's stable for hanging tackle on, is an occasional cause of an injury of this kind. In the simple cases, that is, where the skin only is torn, the injury can be dealt with, first of all by cleansing the part with warm water, and after thoroughly drying it, painting it with iodine; afterwards, adjusting the torn edges by means of sutures (see chapter on Wounds), or what is much simpler, by pins, which are particularly suitable for injuries to the eyelids of the horse, because these can be adjusted according to the degree of swelling, etc. The pins are inserted through the skin about one-eighth of an inch from the margins of the torn part, and then the skin is drawn together by means of horsehair or silk wound round the pins in the form of a figure of eight. The number of pins required will vary with the extent of the wound, but as a rule about three are usually sufficient.

Under ordinary circumstances lacerations of the eye ? lids in the horse heal fairly well, but all will depend upon the precautionary measures which are adopted to prevent the animal from rubbing the wound against the manger, etc. In every instance it is expedient to call in a veterinary surgeon, but when professional advice cannot be obtained the measures outlined should be adopted. 
The treatment recommended may be supplemented by the application, night and morning, of boracic acid ointment, and a small portion of this may, with advantage, be placed between the eyelids. A variable degree of swelling is necessarily an accompaniment wherever the skin is torn, consequently if stitches are inserted these must be so adjusted as to allow for such swelling to occur without producing too much tension upon the sutures, pins, or whatever materials have been employed for bringing the injured edges together. The injured part must be kept clean, and if there is much swelling fomentation with warm water, night and morning, will be of service.

\section{OPHTHALMIA}

Ophthalmia, or inflammation of the mucous membrane lining the eyelids, is of common occurrence, and it arises through various causes, such as injuries to the eyelids, various chemical and mechanical irritants-for instance, lime or chemical manures of various kinds inadvertently gaining access to the eyelids. A frequent cause is through the admission of a particle of chaff, whilst in other instances ophthalmia is associated with catarrh and strangles, but it also exists as recurrent or specific ophthalmia. It is one of those eye affections which, if neglected, implicates structures in contiguity to it. Thus, for instance, opacity of the cornea frequently follows through prolonged irritation.

The symptoms indicative of acute ophthalmia are: extreme redness of the mucous membrane; intolerance to light; excessive lachrymation. These symptoms vary in their severity or otherwise, likewise in their duration and termination. Sometimes there is a purulent discharge from the eye, due to infection by pus organisms, which aggravates the trouble. The treatment must be based upon a knowledge of the causes whenever this can be ascertained. In every instance it is of primary im- 
portance to try to ascertain the cause. If a foreign body has lodged upon the mucous membrane an effort should be made to remove it. In any case the mucous membrane lining the eyelids must be examined, though the painful nature of this affection commonly renders such an inspection and examination a matter of extreme difficulty. If a hayseed or particle of chaff has lodged upon the cornea it sets up both ophthalmia and inflammation of the cornea unless it is removed immediately the accidenthappens. It is impossible to remove it after it has been on the cornea for a few hours, owing to organisation of the inflammatory exudit which has been poured out on the cornea. In a case of this nature the animal becomes at least temporarily blind, and in quite a number of instances a permanent opacity of the cornea remains as a legacy of this pre-existing inflammation.

Treatment and Management.-It is hardly necessary to say very much about this because the most economical and efficient measure will be to have professional advice, and the sooner the better.

Certain palliative means may be adopted, such as, for instance, the application of warm fomentations, or the use of a lead lotion (three grains of acetate of lead to each ounce of water), or the application of boracic acid ointment, night and morning. It is often a difficult matter to remove a particle of chaff from the eye, and various means have been employed, but a camel-hair brush dipped in a strong solution of gum has been employed by the writer in some instances with success. The difficulty in the removal of a foreign body from the eye arises through the existence of a third eyelid-the membrana nictitans - the functions of which are, obviously, for the removal of foreign bodies from the eye.

\section{OPACITy OF THE CORNEA}

We have already alluded to this in the preceding paragraph. The degree of opacity varies considerably, 
just as much as the exciting causes. It may be temporary or permanent ; specific or non-specific; and the degree of blindness varies with the position which the opacity occupies, and also the time the trouble has been in existence. If the opacity has existed for a long time it gradually undergoes a hardening process, and nothing can ever remove it.* Quite a common cause of this trouble is striking the eye with a whip; a blow over the eye with the butt-end of the whip; various irritants, etc. Horses frequently shy at objects in the road when they have slight opacity of the cornea, more particularly if the cloudiness is directly over the pupil.

\section{CATARACT}

This is a fairly common affection in horses and one that may render a horse completely blind. It is a disease affecting the crystalline lens, the capsule covering the lens, or both these structures. As a rule it is of gradual onset, and once established it is permanent, as operations on the horse for cataract are seldom performed. An injury, such as a blow over the eye, may possibly be a cause of cataract, but one of the commonest causes during these last few years has been the so-called specific or recurrent ophthalmia, a disease which produces so much disorganisation within the eye and so frequently recurs that structures in connection with the lens finally become implicated, and cataract is the result. About half a century since specific ophthalmia was in Great Britain a fairly common malady, and used to be known under the title of moon blindness. Since the Great War recurrent ophthalmia has reappeared, principally among the army horses, therefore it is reasonable to assume, now that a large proportion of these animals have been sold, that the trouble referred to will reappear somewhere. 
It is a very hopeless disease to treat, and whatever repair takes place is mainly due to the efforts of Nature, and not to any medicinal value of topical applications. As previously stated, cataract is incurable; renders a horse unsound, but not necessarily less useful for certain purposes, provided that only one eye is implicated. Sometimes, however, both are affected. Cataract may be partial or complete, in accordance with the stage at which the disease has arrived. Its detection is a matter for an expert and requires the use of the ophthalmoscope for critical inspection. But, under ordinary circumstances cataract can be seen as a greenish discoloured area towards the back of the eye, more especially when the pupil is dilated, which happens when the eye is shaded.

There are many other affections of the eye, such as amaurosis, or glass-eye, a disease characterised by the eyes being apparently healthy yet the animal is blind. This is not a common affliction, although it is by no means infrequently met with, and results from variable causes, such as excessive hæmorrhage and pressure upon the optic nerve through injury, abnormai growths, etc.

Amongst other diseases of the eye mention must be made of glaucoma, an evertion and inversion of the eyelids, warty growths on the eyelids, parasites of the eye, luxation or displacement of the eyeball, and tumours of the orbit, all of which produce impairment of sight and other symptoms, associated with the particular part involved.

Before concluding this chapter it is worthy of remark in passing that the most severe injuries to the eye are often followed by almost complete recovery of the eyes to its normal state, indicating what remarkable reparative power is inherent in these organs. 


\section{CHAPTER XXIV}

WOUNDS, FRACTURES AND DISLOCATIONS

THE horse is particularly liable to both wounds and fractures, and it is by no means exempt from dislocations, particularly in one joint, viz. the stifle. The majority of flesh wounds in horses heal readily, but when complicated with a fracture the damage is usually irreparable, and nearly always necessitates the immediate destruction of the animal. There are certain fractures-such as those of the ribs and the pastern-which are capable of repair provided that the animal is placed under favourable conditions for the restoration of the damaged part. It is the absence of flesh below the knees and hocks which either hinders or completely prevents repair. Superadded to these features, however, we have to consider the extreme difficulty experienced in keeping the patient in a position favourable to repair. In the human subject it is quite a different matter, the conditions being exactly the converse. The horse is unquestionably capable of receiving suggestions, and not only receiving but often interpreting them; still, when it comes to a question of pain and restraint the matter is entirely different. Wounds vary from a mere abrasion of the skin to the implication of the flesh, blood-vessels, tendons, and ligaments, or even injury to bone, and in some cases vital parts may be injured, as happens when the cavities of the brain, chest, and belly are severely penetrated. The position of a wound and the relationship it bears to vital structures influence its course and termination. Most of the wounds in a horse consist of laceration of the skin and subjacent flesh, but some are incised or clean cut, exactly as though 
cut with the surgeon's knife. Many of these injuries are accompanied by a good deal of contusion, or bruising, consequently there is a considerable amount of swelling often accompanying the injury. This is particularly the case in the so-called "broken knee" of a horse, usually produced by falling on hard ground; a kick from another horse is sometimes of a similar nature, but very often an injury of this kind produces a fracture, as commonly observed in many of the army horses during the last Great War. When a wound is in the nature of a stab, like that from a bayonet or from some sharp, penetrating body, it is spoken of as " punctured," and punctured wounds are most frequently met with in the feet of horses, through " picked-up nail," and when the farrier pricks the foot during shoeing.* These are among some of the worst injuries to which horses are liable, at any rate so far as their course and termination is concerned. Wounds about the feet can never be treated in a spirit of levity, but should be examined by a veterinary surgeon and dealt with according to his instructions. The size of a wound is no criterion as to the ultimate result, as the most trivial abrasions are occasionally followed by the death of the animal through some disease such as tetanus, or lockjaw. Quite commonly we find most extensive wounds in horses, especially about the buttocks and quarters, on the shoulder, and sometimes on the side, but capable of appearing in any situation. Some extraordinary wounds in horses were met with during the Allies' war as the result of bomb explosions, shrapnel, etc. Thousands of horses were either killed or destroyed as the result of gunfire or some other form of explosion. A compound wound is one in which there is a fracture in addition to the wound. This, of course, materially adds to the treatment of the injury ; in fact, it may necessitate destruction of the animal. As to fractures or broken bones, any bone in the body, no matter how

* A common cause of "Quittor." 
sheltered in position, is liable to be fractured, and it is surprising how apparently trifling an accident may be, and yet the injury out of all proportion to the latter. A fracture can be produced by direct or by indirect violence, and the bone may be broken across transversely, longitudinally, obliquely, or comminuted, i.e. broken into a variable number of small particles. The author has seen both these accidents in the cannon-bone and the long pastern produced in a very simple manner. Direct violence consists of a kick from another horse, contact with a shaft from a cart, or against some other hard and unyielding body, such as a lamp-post, wall, etc., whereas indirect violence may be sudden muscular contraction, as when a horse is pulled to a standstill in a very violent manner. We have seen the radius, or forearm, fractured in this way during polo playing. The arm, forearm, and cannon are occasionally broken by a kick from another horse, but the commonest fracture of all is that of the second thigh, or tibia. In nine cases out of ten it is the result of direct violence, and the bone is usually broken about four or five inches above the hock. The kick is generally delivered from the opposite side to that upon which the injury is inflicted, and nearly always on the inner side of the limb. The fracture is sometimes transverse and sometimes it is oblique, and no matter whether transverse or oblique there is usually considerable displacement of the fractured part. If so, the sooner the animal is destroyed the better for all concerned. It is not an injury where there need be any hesitation, but if there is no displacement, yet the animal is very lame and fracture suspected, its destruction should be deferred. Meanwhile it should be placed in the slings and professional assistance obtained.

There is another fairly common fracture, viz. spilt pastern, usually produced by direct concussion. Sometimes it is quite an easy matter to ascertain whether this injury has or has not occurred, but usually it is difficult 
to tell, especially if it is unaccompanied by any swelling. Certainly lameness and pain, when the fetlock is manipulated, is of some value in assisting one to form an opinion. There are two bones at the back of the fetlock; either or both of these may be broken, but this is an uncommon injury. A broken rib or ribs, unless accompanied by an external wound, is not of much significance, as these structures contain a large amount of spongy bone, and are in a fairly favourable situation for repair to occur. A piece of pitch plaster over the seat of the injury is usually sufficient to keep the injured part at rest.

Probably the reader will think that fractured bone, say in a foal, is capable of exerting a greater degree of reparative power than an adult animal. To a certain extent this is true, but not sufficiently so to warrant one to treat fractures in foals. Sometimes a mare will kick her foal and break its leg. The owner may be anxious to preserve the life of the foal. It is seldom, however, that any good results from surgical means. The usual signs of fracture are sudden lameness, with inability to place weight on the injured limb, pain on manipulation, increased heat, swelling, and crepitus or a grating together of the broken ends of the bone, any of which may be absent. Most fractures are accompanied by displacement, but in certain instances they are not, or at any rate at the time of the injury. When displacement does not occur at the time, it is spoken of as a "deferred fracture." The bones of the pelvis are occasionally broken, but usually the injury is difficult of detection. Under ordinary circumstances it takes from six to eight weeks for the union of a fractured bone to become complete. When a bone is dislocated the limb is rendered useless. Dislocation of the patella, or knee-cap, which is situated at the stifle joint, is practically the only form of dislocation that occurs in the horse, and when it does take place it is commonly in a foal or a colt, although there are exceptions. The chief symptom of this injury is inability to 
draw the limb forward. Plenty of good food and a strong blister is about the most that can be done towards setting this trouble right. Ligaments and tendons are sometimes torn, but both these structures are capable, under proper conditions, of repair. All wounds, no matter whether affecting skin, flesh, tendons, ligaments, or bones, demand one prime factor necessary for their repair, and this is perfect rest-by no means an easy thing to obtain in the horse. When dealing with a wound, either of the skin or flesh, first of all clip the hair off around the seat of the injury with a pair of sharp scissors, or else shave it off. This done, cleanse the wound thoroughly with warm water containing some antiseptic. Any particles of grit, dirt, etc., must be removed. If the wound is bleeding too freely search for the divided vessel, which when found should be ligatured, i.e. tied up with stout silk thread or catgut. Pressure will sometimes do instead. Cold water is useful for the same purpose, but it must be understood that the loss of two or three quarts of blood, or even a gallon or more, in the horse, is of very little importance. Having assured oneself that the wound is clean it can then be sutured or sewn up, using silk or catgut for this purpose. Punctured wounds must never be sewn, but syringed out daily with antiseptic solution. As soon as the wound is dry, certainly not before, paint it with iodine liniment and then proceed to draw the cut edges of the wound together, taking particular care that the stitches are not drawn too tightly, otherwise they will tear out and still further aggravate the injury. Deep wounds of the muscles, such as one commonly sees on the buttocks and quarters, do not do well when they are stitched. If there is a flap of skin hanging down remove this and let the wound heal in an open manner, only keep it clean and dress daily with an antiseptic lotion-say $\frac{1}{2} \mathrm{oz}$. pure carbolic acid to a pint of water, shaking the two well together and if necessary adding the same quantity of glycerine as acid. This will help to dissolve the carbolic, 


\section{THE HORSE}

The great matter when stitching wounds is to adjust them nicely, but never tight, as swelling bursts the stitches. In summer flies are sometimes troublesome. To prevent this smear the wound with eucalyptus ointment once a day: The following will be found a useful dressing for wounds: creosote, $\frac{1}{2} \mathrm{Oz}$., turpentine, $4 \mathrm{Oz}$, olive oil, $8 \mathrm{oz}$. Mix and make wound liniment. The liniment to be applied twice a day, as it will help a wound to heal rapidly. In the case of broken knees the animal must be tied up short to prevent it from lying down, and the knees dressed with cotton wool soaked in the liniment and subsequently fastened on with a linen bandage, and over this an ordinary stable or flannel bandage. Keep the knees clean, but don't wash the raw surface of the wound. There is nothing more detrimental to a wound than to wash the granulating surface off it. It is surprising how very few people are aware of this significant fact. 


\section{CHAPTER XXV}

SOMETHING CONCERNING ORGANIC AND INORGANIC POISONS

Horses, like most other animals, are liable to suffer from the effects of various organic and inorganic poisons when these are taken into the system. If these enter by the mouth the usual result is that inflammation is set up in the stomach and in the intestines, and this may be the cause of the animal's death. Both vegetable and mineral substances act in this manner if these agents are of a poisonous nature. It is of interest to note that, while both arsenic and antimony are such extremely poisonous agents to man and many other animals, antimony, so far as the horse is concerned, does not, when taken internally, cause any irritation or symptoms of poisoning; yet arsenic will if the dose is excessive. Amongst the British plants of a poisonous nature mention must be made of the yew, the foxglove, the deadly nightshade, the hemlock, the dropwort, the water hemlock, the bitter-sweet, the laburnum, the lilac, etc. Perhaps the commonest amongst these is the yew, the leaves of which, when consumed by a horse, are of a very deadly nature, and quite a number of instances of death have been recorded through eating this plant. The yew (taxus) is a wellknown ornamental shrub, commonly growing around suburban villas, and sometimes in hedges; in fact, one occasionally meets with a whole hedge formed of yew. There is an English and an Irish variety of this plant, but they are both equally deadly. The plant seems to be more active at certain seasons than others, but no risk 
should ever be taken whenever and wherever it is found growing. Most people are acquainted with the yew as an ornamental shrub and the various devices which are fashioned out of it. The leaves are about an inch long, dark green on the upper, but lighter on the lower side, and when young of a very bright green, standing out in marked contrast to the leaves of the previous year. The poisonous properties of the yew were known to the ancient Greeks and Romans, and have been fully established by modern experience. Judged from a toxicological standpoint, the yew occupies an intermediate position between the foxglove and the savin. Death occurs so rapidly after partaking freely of this plant that there is very little time to observe any symptoms. It produces coldness of the surface of the body, rapid action of the heart, trembling, and other urgent signs of pain and collapse. Although a very ornamental shrub it should never be grown in hedges, more especially at the front of houses, as it is very liable at any time to be consumed by any horses left unattended there.

Another plant which frequently grows on hedge-banks and around pastures is that known as the foxglove, the purple flowers of which are well known to almost every one. This plant bears a rosette of leaves close to the ground and these are much lighter on their under surface than above. They have been known to be gathered in mistake for those of the prickly comfrey, and with fatal results when cut up and given to horses. Foxglove leaves, when dried and powdered, have marked diuretic and sedative properties, for which purpose they are sometimes medicinally employed in veterinary practice. Both the flowers and the leaves are poisonous.

The deadly nightshade and the bitter-sweet belong to the same natural order as the potato, and they are both poisonous plants, but the deadly nightshade more so to the horse than the bitter-sweet. The latter is quite a common plant found growing in hedges. It bears bright purple 
flowers with yellow centres. It is a shrub of a trailing character with green berries which subsequently become, when ripe, red. The belladonna, or deadly nightshade, also known as the common dwale, flowers in June, the flowers being of a dusky brown. In spite of its poisonous effects as much as $8 \mathrm{lb}$. have been given to a horse without any bad results. An extract prepared from the leaves is extensively employed in veterinary practice.

The hemlocks are characterised by their hollow stems, their compound leaves and the compound nature of their inflorescence. They belong to the same family as the parsley, celery, etc. The water hemlock is fairly common in ditches and ponds, whilst the spotted hemlock is often found growing on banks, around woods, etc. Both the stem and the leaves are spotted. The poisonous symptoms produced by these plants are variable, but usually those indicative of colic followed by collapse. In cases of poison by any of the foregoing plants first-aid treatment comprises the administration of a pint of linseed oil mixed with half a pint of gin, the whole to be administered immediately the symptoms are observed. In every suspected case of poisoning the earlier professional assistance is obtained the better.

Arsenic is occasionally surreptitiously given to horses by carters and grooms, and the doses are often sufficiently large to kill a horse. It is used in the form of arsenious acid or arsenic trioxide, and it is a heavy white crystalline powder. The proper dose for the horse is from 4 to 8 grains, but horse dealers have been known to give as much as would lie on a shilling, and this would probably weigh 3 or 4 drams. The administration of such lethal doses has, on numerous occasions, landed the horsekeeper in prison, and rightly so. Even when this drug is prescribed medicinally by a professional man, its effects have to be watched, as it is one of those substances which have a tendency to accumulate in the liver, from which it may at any time be suddenly swept into the system, 
and produce acute gastro-enteritis, followed by death. Horse-keepers and grooms reading these remarks must take warning and accept this as the author's timely intervention. Arsenic is given for the purpose of improving the condition of the coat and skin and also that of the wind, on all of which it has a marked effect. Arsenic forms a constituent of many sheep dips and some weed killers, and it has also been employed as a dip for horses in the treatment of certain skin diseases, such as mange, but experience proves that it is distinctly inferior to the ordinary lime and sulphur dip for this purpose. The leading symptoms in arsenical poisoning are those of very severe colic and general signs of collapse. Before concluding this chapter we must not forget to mention another drug occasionally given to horses by grooms, and this is oil of vitriol, or strong sulphuric acid administered by pouring it on loaf sugar, employed for a similar purpose to arsenic, but it is extremely dangerous and its use deserving of the most severe condemnation. The administration of such drugs as turpentine, strong liquid ammonia and carbolic acid to horses necessitates thorough dilution of these corrosive agents, otherwise most serious damage may be done to the mouth, lips, tongue, throat, gullet, and stomach, through ignorance. We have known a soldier administer strong liquid ammonia along with a small quantity of water to a horse when it had colic; the result was appalling, and as cruel as it was possible to conceive. No matter whether employed for internal or external use the drug last named should always be freely diluted with some bland agent, such as linseed or olive oil, and then it can be used with safety.

In smelting districts horses sometimes suffer from lead-poisoning. 


\section{INDEX}

Actinomycosis, 163

Administering medicine to horses, I 23, I 24

Affections of the respiratory and circulatory systems, $164-72$

Age, 47

Age as indicated by teeth, 82-90

Agistment of horses, 25, 26

Anatomical outlines of the construction of the horse, I 30-45

Anthrax, I 56, I 57

Arthritis in foals, I 58 , I 59

Azoturia, I8I

Bedding, 33, 34

Blistering and firing, I24

Bone-spavin, 192-94

Breathing, I 22

Breeding heavy horses and the selection of sire and dam for this purpose, $56-58$

Broken wind, 166,167

Bruised heel, I 20

Bursal enlargements or wind galls, I9O, I9I

Buying a light horse and what to avoid in selecting same, 77-8I

Canker of the foot, I I 4, I I 5

Care of mare and foal, 59-64

Castration of colts, I 26-28

Cataract, 22 I, 222

Catarrh, 1 47-49

Causes of laminitis, I IO

Cleveland Bay, The, 70, 7 I

Clipping, 2O, 2 I

Clothing and bandages, 22

Clydesdale, The, 38-40
Colic, I 76, I 77

Collar and saddle galls, 209-I I

Colour, 47-55

Common affections of the eye, Some, 2 I6-222

Complaints of the digestive organs, Some, I 73-I 79

Cracked heels, 2 I 2, 2 I 3

Curb, I9I, I92

Cutting or brushing, I I 9

Dam, Selection of, 56-58

Diabetes or excessive urination, I 81, I 82

Diarrhcea in foals, 178

Digestive system, The, I43-45

Diseases of bones, joints, tendons and ligaments, I 85-95

Diseases of the feet, 108

Dislocations, 223-28

Dressing for mange in horses, 205

Epilepsy or vertigo, 184

Eye, Some common affections of, 2 I 6-22

Eyelids, Injuries to, 218, 2 I9

Facts of general interest, I 2 I-29

False quarter, II 4

Farmer's horse, 44, 45

Feeding sick horses, I 26

Feet, Diseases of, Io 8

Fever powders, I 29

Fomentations, 1 25, I 26

Forage, The horse and its, 26-33

Forging, I I 9

Foot in health and disease, The, IO2-2O

Foot, Structure of, I04-108 
Founder (laminitis), 108-12

Fractures, 223-28

General management of horses, I I 5-34

Glanders, 1 54-56

Grease, 2 I 3-I 5

Grooming, I 7-20

Hackney or harness horse, The, $67-70$

Healing ointment, 128

Heart, The, I 7 I, I 72

Heavy draught horses, $35-46$

Heavy draught horses, age, sex, colour, selection, soundness, etc. $56-58$

Horse and its forage, The, 26-33

Hunter, The, 73

Hygiene of the stable, I I-I4

Infectious stomatitis, I $6 \mathrm{I}, \mathrm{I} 62$

Infective diseases, Specific, I46I 63

Influenza, I 5 I-4

Injuries to the eyelids, 2 I 8-2 I9

Inorganic poisons, 229-32

Internal structure of a horse, I 39, I 40

Joint-ill or arthritis in foals, 158 , I 59

Lameness in the horse, 93-97

Laminitis or founder, 108-12

Laminitis, General management and treatment of, III, I I 2

Lice, 205, 206

Ligaments, Diseases of, I \&5-95

Light van and tradesman's horse, 71

Lockjaw (tetanus), I 57, I 58

Lymphangitis (weed), I 78, I 79

Mange, I97-20I

Management of horses, I 5-34

Mare and foal, their management

from summer to winter, 59-64

Mud rash, 212

Muscular System, The, I 38, I 39
Navicular disease, I I 2 , I 13

Nervous system, The, I 83, I 84

Nettle rash (urticaria), 2 I 5

Opacity of the cornea, 220, 22 I

Open joint, 190

Ophthalmia, 219, 220

Organic and inorganic poisons, Something concerning, 229-32

Parasitic mange order, I9I I, 20I203

Percheron, The, 42, 43

Physicking horses, I22, 123

Pleurisy, I 7 I

Pneumonia, 168-71

Poisons, Something concerning organic and inorganic, 229-32

Ponies, 74

Pulse, The, I 2 I

Purpura, I60, I6I

Preparation of the foot for shoeing, 98-IOI

Rheumatism, I 59, I 60

Ring-bone, I 88 , I 89

Ringworm, 206-9

Rules for prevention and cure of mange in horses, 203, 204

Saddle horse or rider, The, $65-76$ Saline fever powders, I 29

Sand-crack, I I 3, I I 4

Scour in foals, 178

Seborrhœa (grease), 2 I $3^{-1} 5$

Septic laminitis, 64

Shire, The, 35-37

Shoes and shoeing, 98-101

Side-bone, I I6-i 8

Sire, Selection of, 56-58

Sitfast, 2 I I, 2 I 2

Skeleton of horse, I 30-8

Skin affections, I96-2I 5

Slipped shoulder, I 86

Sore throat, 167,168

Soundness, etc., $56-58$

Splint, 186-8

Stable hygiene, I I -I 4

Stables and stable construction, II-I4 
Stomatitis, Infectious, I61, I 62 Strained tendons and ligaments, I94, 195

Strangles, 149-5 I

Stringhalt, $183, \mathbf{1} 84$

Structure of foot, 104-8

Suffolk, The, 40-42

Summering horses, 24, 25

Temperature, I 21,122

Tetanus (lockjaw), 157, 158

Thrush, I I 5, I 6

Tonic powders, 128

Tuberculosis, 162,163
Urinary and generative organs, I 45 Urinary organs, Some affections of, $180-182$ trix? ver

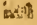

Vanner and tradesman's horse, 45,46

Vertigo, 184

Vice, 91,92

Washing, 22

Watering, 22

Wintering horses, 24, 25

Wound lotion, I 28

Wounds, fractures and dislocations, $223-8$ 
Printed in Great Britaln of

(the THapflower Pres?

CPlpmouth

William Brendon \& Son It? 


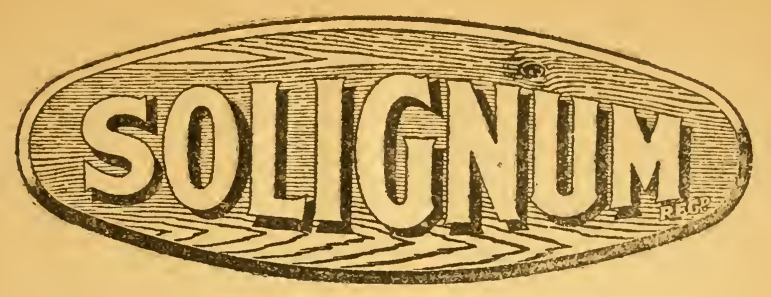

\section{WOOD PRESERVING STAIN}

should be used for all woodwork in and about stables, cowsheds, barns, piggeries, etc.

Read this striking testimonial and write to Major and Company, Limited, 205 High St., Southwark, London, S.E. 1, for particulars and colour sheet, mentioning "The Horse."

Messrs. Major \& Company, Ltd.,

roth May, 1920. 205 High Street,

BOROUGH, S.E.

Dear Sirs,

Kindly forward me one drum of Solignum for use in my stables. I am a great believer in Solignum, being simply a marvellous disinfecting and antiseptic preparation which I recommend to many of my friends. Solignum during the war, used by the Government, was of the greatest benefit in Remount Depots, and absolutely indispensable, and I was never without same.

Kindly send to my stables, and oblige

Yours faithfully,

(Signed) P. Hamilton Hughes

(late Army Remounts Service).

P.S. The above remarks are entirely unsolicited by your Company.

MAJOR and COMPANY, Ltd. 
All practical Farmers who want to keep abreast of the times get at once a copy of

FARMING ON FACTORY LINES

OR

Continuous Cropping for Large Farmers

BY

\section{T. WIBBERLEY, N.D.A., N.D.D. \\ (Of Queen's University, Belfast).}

Second Edition 6/- net (postage 4d.)

Qu It forms the great authoritative test book on the Wibberley Continuous Cropping System, and is a new and frankly revolutionary guide to ALL-WEATHER Farming and to cheaper Milk, Corn and Beef Production.

"In times past the climate has often conquered the British Farmer, but it has not conquered Wibberley. He has conquered it, turning what otherwise would be adverse climatic conditions to advantage in tilling the land.

"It sounds impossible. It reads like a fairy tale-yet the whole of the scheme of 'Wibberleyism' or 'Continuous Cropping,' 'Farming on Factory Lines'-as the system is variously termed-is in reality beautifully simple. It is so effective that one wonders what our highly paid officials have been thinking about, when they have not hammered out some such a tillage system as Wibberley's years before Wibberley was born."-The SMallholder.

\section{Read all about it in this new and valuable work.}

Can be obtained by order from any Bookseller, or post free for $6 / 4$ from

\section{Messrs. C. ARTHUR PEARSON, Limited,}

18 Henrietta Street, London, W.C. 2. 


\section{Books on Agricultural}

\section{and Kindred Subjects.}

\section{Farming on Factory Lines, or}

Continuous Cropping for Large Earmers. By PROFESSOR T. WIBBERLEY, N.D.A., N.D.D.

\section{Second Edition.}

PRICE 6/= NET (Postage 4d. extra).

It forms the great autboritative textbook on the Wibberley Continuous Cropping System, and is a new and frankly revolutionary guide to ALL WEATHER Farming and to cheaper Milk, Corn and Beef Production.

The Horse. In Health, Accident and Disease. By Frank T. Barton, Capt. R.A.V.C., M.R.C.V.S. Crown 8vo. Cloth, with eight Photographs and other illustrations. Price $5 /$ net (postage 5d.).

A new work by a well-known authority. The volume will supply all the information necessary for those interested in the well-being of horses.

\section{Farm Tractors.}

By E. T. Brown. Author of "Poultry for Profit," etc. Fully Illustrated. Crown 8vo. Cloth. Price $3 / 6$ net.

A practical Handbook on the selection and management of a Tractor.

\section{Continuous Cropping}

And Tillage Dairy Farming For Small Farmers, etc. By PROFESSOR T. WIBBERLEY, N.D.A., N.D.D.

Third Edition, Crown 8vo. Cloth. Price $3 / 6$ net; post free, $3 /$ ro.

\section{Dairy Farming.}

By J. C. Newsham, F.L.S., Author of "Farming Made Easy," etc. Crown 8vo. Cloth. Price $3 / 6$ net (postage 5 d.).

All about Cowkeeping, Milk, Butter, Cheese, etc.

\section{Farming Made Easy.}

An invaluable guide for all those commencing farming. By J. C. Nrwsham, F.L.S., Author of "The Potato Book," etc. Crown 8vo. Clotb. Price $3 / 6$ net (postage 4 d. extra).

\section{Poultry for Profit.}

By E. T. Brown. Crown 8vo, cloth, with 15 full-page Illustrations. Price $3 / 6$ net (postage 4d. extra).

\section{The Pig: Breeding, Rearing and Housing.}

By Sanders Spancer. Crown 8vo, cloth, with $x 5$ full-page Illustrations. Price $3 / 6$ net (postage 4 d.).

\section{Insect Pests and How to Beat them.}

Including Notes on Plant Diseases, Soils and Manures. By James Sarsfiel. . Crown 8vo, cloth, with illustrations, by the Author, of every insect described in the text. Price $3 / 6$ net (postage 4 d.).

\section{Roses and How to Grow them.}

By EDwin Beckett, V.M.H., F.R.H.S. Crown 8 vo, cloth. With portrait frontispiece. Price $2 / 6$ net (postage 3 d. extra).

\section{ARTHUR PEARSON, LIMITED.}




\section{SOME USEFUL HANDBOOKS}

\section{FOR SMALLHOLDERS AND OTHERS.}

\section{The Smallholder's Year Book. Published annually}

Price $2 /-$ net (postage $4 \mathrm{~d}$.)

The Smallholder's Year Book is now an institution. It is the recognised court of appeal in all matters connected with the land, in gardening, farming, poultrykeeping, goat, rabbit and bee-keeping circles. It contains the cream of all the information that has ever appeared in THE SMALLHOLDER. It solves at a glance every problem that is ever likely to puzzle YOU.

The Hobby Gardener. By A. C. Marshall, F.R.H.S. With 22 full-page Illustrations showing clearly the various operations throughout a year's work in the garden. In Stiff Threecoloured Cover. Price $1 / 6$ net, post free $1 / 9$.

Greenhouses: How to Make and Manage Them. By William F. Rowles. With numerous Diagrams. Cloth. Price $I / 6$, post free $I / 9$.

The Dog: In Health and Disease. By F. M. ARCHER. With I 2 Illustrations by S. T. DADD. Cloth. Price I/6, post free $I / 9$.

Cage and Singing Birds. By George Gardner. With numerous Illustrations. Cloth. Price $\mathrm{I} / 6$, post free $\mathrm{I} / 9$.

Some of the Contents are:-Birds for Song, for Exhibition and for Breeding - Care of Young-Seeds : how and what to buy-Moulting for Song and for Exhibition-Colour-feeding : how it is done-Diseases of Cage Birds and how to treat them-Bird Fever-Parasites and how to destroy them, etc. etc.

An Easy Poultry Guide. By Edward Brown, F.L.S. With 8 full-page Illustrations and other Diagrams. Pocket size. Cloth. Price $\mathrm{r} /$ - net, post free $\mathrm{I} / 2$.

Yar on Weeds. By "Farmer Giles." Price 6d. net, post free 7 d.

This book gives a full description and illustrations of the thirteen proscribed weeds, also a complete list of all other farm and garden weeds, with sketches, full descriptions, and preventive measures.

War-Time Farming. By T. Wibberley. Price 6d. net, post free $7 \mathrm{~d}$.

This small book tells how the man on the land can use it to the greatest advantage.

Any of these books may be ordered through your bookseller, or will be sent postfree on receipt of the price mentioned by

A. F. SOWTER, Publisher, "Smallhoider and Small Owner" Offices, 16.18, HENRIETTA STREET, LONDON, W.C. 2. 

C)

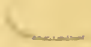



